\title{
Incentives in multi-task settings
}

Citation for published version (APA):

Brüggen, A. (2005). Incentives in multi-task settings. [Doctoral Thesis, Maastricht University]. [s.n.]. https://doi.org/10.26481/dis.20051214ab

Document status and date:

Published: 01/01/2005

DOI:

10.26481/dis.20051214ab

Document Version:

Publisher's PDF, also known as Version of record

\section{Please check the document version of this publication:}

- A submitted manuscript is the version of the article upon submission and before peer-review. There can be important differences between the submitted version and the official published version of record.

People interested in the research are advised to contact the author for the final version of the publication, or visit the DOI to the publisher's website.

- The final author version and the galley proof are versions of the publication after peer review.

- The final published version features the final layout of the paper including the volume, issue and page numbers.

Link to publication

\footnotetext{
General rights rights.

- You may freely distribute the URL identifying the publication in the public portal. please follow below link for the End User Agreement:

www.umlib.nl/taverne-license

Take down policy

If you believe that this document breaches copyright please contact us at:

repository@maastrichtuniversity.nl

providing details and we will investigate your claim.
}

Copyright and moral rights for the publications made accessible in the public portal are retained by the authors and/or other copyright owners and it is a condition of accessing publications that users recognise and abide by the legal requirements associated with these

- Users may download and print one copy of any publication from the public portal for the purpose of private study or research.

- You may not further distribute the material or use it for any profit-making activity or commercial gain

If the publication is distributed under the terms of Article $25 \mathrm{fa}$ of the Dutch Copyright Act, indicated by the "Taverne" license above, 


\section{INCENTIVES IN MULTI-TASK SETTINGS}


Incentives in Multi-Task Settings

(C) A. Brüggen, Maastricht 2005 ISBN 90-9020140-8

Printed by: $B+W$ Computerformulare 


\title{
INCENTIVES IN MULTI-TASK SETTINGS
}

\author{
PROEFSCHRIFT
}

ter verkrijging van de graad van doctor aan de Universiteit Maastricht, op gezag van de Rector Magnificus, Prof. Mr. G.P.M.F. Mols volgens het besluit van het College van Decanen in het openbaar te verdedigen

op woensdag 14 december 2005 om 16.00 uur

door

Alexander Brüggen 
Promotor

Prof. Dr. Frank Moers

\section{Beoordelingscommissie}

Prof. Dr. R. H. G. Meuwissen RA

Prof. Dr. J. F. M. G. Bouwens (Universiteit van Tilburg)

Prof. Dr. Ir. B. Dellaert 


\section{ACKNOWLEDGEMENTS}

The process of writing a dissertation is long, and I am grateful to many people who supported me. First of all, I would like to thank my promoter Frank Moers for his supervision. His critical views, ideas, encouragement and enthusiasm have helped me a lot in the process of writing this dissertation. Frank was also the one who got me into contact with research in accounting. I owe Frank debt also for his patience, a character trait that is not one of my strengths. Besides my promoter, I would like to thank Roger Meuwissen, Jan Bouwens and Benedict Dellaert for the prompt evaluation and approval of the manuscript of this dissertation. I would like to thank the supervisory board of the Postgraduate Programme in Controlling of the Universiteit Maastricht for their financial support. I also thank METEOR for sponsoring one of the experiments. I thank my colleagues of the Department of Accounting and Information Management at Maastricht University for their support and the enjoyable work environment during the last four years. I appreciated discussions on accounting issues, on the preparation of food in the mensa, and many other topics. I would especially like to thank Robbert-Paul, Rick, Erik, Felix, Johan and Caren for their help, suggestions, and cooperation when doing the experiments for this dissertation. I am very grateful to my friends, and especially to Rüdiger, Stefan, Olli, Carsten, Heiko ("die kölsche Jonge"), Erik, Joop and Jörg (who helped me to reduce my wine supply), and to Jule for their support and friendship. I owe my family, and especially my mother and my brother an immense debt for their support. Most of all, I would like to thank Lisa for her warmth, understanding and love. Words cannot express my gratitude. 


\section{CONTENT}

$\begin{array}{lll}\text { Chapter } 1 & \text { Introduction } & 1\end{array}$

1.1 Introduction to research on financial incentives 1

1.2 Objectives of this dissertation 2

1.3 Research method 3

1.4 Contributions 4

1.5 Outline of this dissertation 5

$\begin{array}{lll}\text { Chapter } 2 & \text { Agency Theory } & 7\end{array}$

2.1 Introduction 7

2.2 The Principal-Agent (P/A) problem 7

2.3 The basis $P / A$ model $\quad 8$

2.4 Precision and sensitivity in performance measures 11

2.5 Multi-task agency settings 13

2.6 Conclusion 19

Chapter 3 Empirical Evidence 21

3.1 Introduction 21

3.2 Empirical evidence on incentive effects 21

3.3 Assumptions and challenges of the traditional 24

P/A model

3.4 Conclusion $\quad 32$

Chapter $4 \quad$ The Role of Social Incentives in 33

\section{Multi-Task Agency Settings}

4.1 Introduction 33

4.2 Theory and hypotheses 35

4.3 Experimental method 41

4.4 Results 44

4.5 Discussion and conclusion $\quad 55$ 
Chapter 5

5.1 Introduction

5.2 Theory and hypotheses

5.3 Experimental method

5.4 Results 72

5.5 Discussion and conclusion

Chapter 6 Summary and Conclusion

80

6.1 Introduction

80

6.2 Summary

80

6.3 Implications

84

6.4 Limitations

87

6.5 Future research

88

References

91

Appendix A

Appendix B

110

Summary in Dutch

Curriculum Vitae 


\section{CHAPTER 1}

\section{Introduction}

\subsection{Introduction to research on financial incentives}

One of the major concerns in management accounting is the evaluation of employees and the design of compensation schemes that are related to performance evaluation. Problems and difficulties of managerial compensation are frequently treated in the popular and business press. Excessive remunerations of CEOs, for instance, draw the attention not only of shareholders but also governments, labor unions and the investment community (Indjejikian 1999). Despite pitfalls and misuse of financial incentives and bonus plans in firms, there seems to be a general consensus that reward systems are critical for the success of firms. The role of reward systems has not only attracted the attention of the business community and its stakeholders, but also academics. The design of incentives, people's reaction to monetary rewards, and the role of various kinds of performance evaluations have been the interest of researchers not only of economic disciplines, but also sociologists and psychologists. Besides possible performance effects of financial incentives, issues such as pay equity and fairness considerations are important areas of research. Research on the role of financial incentives has been going on for decades. Nevertheless, due to the complexity of this area of research, there are still many questions that remain unanswered. This dissertation tries to answer some 
questions that arise in the context of financial incentives and helps to clarify the role of financial incentives and other motivational mechanisms.

\subsection{Objectives of this dissertation}

The purpose of this dissertation is to examine the role of financial incentives and other motivational mechanisms in multi-task principal-agent settings. In principalagent settings, a principal delegates decision-making authority to an agent. The agent is hired to do the job for the principal. It is thus important for the principal that the agent takes actions that are in line with the interests of the principal. However, the agent can take private actions that are not observable by the principal. Perfect monitoring is thus not possible and a so-called moral hazard problem arises. To make sure that the agent takes the desired action, the principal can give the agent incentives based on performance measures, so that the agent gets rewarded for performance that is in line with the objectives of the principal. The use of performance measures for compensation purposes is also referred to as the 'decision-influencing' role of performance measures. Performance measures used to provide the agent with better information is considered as the "decislonfacilitating" rolle of performance measures.

Whereas the main concern in the 'traditional' principal-agent model is to induce effort of the agent, this main concern changes in a multi-task setting. If an agent is faced with more than one task and effort on all tasks is crucial for the principal, it is not only impiortant to induce effort at all, but also to induce the effort allocation as desired by the principal. An agent faced with more than one task and multiple performance measures with different levels of precision makes management control more complex, because performance measurement is more difficult. Further, agents may react differently to performance measures with different levels of noise. More specific $_{y}$ agents may prefer precise performance measures over noisy measures. A challenge for the management accounting discipline is the development of evaluation and compensation schemes that overcome problems of multi-task agency 
settings. Based on the economic literature, I examine the role of financial incentives in multi-task settings where performance on one task is measured precisely, while on another task it is measured with noise (or not at all). Furthermore, I analyze the role of other motivational mechanisms, such as social incentives, ethical concerns of individuals, and career concerns on effort allocation in multi-task settings.

More specific, this dissertation helps to find answers to the following research questions:

1. How do explicit financial incentives influence effort allocation in multi-task agency settings?

2. What role do other forms of incentives, such as social incentives and career concerns, play?

\subsection{Research method}

In this dissertation I use experiments to answer the above research questions. There are two experimental studies in this dissertation that investigate the role of different forms of incentives in multi-task agency settings. Experiments are chosen for several reasons. First of all, archival data on the effect of different incentives on effort of agents in multi-task settings is hardly available in firms. In particular, data on social incentives, incentives due to career concerns, and effort allocation is difficult to obtain, if at all possible. Second, experiments allow the examination of causal mechanisms, where an independent variable affects a dependent variable, so that strong causal inferences can be drawn. In experiments, there is a trade-off between external validity and internal validity. Whereas external validity refers to the extent to which results are "realistic" and close to real-life situations, internal validity is concerned with the extent to which an observed covariation between two variables reflects a causal relationship. The higher the internal validity the better a researcher is able to draw a conclusion on causal mechanisms. In the two studies, I increase internal validity to be able to draw a clear conclusion on the relationships 
between the manipulated variables. $\mathbb{I}$ abstract real-life situations into an experimental setting, and "translate" the conclusions back into real-life by discussing managerial implications of the results of this dissertation.

The studies examine the role of incentives in multi-task settings from different perspectives. In the first study, I examine the role of financial incentives and social incentives on effort allocation of agents when individuals need to perform multiple tasks and performance can be measured on only one task. In a $2 \times 2$ experiment, I manipulate two forms of incentives, financial and social incentives. In addition, I consider ethical concerns in this context, as this variable can be regarded as the individual equivalent of the social incentive variable. In the second study, I investigate the effect of financial incentives and career concerns of agents in a multi-task setting, where performance of agents is measured precisely on one task and with noise on another task. Agents with career concerns take into account that current performance possibly affects future compensation. I run a $2 \times 3$ experiment where I manipulate the form of compensation and career concerns. Participants of this experiment work on two tasks. In the second experiment I thus investigate the role of explicit financiall incentives and implicit financial incentives in form of career concerns on effort allocation of agents.

\subsection{Contributions}

This dissertation contributes to the literature in several ways. First, results indicate that in addition to explicit financial incentives, implicit financial incentives in form of career concerns and social incentives have an influence on individual behavior.

Second, Holmström and Milgrom (1991) show that in a multi-task setting a fixed wage is optimal for effort allocation in the setting where performance on one task is measurable but not on another task, i.e., agents allocate their efforts according to the preferences of the principal. However, a fixed wage may not be optimal in a multi-task setting for two reasons: one reason is that despite a congruent effort 
allocation under fixed wages, overall effort may be lower compared to a setting with financial incentives. So, congruent effort allocation may harm the overall effort level and the net effect might be a lower pay-off to the principal. Another reason is that career concerns lead to an effort bias towards a task that is favored by a labor market, so that in presence of career concerns agents are not indifferent between tasks anymore.

Third, whereas the economic literature suggests that financial incentives and career concerns are substitutes, it appears that explicit financial incentives and career concerns complement each other in a multi-task setting. Given that there are career concerns for agents, financial incentives play an important role to counteract the incentive effects of career concerns that are determined exogenously. Explicit financial incentives thus help firms to balance the two forms of incentives.

Fourth, the economics literature predicts a negative relationship between noise in a performance measure and the incentive weight on the performance measure in contracts. However, as financial incentives and career concerns complement each other this relationship tends to be positive because financial incentives are used to counteract the motivational effects of career concerns. Therefore, it is necessary to increase the incentive weight on tasks measured with noise, because the labor market already "takes care" of the incentive weight on the precisely measured task.

\subsection{Outline of this dissertation}

This dissertation is organized as follows. In the next chapter I explain analytical models on the role of financial incentives in agency theory, and in particular multitask principal-agent models. In the third chapter I discuss empirical research on financial incentives and concerns with respect to the assumptions of the traditional principal-agent model. I describe an experimental study on the role of financial and social incentives in a multi-task agency setting in the fourth chapter. The subsequent chapter deals with a study on the role of career concerns as implicit 
incentives. In the last chapter of this dissertation I provide a discussion on the results of this dissertation, its limitations, directions for future research, and conclusions. 


\section{CHAPTER 2}

\section{Agency Theory}

\subsection{Introduction}

The objective of this chapter is to explain and describe agency theory and its application in theoretical models. These models form the starting point for this dissertation. In the first part of this chapter I describe agency theory by means of a theoretical principal-agent model. In addition to a basic principal-agent model, I develop a multi-task principal-agent model in the second part of this chapter.

\subsection{The Principal-Agent (P/A) problem}

The P/A problem can be illustrated as follows: a principal delegates decision-making authority to another person, an agent. There may be many reasons why someone may delegate decision-making authority to someone else. An often used example is that of an owner of a business, who lacks the time of managing the business by himself. Consequently he hires a manager to run the business for him. It is then important for the principal that the agent acts in line with the interests of the principal. When the privately taken actions of an agent and his abilities are observable to both principal and agent, incentive problems do not occur and a socalled first-best solution is possible. Information asymmetry with regard to the true 
abilities of the agent can lead to a problem of hidden information, also referred to as adverse selection. In case the private actions of the agent are not observable to the principal the agent may take actions that are not necessarily in line with the objectives of the principal. Such a conflict is considered as moral hazard. To reduce moral hazard problems, there is a trade-off between high levels of monitoring and high levels of performance-based compensation to the agent. However, when the agent receives a compensation that is increasingly depending on his performance, the agent faces more risk. In order to agree to a contract under these circumstances, the agent needs to be compensated for the additional risk he bears. It is thus not only information asymmetry, but also the risk- and effort-aversion of the agent that lead to agency problems (Baiman 1990). Without a properly developed incentive scheme, such agency problems can result in a reduction of firm value, also referred to as agency costs (Lambert 2001).

\subsection{The basic P/A model (Holmström 1979)}

In basic models of P/A theory, a principal hires an agent for one period. It is assumed that the agent is risk- and effort averse and that the principal is riskneutral. In taking action the agent chooses a certain level of effort. The effort ' $e$ ' of the agent together with a random state of nature " $\theta$ " is unobservable to the principal or too costly to be monitored completely. The effort of the agent leads to an outcome $x=x(e, \theta)$. The utility function of the principal is determined by wealth and is given by $G\left(W_{p}\right)$. In contrast, the utility function of the agent is given by $H\left(w_{A}\right)$, which is determined by the compensation of the agent and his effort choice. More specific ${ }_{r}$ it is assumed that the utility function of the agent is composed of the utility of the compensation and the disutility of effort:

$$
H\left(w_{A}\right)=U(s(x))-V(e)
$$

A certain part of the payoff goes to the agent, and the other part is going to the principal. The share going to the agent can be described by $s(x)$, and the share 
going to the principal can be described by $r(x)=x-s(x)$. Let $F(x, e)$ be the distribution of $x$ and let $f(x, e)$ be a density function. In a setting where the effort of the agent is observable, the P/A problem can be described by the following equations:

$$
\max . \int G(x-s(x)) f\left(x_{t} e\right) d x
$$

$$
\text { s.t. } \int[U(s(x))-V(e)] f(x, e) d x \geq \tilde{u}
$$

In equations (2) and (3), the optimal contract needs to satisfy the objective of the principal to maximize his utillity, but at the same time it is necessary to make sure that the agent receives at least his reservation wage $\bar{u}$. The constraint (3) is referred to as participation constraint. An incentive problem does not exist because the effort of the agent is observable and the principal can specify the effort the agent has to take. The principal will pay the agent a fixed wage if he works according to the objectives of the firm, and will penalize the agent if he does not work as desired by the firm. Using $\lambda$ as multiplier for the constraint (3), and solving the Lagrangian, one can specify the optimal contract:

$$
\frac{G^{\prime}(x-s(x))}{U^{\prime}(s(x))}=\lambda
$$

The compensation of the agent is thus a constant, which is set at the ratio of the marginal utility of the principal and the agent. The optimal solution is an optimal way of risk sharing between the principal and the agent. In equation (4) the only risk is the outcome $x$. In case the principal is risk-neutral and the agent risk-averse, Holmström (1979) shows that the optimal contract satisfies

$$
\frac{1}{U^{\prime}(s(x))}=\lambda
$$


As $\lambda$ is a constant, the left side of the equation must be a constant, too. So, the principal accepts to bear all risk and pays the agent a fixed wage to protect the agent from risk.

In a setting where the effort of an agent is not observable, a first-best solution as in (4) is not possible. Only a second-best solution can be achieved and the P/A problem can then be described by the following equations:

$$
\max . \int G(x-s(x)) f(x, e) d x
$$

$$
\begin{array}{ll}
\text { s.t. } & \int[U(s(x))-V(e)] f(x, e) d x \geq \bar{u} \\
& \int U(s(x)) f_{a}(x, e) d x=V^{\prime}(e) .
\end{array}
$$

Similar to the first-best solution, the optimal contract needs to induce action that is congruent with the objective of the principal. This contract is constrained by the participation constraint, i.e. the agent needs to accept the contract. In addition, however, it is necessary to induce the agent to deliver the "right" effort, l.e., the marginal revenue of the agent must equal his marginal costs $(8)$. This constraint is called the incentive compatibility constraint. As can be seen, the P/A model increases from a model of optimal risk-sharing to a model of risk-sharing and providing agents with incentives to take the right effort.

Letting $\lambda$ be the multiplier for the first constraint (7) and $\mu$ be the multiplier for the second constraint (8) and solving the Lagrangian leads to the second-best contract specified as follows:

$$
\frac{G^{\prime \prime}(x-s(x))}{U^{\prime}(s(x))}=\lambda+\mu \cdot \frac{f_{a}(x, e)}{f(x, e)}
$$

This result implies that the agent receives a fixed component $\lambda$ plus a component depending on the outcome $x$. Furthermore, the higher the level of $x$ gets the higher the variable compensation. This may appear desirable at first. However, increased emphasis on output $x$ means an increased level of risk to the agent (due to the 
nolse in the relationship between $e$ and $x$ ). The agent must be compensated for this extra risk so that the total compensation costs increase as well. Holmstrom (1979) shows that a performance measure is valuable if (and only if) it is informative of the action of the agent. This finding is called the informativeness principle.

\subsection{Precision and sensitivity in performance measures}

To keep the negative effects of moral hazard low and to reduce agency costs, performance measures are used to monitor manageriall action. A large stream of research concentrates on the construct of an optimal performance measure for managerial action (Banker and Datar 1989). One important criterion is that the performance measure is congruent with the objectives of the principal (Feltham and Xie 1994). Another criterion for an optimal performance measure is its precision. A problem is that managerial effort can often not be measured precisely. In other words, an agent delivers effort e that leads to performance, but due to noise in the available performance measures, measured effort can be over- or understated. The following model explains how noise in performance measures can weaken the possibility to use performance measures for contracting purposes. ${ }^{1}$ Performance $x$ of an agent is measured as follows:

$$
x=f e+\varepsilon
$$

where $f$ is a sensitivity factor and $\varepsilon$ reflects uncontrollable factors with $\varepsilon \sim N\left(0, \sigma^{2}\right)$. The agent's compensation $s(x)$ is composed of a fixed amount a and a variable amount $\beta$ that is linked to performance $x$ :

$$
s=a+\beta x
$$

\footnotetext{
'This model is a LEN model. A contract between a risk-neutral principall and a risk-and effort averse agent is specified by a linear compensation function $(L)$. The agent's preferences are given by a negative exponential utility function with $r$ as coefficient of constant absolute risk aversion ( $E$ ). Random variables are normally distributed $(N)$.
} 
The cast of effort to the agent is given by $C(e)=1 / 2 e^{2}$. The certainty equivalent of the agent (CEA) can then be formulated as

$$
\begin{aligned}
C E A= & E[s]-C(e)-1 / 2 r \operatorname{Var}(s) \\
& =a+\beta f e-1 / 2 e^{2}-1 / 2 r \beta^{2} \sigma^{2}
\end{aligned}
$$

The CEA is thus the wage to the agent minus the costs of effort and minus a risk premium where $r$ is the constant absolute risk aversion of the agent and $\sigma^{2}$ is the noise variable. The term $\beta^{2} \sigma^{2}$ reflects the variance of wealth of the agent. The firstorder condition for the CEA is:

$$
\beta f-e=0 \quad \Leftrightarrow \quad e^{*}=\beta f
$$

The certainty equivalent for the principal (CEP) is given by

$$
\begin{aligned}
C E P= & E[x]-E[s] \\
& =f e-a-\beta f e
\end{aligned}
$$

To derive the total certainty equivalent (TCE) one can simply add the CEA and the CEP so that the TCE is given by:

$$
\begin{aligned}
\text { TCE } & =E[X]-C(e)-1 / 2 r \beta^{2} \sigma^{2} \\
& =f e-1 / 2 e^{2}-1 / 2 r \beta^{2} \sigma^{2}
\end{aligned}
$$

Inserting the optimal effort $e^{*}$ into the TCE and taking the first derivative with respect to $\beta$ leads to the optimal incentive weight $\beta$ :

$$
\beta=\frac{f}{f^{2}+r \sigma^{2}}
$$

$\beta$ is thus the optimal weight in an incentive contract. One can see from the equation of the incentive weight $\beta$ that the effectiveness of financial incentives is restricted by the level of noise in a performance measure $\left(\sigma^{2}\right)$. The noisier a performance 
measure is the lower the weight $\beta$ gets and the less it is used in an optimal contract (Prendergast 1999). This finding has important implications for contracting and it underlines the necessity to find performance measures that are low in noise.

Adding an extra performance measure is valuable except for the situation when the existing performance measure is a sufficient statistic for the extra measure (Holmstróm 1979). An additional performance measure is valuable only if it adds something to the power of inference based on the existing performance measure. However, whereas the informativeness condition of Holmström (1979) suggests that an additional performance measure should be used if it is informative irrespective of its noise, there is little insight on how the additional performance measure should be used in compensation contracts, i.e., how the relative weight of several performance measures should be determined. Banker and Datar (1989) examine precision and the sensitivity of a performance measure. They show that the relative weight of a performance measure is proportional to its sensitivity and precision. More specific they define the intensity of a performance measure as the product of its sensitivity and precision and show that it is optimal to add a performance measure for managerial evaluation if the intensity of the additional performance measure is different from the existing measure. The noisier and less sensitive a signal, the lower becomes its welight. In addition to precision, sensitivity of a performance measure thus plays an important role in performance evaluation and compensation contracts.

\subsection{Multi-task agency settings}

Whereas the P/A models described in the previous sections refer to single-task settings, models where an agent is confronted with more than one task leads to a different setting, i.e. a multi-task setting. An increasing stream of analytical research has analyzed $P / A$ relationships in multî-task settings (e.g. Banker and Datar 1989, Holmström and Milgrom 1991, Feltham and Xie 1994, Hemmer 1996). There are two important differences between single-task settings and multi-task 
settings. Whereas incentives in single-task models serve to allocate risks and to motivate work (congruent with the principal's objectives); incentives in multi-task settings serve not only to induce high effort, but additionally serve to direct the attention among different tasks. Moreover, in case the responsibility of an agent can be separated into different tasks, job design becomes an important issue in multitask P/A models (Holmström \& Milgrom 1991, labeled HM hereafter). However, there are many situations where different tasks cannot be assigned to different agents, for example the job of a university professor. Roughly this job could be divided into teaching and research activities. For the superior of the professor (department chair, for example) it is necessary to stimulate effort not only on teaching but also on research activities. The focus of my research is not on job design issues but rather on the use and effects of incentives in multi-task settings.

In the general model of HM, an agent makes a choice of a vector of effort $e=\left(e_{1}, \ldots, e_{m}\right)$. The cost of effort is depicted by $c\left(e_{1}, \ldots, e_{m}\right)$. The gross benefits to the principal generated by the efforts of the agent are given by $x\left(e_{1}, \ldots, e_{m}\right)$, where $x$ is not contractible. Furthermore, the efforts of the agent lead to signal $y(e)=z(e)+\varepsilon$. In contrast to previous research on agency theory, HM do not assume that work is in general unpleasant to the agent. In fact, an agent is willing to provide some effort even under a fixed wage contract and is indifferent among a range of effort allocations. Thus, it is assumed that the agent is willing to follow, up to a certain point, the preferences of the principal under a fixed wage contract. Put formally, there is a certain number $\overline{\mathrm{e}}>0$, where $\mathrm{C}^{\prime}(\mathrm{e}) \leq 0$ for $\mathrm{e} \leq \mathrm{e}$ and $\mathrm{C}(\overline{\mathrm{e}})=0$.

In a multi-task setting where performance on one task is measurable but not on another task, HM show that a fixed wage may be optimal as incentives may lead to effort distortions. ${ }^{2}$ Using the example of a contractor for home remodeling, suppose that effort $e_{1}$ on one task (e.g.s helpful advice or attention to detail) is immeasurable, but effort $e_{2}$ on another task (e.g., timely completion) is measurable (with noise). The measured effort is one-dimensional and given by $z\left(e_{1}, e_{2}\right)=z\left(e_{2}\right)$. The performance measure $y$ is thus simply modeled as $y=e_{2}+\varepsilon_{y}$.

${ }^{2}$ This holds under the assumption that effort on the unmeasured task is crucial for the firm. 
The agent's efficient compensation contract is given by $w=a+B y$. The value generated by the two types of efforts $e_{1}$ and $e_{2}$, in this example the value for the home-owner, is given by the function $x\left(e_{1}, e_{2}\right)$. Effort $e_{1}$ is considered as very important to the princlpal (the home-owner), and both $e_{1}$ and $e_{2}$ are valuable. It is assumed that $x$ is increasing and that $x\left(0_{1} e_{2}\right)=0$, for all $e_{2} \geq 0$. HM demonstrate that it is optimal in this setting to pay the agent a fixed wage, i.e., $\beta=0$. In case $\beta=0$ the principal can tell the agent to choose effort level $\overline{\mathrm{e}}$ where $C^{\prime}(\overline{\mathrm{e}})=0$ and to choose $\tilde{\mathrm{e}}_{1} \in[0, \overline{\mathrm{e}}]$ to maximize $X\left(\overline{\mathrm{e}}_{1}, \overline{\mathrm{e}}-\overline{\mathrm{e}}_{1}\right)$. The total wealth will be $X\left(\overline{\mathrm{e}}_{1}, \overline{\mathrm{e}}_{-} \overline{\mathrm{e}}_{1}\right)-C(\overline{\mathrm{e}})$. If $\beta>0$, $e_{1}$ will be zero and the total wealth will be

$0-C(\overline{\mathrm{e}})-1 / 2 r \beta^{2} \sigma^{2} \leq-C(\overline{\mathrm{e}})<X\left(\overline{\mathrm{e}} 1, \overline{\mathrm{e}}-\overline{\mathrm{e}}_{1}\right)-C(\overline{\mathrm{e}})$

because e is cost minimizing for the agent.

The analysis of HM above shows that financial incentives may not always be the optimal solution. A fixed wage contract is optimal if performance is measurable on one task but immeasurable on another one that is important to the firm. With an incentive contract, the agent would divert most of his attention away from the task that is not measured to the task that is measured.

An important assumption of the model developed by HM is that the two tasks are substitutes. This means, increasing effort on one task will increase the marginal costs of effort for the other task. The fact that an agent is confronted with several tasks can constrain the tradeoff between risk and incentives. Concentrating on one task limits the opportunity to put effort on the other task. Important is thus not only the level of measurability of the activity of an agent, but also the level of substitutability of efforts on tasks (Holmström and Millgrom 1991). Dikolli and Kulp (2002) investigate the issue of substitute and complementary efforts. If efforts on tasks are substitutes of each other, a change in the effort allocation of the agent can lead to higher costs of effort and as a consequence, to higher compensation costs. In contrast, in case tasks are complementary to each other, effort on one task 
reduces the marginal costs of delivering effort on the other task. Following this; inducing performance on one task can - at some point - lead to spillover effects on the other task, thus inducing also some effort on the other complementary task. In addition, the need for an extra performance measure for the second task is also decreasing if tasks are complementary (Dikolli \& Kulp 2002).

Based on studies by Holmström and Milgrom (1991) and by Dikolli and Kulp (2002) it is possible to characterize the optimal incentive weights for an agent on two tasks. I use an example based on a LEN model to show optimal incentive weights. The basic model assumes that a risk-neutral principal hires an employee (agent), who is risk- and effort averse. The agent has to perform two different tasks. The firm's noncontractible profit $x$ is affected by both tasks, and thus both types of effort $e_{1}$ and $e_{2}$.

$$
x=b_{1} e_{1}+b_{2} e_{2}+\varepsilon_{n}
$$

The variables $b_{1}$ and $b_{2}$ are the marginal impact of effort $e_{1}\left(e_{2}\right)$ on $\times$ (i.e., they indicate how important the two types of effort are to the principal). As actual effort of the agent cannot be observed, performance measures are used for compensation purposes. In this model, performance can be measured on one task, only, and is given by

$$
y_{1}=f e_{1}+\varepsilon
$$

Such a case can occur when a performance measure on one task is simply not existing, too costly for the principal, or the existing performance measures are too noisy. The principal offers the agent a contract that includes a fixed component and a variable component that is based on the available performance measure.

$$
s=a+\beta y_{1}
$$


However, due to $(10)$, the principal requires the agent not only to deliver effort $\left(e_{1}\right)$ on one task (focusing on $y_{1}$ ) but also to deliver effort $\left(e_{2}\right)$ on the other task. One important distinction between different forms of effort is how far efforts are substituting or complementing each other. Substituting effects increase the marginal costs of $e_{2}$ while delivering $e_{1}$. Complementary effects have the consequence that the marginal costs of $e_{2}$ decrease while delivering $e_{1}$. This characteristic is captured by the cost of effort $C$ for the agent.

$$
\begin{aligned}
& C\left(e_{1,2}\right)=1 / 2\left(e_{1}{ }^{2}+e_{2}^{2}\right)+k e_{1} e_{2} \quad \text { with }|k|<1 \\
& \mathrm{C}_{1}{ }^{\prime}>0 \quad \mathrm{C}_{12}{ }^{\prime \prime}>0 \quad \text { substitute effects } \\
& \mathrm{C}_{1}{ }^{{ }^{\prime}}>0 \quad \mathrm{C}_{12}{ }^{\prime \prime}<0 \quad \text { complementary effects }
\end{aligned}
$$

The factor $k$ is a variable that indicates whether efforts are complementary or substituting. In case $k>0$, efforts are substitutes, meaning that performing on one task increases the marginal costs of performing on the other task. In case $k<0$, efforts are complementary, meaning that performing on one task lowers the marginal cost of performing on another task. The certainty equivalent of the agent (CEA) is therefore given by:

$$
\begin{aligned}
C E A & =E[s]-C(e)-1 / 2 r \operatorname{Var}(s) \\
& =a+\beta f e_{1}-1 / 2\left(e_{1}{ }^{2}+e_{2}{ }^{2}\right)-k e_{1} e_{2}-1 / 2 r \beta^{2} \sigma^{2}
\end{aligned}
$$

The first-order conditions for the agent are as follows:

1. $\beta f-e_{1}-k e_{2}=0 \Leftrightarrow \quad e_{1}=\beta f-k e_{2}$

2. $-e_{2}-k e_{1}=0 \Leftrightarrow e_{2}=-k e_{1}$

The first-order conditions above then lead to the optimal efforts ${ }^{3}$

1. $e^{*}=\frac{f \beta}{1-k^{2}}$

\footnotetext{
${ }^{3}$ Note that the variable $k$ is defined by $|k|<1$.
} 
2. $e^{* k_{2}}=\frac{-k f \beta}{1-k^{2}}$

The certainty equivalent of the principal (CEP) is given by

$$
\begin{aligned}
C E P= & E[x]-E[s] \\
& =b_{1} e_{1}+b_{2} e_{2}-a-\beta f e_{1}
\end{aligned}
$$

As shown earlier in this chapter, to derive the total certainty equivalent (TCE) one can simply add the CEA and the CEP so that the TCE is given by:

$$
\begin{aligned}
\text { TCE }= & E[x]-C(e)-1 / 2 r \operatorname{Var}[s] \\
& =b_{1} e_{1}+b_{2} e_{2}-1 / 2\left(e_{1}^{2}+e_{2}^{2}\right)-k e_{1} e_{2}-1 / 2 r \beta^{2} \sigma^{2}
\end{aligned}
$$

Inserting the optimal levels of effort of the agent into the TCE, taking the first derivative of this function with respect to $\beta$, and solve it for $\beta$ leads to

$$
\beta=\frac{f\left(b_{1}-b_{2} k\right)}{f^{2}-r \sigma^{2}(k-1)(k+1)}
$$

This is the optimal incentive weight in a contract for an agent. In case the principal considers both types of effort as equally important, $b_{1}=b_{2}$, the equation for the incentive weight would change into

$$
\begin{array}{lll}
\beta=\frac{b f(1-k)}{f^{2}-r \sigma^{2}(k-1)(k+1)} . & \\
\beta=0 \quad \text { if } & k \rightarrow 1 \\
\beta=\frac{2 b}{f}>0 \quad \text { if } & k \rightarrow-1
\end{array}
$$

This result clearly shows that the optimal incentive weight $\beta$ should be zero in case both tasks are equally important to the principal and efforts on the two tasks are perfect substitutes. The principall pays the agent the fixed wage component a, only 
(cf. Holmström and Milgrom 1991)." In case the tasks complement each other, the incentive weight should be positive. Results show that noise in performance measures, as well as the characteristics of effort, lie, substitute or complement efforts, are important criteria in multi-task settings to determine contracts. Fixed wages can thus be optimal in multi-task settings where tasks of an agent do not complement each other.

\subsection{Conclusion}

In this chapter I describe models that are the basis for many studies in economic research. In the first part of this chapter, I show that agency problems exist when effort of an agent is not observable to the principal. A first-best solution is not possible, so only a second-best solution can be achieved. It is necessary to induce the agent to work by linking his personal pay-off to his effort. This is done by means of performance measures that are used to evaluate and compensate the agent. I stress the importance of performance measures and the implications of noise in performance measures for their use in evaluating and compensating agents.

Whereas in single-task models, the focus is to induce the agent to work at all, the focus changes in case of a multi-task setting. In multi-task settings, it is important not only to motivate an agent to work, but it is at least as important to induce an agent to allocate his effort according to the objectives of the firm. Extending an agency setting to several tasks makes the agency problem more complex, as performance-based incentives may lead to effort distortions.

As shown in this chapter, explicit financial incentives are optimal in single-task settings to induce the agent to deliver effort. In multh-task settings, however, financial incentives might not be optimal because they can lead to an effort allocation that is possibly not in line with the objectives of the principall.

\footnotetext{
${ }^{4}$ This conclusion assumes that agents are willing to provide effort in absence of financial incentives.
} 
Consequently, under the assumption that agents are willing to provide some effort, a fixed wage may be optimal in multi-task settings. 


\section{CHAPTER 3}

\section{Empirical evidence}

\subsection{Introduction}

In the previous chapter I explained economic theory and agency models. The objective of this chapter is to discuss the empirical literature on economic theory and to discuss the assumptions made in the traditional agency model. ${ }^{5,6}$ In the first part of the chapter, I discuss empirical evidence on the effects of financial incentives. The second part of this chapter deals with empirical findings that raise concerns about the assumptions of economic theory and reveal doubts on the validity of these assumptions.

\subsection{Empirical evidence on incentive effects}

A large stream of literature has examined the role of financial incentives on agents empirically. One of the fundamental questions is whether incentive pay has an influence on employee behavior (Indjejikian 1999). According to many studies in the incentive literature, the answer is 'Yes". There is evidence for a positive relationship between financial incentives and effort that ultimately leads to higher task performance of individuals (Bonner and Sprinkle 2002). Many empirical studies

\footnotetext{
"I consider field data, archival data and experimental data as empirical data.

"The literature also uses the term "classical" agency theory.
} 
using field and archival data suggest a positive relationship between the use of financial incentives and performance (Larcker 1983; Banker et al. 1996a/b; Wallace 1997; Banker et al. 2001). In addition, several experimental studies give support for the positive effects of financial incentives on performance (e.g., Chow 1983; Bailey et al. 1998; Sprinkle 2000; Bonner et al. 2000). The studies mentioned in this section are a selection that is descriptive of its relevant field.

Larcker (1983) finds that managers make different decisions when they receive a performance-based compensation plan compared to compensation contracts with a fixed salary. The introduction of a performance-based element in the compensation contracts of managers leads to higher capital expenditures compared to companies where managerial compensation is not linked to performance. Banker et al. (1996a) examine the effect of the introduction of a performance-based incentive plan in a retail establishment. One finding is that sales increase after the introduction of the incentive plan, and increase even further over time. In addition, sales are relatively lower in the peak season when more seasonal workers are employed. The latter finding can be explained by the fact that seasonal workers do not participate in an incentive plan (Banker et al. $1996 \mathrm{a}$ ). In another study, Banker et al. (1996b) find further support for the positive performance effects of financial incentives. They investigate the impacts of performance-based incentive compensation in the retail industry taking into account contextual variables, such as intensity of competition, customer profile and behavior-based controls. Performance effects are stronger in highly competitive and upscalle markets compared to lower scale markets with lower competition, because efforts in finding new customers is more effective in highly competitive markets than in less competitive ones (Banker et al. 1996b). Banker et al. (2001) find additional support for the positive effects of financial incentives on performance. In their study, performance of sales employees continuously improves after the introduction of a performance-based incentive plan. Reasons for this continuing improvement are two different effects, a selection effect and an effort effect. The selection effect describes the fact that less productive employees will leave the firm (or will not seek employment in this firm). The effort effect actually shows that employees respond to financial incentives and increase their efforts 
(Banker et al. 2001). Wallace (1997) examines the impact of a compensation plan based on residual income on decisions of managers. He finds that performancebased compensation leads to different decisions of managers compared to managers without a performance-based compensation. Residual income increases after compensation is linked to residual income as performance measure, suggesting a shift in managerial attention. His findings thus support the idea that financial incentives influence managerial behavior ("You get what you pay for.").

The effects of financial incentives are also investigated in numerous experimental studies. Many experiments provide support for the empirical findings above (Bonner et al. 2000). Chow (1983), for example, finds in an experiment that piece-rate schemes have a positive effect on motivation and performance in a decoding task. Further, individuals who could self-select their compensation scheme outperformed those who could not choose their compensation scheme, which suggests a selection effect as mentioned earlier. Bailey et al. (1998) give additional support for the positive effects of financial incentives on performance of individuals. Bailey et al. (1998) find in an assembly task that initial and overall performance is higher in the treatment groups with piece-rate schemes and goal-contingent pay compared to treatment groups with fixed pay. However, the performance effects of financial incentives decrease with increasingly complex tasks that require more cognitive skills than very simple tasks (Bonner et al. 2000). Sprinkle (2000) examines the effect of incentives on performance of subjects with a cognitive task and considers learning effects in particular. Incentives lead to higher performance as subjects devote more time on a task and improve the use of information on the task. Performance improvements in this complex setting occur only after considerable time and feedback.

There is thus evidence suggesting that financial incentives thave an effect on individuals. Compensation linked to performance has an influence on the behavior of agents. Incentives are thus an effective device for principals to influence the action of an agent. Besides an effort effect, there is a selection effect which helps firms to increase performance. 


\subsection{Assumptions and challenges of the traditional P/A model}

\subsubsection{Critical introductory remarks}

Despite the empirical evidence on the effects of financiall incentives on performance of agents, the traditional P/A model is frequently criticized for being too simple to explain employer-employee relationships. There are several assumptions of the traditional P/A model that are limiting its application and in some cases may be even incorrect. First, the classical P/A model assumes that agents are risk-and effort averse. As mentioned by Indjejikian (1999), there are concerns that risk- and effort aversion is not as important as suggested by traditional P/A models. He concludes that the agency problem is less a problem of getting the agent to work harder, but rather to motivate him to take the right actions. Second, an assumption of the traditional P/A model is that employer-employee relationships consist of formal arrangements involving explicit contracts. However, these relationships often include several informal understandings on the duties of an agent. Performance evaluations are frequently based on a variety of informal and qualitative judgments (Indjejikian 1999). A third assumption of the traditional P/A model is that individuals are wealth-maximizers, and will shirk (or deliver no effort) unless it contributes somehow to their own economic well-being (Bonner and Sprinkle 2002). Given the empirical findings on the effects of financial incentives, there is no doubt that individuals are mativated by extrinsic incentives. However, people do not only work for pure economic reasons. There are also other reasons that play an important role for an agent to work. Individuals working in a social environment are influenced by peers and are concerned with their social standing (Indjejikian 1.999). Ethical concerns of individuals and fairness considerations are not considered and limit the explanatory role of the traditional P/A model. Finally, the traditional P/A model is rather short-term oriented. As mentioned by Indjejikian (1999), erioployeremployee relationships are usually long-term relationships where employees learn and can improve their productivity. At the same time, employers can alter and redesign compensation contracts. Agents are thus engaged in long-term contracts rather than short-term contracts, as assumed in traditional P/A models. Long-term interests of an agent, career concerns, and the possibility of the principal to change 
and revise incentive contracts are issues that play a role in most employeremployee relationships (Indjejikian 1999).

In this dissertation, I address two of the above-mentioned assumptions that individuals are money-maximizing and that most $P / A$ relationships are short-term oriented. Reason for this is the importance of these issues especially in multi-task settings. Effort of agents in multi-task settings may be influenced not only by explicit financial incentives, but also other motivational mechanisms, like social incentives and implicit financial incentives, that are neglected in traditional $P / A$ models.

\subsubsection{Individuals as effort-averse money-maximizers}

Economic theory is based on strict assumptions concerning the preferences of principals and agents. One important assumption of standard P/A theory is that individuals are selfish and opportunistic. Despite the suggested positive effects of financial incentives mentioned in the previous section, the use of fixed wages independent of performance is still very common. Economic theory suggests that it is optimal for an agent to follow a random or myopic strategy to minimize costs of effort. However, there is much anecdotal evidence as well as experimental evidence that this rarely happens in reality. For example, in the experiment by Sprinkle (2000), participants have to perform a cognitive task over several periods and receive either a performance-based compensation contract or a fixed wage. In contrast to the prediction of economic theory, performance of subjects with a fixed wage contract is nonzero. In fact, individuals deliver a considerable amount of effort although their performance is irrelevant for their own payoff. It seems that individuals derive some utility from working and that reasons other than pure economic ones play a role in individual decision-making.

Besides utility from working, people have a need for fairness and reciprocal behavior. Reciprocity is the desire to be kind to those people who are kind to oneself (Fehr and Gächter 1998). People who are treated in a kind way respond frequently 
not as selfishly as predicted by economic theory, but also respond in a friendly way. There appears to be a positive relationship between fair wages and effort (Akerlof 1980). Hannan (2005) investigates in an experiment this relationship and finds that workers with a higher wage than the market clearing wage deliver more effort because of reciprocal reasons. This reciprocal behavior can develop to a social norm in a group. To sustain this behavior in a group of people there must be sufficiently enough people who are motivated by reciprocity. In a group of people, a social norm of reciprocal behavior can be sustained because of possible social sanctions towards that person deviating from the social norm (Akerlof 1980). In a large group of people, however, it is highly likely that there are individuals who are not acting according to the social norm of reciprocity, but who act with negative reciprocity (e.g., free-riding). Free-riding is thus likely in a setting with a rather pessimistic outlook on the reciprocal behavior of others. If individuals have no opportunity to punish free-riders, it is almost impossible to sustain a norm of reciprocity. This changes when individuals have the chance of direct retaliation. If reciprocally motivated individuals have the chance to take costly actions to punish free-riders, the impact of negative reciprocity changes. Punishing free-riders is a credible threat by reciprocally motivated individuals. ${ }^{7}$ So, in case individuals have the chance of direct retaliation, negative reciprocity induces reciprocally motivated individuals to punish those deviating from the norm of reciprocity so that the social norm can be sustained (Fehr and Gächter 1998). Several experimental studies have investigated the roles of reciprocity and fairness in decision-making (Fehr et al. 1993; Fehr et al. 1997; Fehr et all. 1998; Fehr and Gächter 1999; Hannan 2005).

Fehr et al. (1993) run a market experiment where principals make wage offers to workers, and in returm, workers can accept or reject offers and deliver effort at own personal costs. The authors find support for the view of Akerlof (1980). Wages higher than the equilibrium wages result in a friendly response by the workers with effort that is higher than necessary. Participants have a feeling of reciprocal behavior and fairness in a sense that principals who offer high wages are

\footnotetext{
${ }^{7}$ Punishment is not a credible threat by individuals who free-ride, as those individuals are selfish and punishment is costly.
} 
"rewarded" with high effort. Hannan (2005) also finds support for the role of reciprocal behavior. In addition, she finds that reciprocal behavior of agents is affected by firm profits. More specific, when wages remain unchanged but firm profit increases, individuals "punish" firms whose profits increase by delivering less effort (Hannan 2005).

It has frequently been argued that in competitive markets the competitive equilibrium will be achieved within several periods. However, in the experiment by Fehr et al. (1998) on social norms in experimental labor markets, reciprocity is a persistent phenomenon. The market clearing wage is not reached even after several periods. Subjects have a preference for fair behavior in a way that fairness is dominating purely economic reasoning over time. The fact that reciprocal behavior is persistent shows that this behavior is a norm for people.

Social norms develop in many groups and seem to become stronger in groups where social distances between members are low. Fehr and Gächter (1999) investigate in an experiment the roles of social interaction and social rewards on people's willingness to contribute to a public good. Participants are assigned to stranger and no-stranger treatments to account for social distances. An important finding is that social approval alone has only a weak effect on the provision of a public good. However, if social distance between participants is low and there is some form of group identity, social approval leads to a strong reduction in freeriding.

Reciprocal behavior is voluntary and based on fairness and the belief that the other party acts in a similar way. However, in combination with performance-based incentives, reciprocal behavior may be in conflict because the provision of performance-based incentives can create an atmosphere of distrust and even threat (Fehr et al. 1997).

The findings by Fehr et al. (1993), Fehr et al. (1997), Fehr et all. (1998), Fehr and Gächter (1999), and Hannan (2005) show that reciprocal behavior is important for 
individuals and even preferred over the theoretically predicted opportunism and selfish behavior. Absent economic incentives, people seem to have a preference for reciprocal behavior that exists not only in one-shot games, but is sustained over longer periods. Being treated friendly leads individuals also to respond friendly.

Clearly, it is difficult if not impossible to account for all kind of personal characteristics of people in economic theory. ${ }^{8}$ In the next section, however, I elaborate on individual characteristics, such as honesty and ethical concerns, which seem to have an important influence on decision-making of people (Evans et al. 2001; Stevens 2002).

In an experimental study by Evans et al. (2001), participants act as agents and receive cost information on a production process that is not known to participants acting as principals. The experimental task is then to report cost information for budgeting purposes to the principal. The higher the reported costs, the higher the payoff to the agent as all budget proposals are generally accepted. Overall results show that people sacrifice wealth for their desire of being honest. Even iff the payoff to lying increases, individuals do generally not seem to lie more. Preferences for honesty, however, vary in strength so that there are people who act more opportunistic than others (Evans et al. 2001). Stevens (2002) finds in an experiment with a budgeting task that individuals with high levels of ethical concerns engage less in shirking activities than those individuals with low levels of ethical concerns. The desire of acting in an ethically good manner is thus higher than the desire to increase personal wealth.

The results of these studies show how personal characteristics can influence the results and furthermore how personal variables such as preference for honesty or ethical concerns can lead to different results than those predicted by traditional agency theory. ${ }^{9}$

\footnotetext{
${ }^{a}$ Fischer and Huddart (2004) include social norms in an agency model and show that social norms can have both beneficial and harming effects for an organization.

${ }^{9}$ In a recent study, Stevens and Thevaranjan (2005) try to incorporate ethical concerns and ethical sensitivity into an agency model. In particular, they show how an effort-level
} 
In the section above, I discuss research findings that raise concerns on the moneymaximizing assumption made in traditional $P / A$ models. This section shows that individuals do frequently not act as predicted by traditional agency theory. Social norms, such as reciprocal behavior and feelings of fairness seem to be at least as important as economic payoff. In addition, personal preferences for honesty and ethical concerns play an essential role in principal-agent relationships.

\subsubsection{Explicit versus implicit incentives}

To capture relationships between a principal and an agent better, extensions of the traditional P/A models are necessary. In particular, it is necessary to include longterm considerations of an agent and career concerns so that employer-employee relationships can be better explained.

Research on the design and effect of financial incentives suggests that the role of explicit contracts is important to induce agents to take the desired level and allocation of effort and to reduce moral hazard. Whereas the role of short-term incentives is important for the choice of effort, dynamics of principal-agent settings are neglected in many incentive studies. Dynamics are important because current action and performance of agents can have effects on the design of contracts in later periods. For example, Fama (1980) states that moral hazard is removed by market forces because managers are concerned with their reputation. The role of multi-period contracts has been investigated in studies where current efforts not only have an effect on current compensation but also on compensation in the future (e.g., Fama 1980; Gibbons and Murphy 1992; Holmström 1999; Prendergast 1999; Andersson 2002; Autrey et al. 2003). This part of the chapter deals with the dynamic effects of the role of financial incentives, and in particular with the role of short-term explicit incentives versus long-term implicit incentives, an issue that is neglected in traditional agency models.

specified by the principal can lead to an optimal fixed wage, because agents with high ethical concerns suffer a utility loss if they do not act as demanded by the principal and do not meet the specified effort level. 
Individuals are concerned with the prospects of thelr career. Their current performance is a signal of their ability and may influence their compensation and career prospects in the future. More specifically, individuals who show high performance are more likely to receive higher payment in the future than individuals with low performance. This relationship between current performance and future compensation can lead to career concerns where people take action not only to improve their current pay but also potential future pay. Agents give the labor market a signal with respect to their ability and the principal responds to this signal by paying the agent the market wage for the signaled ability. ${ }^{10}$ Firms, as part of a labor market, compete for highly talented employees. Consequently, they need to increase compensation of the employee to the market price for that employee, as otherwise employees who are talented and underpaid can find a better paid employment in another firm. In other words, signaling in the current period can possibly lead to higher compensation in later periods because the labor market considers the employee engaging in signaling behavior as talented (and possibly underpaid).

Career concerns of an agent, hence the concern that performance in the current period potentially has an influence on the compensation in future periods, is a form of implicit incentives. Gibbons and Murphy (1992) define total incentives of agents as a combination of explicit and implicit incentives. Explicit incentives are financiall incentives based on current performance and are received in the current period. Gibbons and Murphy (1992) argue that career concerns and their incentive effects are highest in early stages of an agent's career and lowest when an agent is close to retirement. It is thus necessary to optimize the total level of incentives depending on the individual situation of the agent. Ceteris paribus, the total level of incentives, i.e., explicit incentives plus implicit incentives does not change over time, but the weight of each type of incentive differs. Accordingly, Gibbons and Murphy (1992) predict that the level of explicit incentives is lower in early stages of an agent's

\footnotetext{
${ }^{10}$ Signalling activities play not only a role when actual abillity of an agent is unknown. Irlenbusch and Sliwka (2003) find that agents engage in signalling activities even when their ability is known to the labor market to improve their reputation and to show their willingness to work hard.
} 
career but higher if an agent is nearing retirement. In an empirical test with compensation data of CEOs, they find evidence for their predictions. Explicit incentives for CEOS increase the closer the CEO gets to retirement, suggesting that for an agent getting less interested in making a career, incentive effects due to career concerns become less important (Gibbons \& Murphy 1992). To motivate the agent to deliver effort, explicit financial (short-term) incentives are necessary to outweigh the lack of implicit long-term incentives due to career concerns.

Career concerns can thus be a strong motivator for agents to deliver effort. However, in a dynamic incentive model Holmström (1999) shows how career concerns can have distorting effects. Risk-taking behavior, for example, is not necessarily stimulated by career concerns. There often is an incongruity of risktaking between an agent and a firm. Whereas firms demand a certain level of risktaking, risk-averse agents often engage in risk-avoiding behavior. This seems plausible for an agent with career concerns, because a project that failed may have a negative effect on his future compensation, as a failed project may signal low ability. For an agent with career concerns it is important to finish projects successfully because of the signal to the labor market connected with such a project. As a consequence, an agent will try to choose projects that are primarily low in risk but not necessarily in line with the objectives of the firm. This is the potentially harming effect of career concerns (Holmström 1999). Career concerns can on the one hand motivate the agent to work, but on the other hand lead to effects that are possibly not in line with the objectives of the principal.

The above discussion demonstrates how important long-term considerations of an agent and career concerns are in employer-employee relationships. It is thus necessary to extend agency models further to reflect reality better. As shown by Gibbons and Murphy (1992) as well as by Holmström (1999), Prendergast (1999), Andersson (2002) and Autrey et al. (2003), career concerns have important implications for the design of incentive schemes. 


\subsection{Conclusion}

The objective of this chapter is to discuss empirical evidence with respect to agency theory. The first part of this chapter presents empirical evidence on the effects of financial incentives on behavior of agents. The effect that financial incentives influence behavior of agents is supported by archival, field and experimental data. Furthermore, the second part of this chapter addresses some challenges of agency theory, and in particular the assumptions that individuals are money-maximizing and the role of long-term considerations of agents, such as career concerns. Research on reciprocal behavior and social norms gives reason to doubt the validity of the assumption that individuals are money-maximizing. Implicit non-financial incentives thus play an important nole for individual decision-making. This chapter also reveals that implicit financial incentives of agents and especially long-term considerations like career concerns can have strong incentive effects.

Total incentives of agents consist of explicit financial incentives, as discussed in chapter 2, but also of implicit financial incentives and implicit non-financial incentives. People are thus not only motivated by explicit monetary incentives, but also by other sources of motivation like social status, reputation and long-term implicit incentives. The conclusion of Holmström and Milgrom (1991), that a fixed wage is optimal in a multi-task setting where performance is measured on only one task is drawn on the sole existence of explicit financial incentives. However, I argue in this chapter that behavior of individuals is driven by total incentives, i.e., the combination of current explicit financial incentives, as described in traditional agency models, and implicit financial and non-financial incentives. Based on the discussion of chapter 2 and chapter 3 the question arises how implicit financial and non-financial incentives affect behavior given the use of explicit financial incentives. 


\section{CHAPTER 4}

\section{The Role of Social Incentives in Multi-Task Agency Settings}

\subsection{Introduction}

In this study I investigate the role of financial incentives and social incentives in multi-task settings. While incentive contracting in single-task settings is concerned with inducing the agent to provide effort, the main concern in multi-task settings is the allocation of this effort over multiple tasks (Holmström and Milgrom 1991). In case the agent's multiple tasks are measured with varying levels of noise, financial incentives can cause a problem of managers shifting their attention to those tasks where effort is measured more precisely. Holmström and Millgrom (1991) conclude that a fixed wage may be optimal in this setting to assure a congruent effort allocation, even though overall effort is likely to be lower. This conclusion is consistent with the prevalence of fixed wages in practice, but it is inconsistent with the casual observation that incentives are often used in settings that are characterized by multi-tasking. Although the theoretical literature provides a number of economic explanations for this latter observation (see e.g., Prendergast 2002a), I examine to what extent the above conclusion holds when agents are also exposed to motivational mechanisms other than financial incentives. "1 More specifically, I examine whether individuals act in a congruent (non-congruent) way in the absence (presence) of distorted financial incentives and whether social incentives influence effort allocation.

\footnotetext{
${ }^{11}$ It should be noted that the purpose of this study is not to design an experiment that resembles the set-up of the Holmstrom and Milgrom (1991) madel, but to test the implications of this model.
} 
Previous research indicates that nom-economic factors are relevant in decisionmaking and control (Ashton 1990; Awasthi and Pratt 1990; Libby and Lipe 1992; Bonner and Sprinkle 2002; Sprinkle 2003). Especially social incentives seem to play an important role in modern work environments (Fehr and Gächter 1999; King 2002; Towry 2003; Coletti et al. 2004) and the economics literature has also started to incorporate these issues into agency models (e.g., Fischer and Huddart 2004). Sacial norms can provide an incentive for individuals to follow a certain course of action, which might be different from that based on financial incentives. In multitask settings, this implies that the potential distorting effects of financial incentives might be (partly) offset by social incentives. As a result, sacial incentives can have a decision-influencing rolle for individuals and can be important for incentive contracting.

I examine how congruent social incentives affect the impact of distorted financial incentives on effort allocation when individuals need to perform multiple tasks. More specifically, I run a $2 \times 2$ experiment to examine whether social incentives that are congruent with the firm's objective alleviate the negative effects of distorting financial incentives. In the experiment, subjects have to choose an overall effort level, and subsequently allocate their effort between two tasks. The firm's preferred effort allocation is 50/50. I randomly assign subjects to one of the following four treatments: (1) fixed wage/no social incentives, (2) financial incentives on one task/no social incentives, (3) fixed wage/congruent social incentives, and (4) financial incentives on one task/congruent social incentives.

I find that subjects who receive distorting financial incentives allocate significantly less effort to the unmeasured task compared to subjects who receive a fixed wage. However, this effort distortion is significantly lower when subjects face congruent social incentives. When subjects receive distorting financial incentives, the effort allocated to the unmeasured task is approximately twice as large in the presence of congruent sociall incentives compared to the absence of such incentives. I further find that ethical concerns (individual norms) reinforce the positive effects of social 
incentives (group norms). Finally, I provide further evidence that individuals deliver significantly more overall effort with financial incentives than with fixed wages.

This study contributes to the literature in a number of ways. First, it is one of the first studies to experimentally examine issues of effort allocation in multi-task settings. Second, it extends the literature on social incentives by indicating the relevance of these types of incentives in multi-task settings. I indicate that there are settings where financial incentives are preferred over fixed wages even though part of the agent's job cannot be measured. Third, it provides additional evidence of the role of ethical concerns in individual decision-making. Finally, the study provides support for the recent claim that the agency problem is not only about inducing agents to deliver effort but also about getting the agent to take the 'right' action.

The remainder of this chapter is organized as follows. In section 4.2 I discuss the theoretical background and develop the hypotheses. In section 4.3 I describe the experimental method and in section $4.4 \mathrm{I}$ present the results. I discuss the implications of my results and conclude this chapter in section 4.5 .

\subsection{Theory and hypotheses}

\subsubsection{Financial incentives}

Agency theory is concerned with the design of optimal incentive contracts by a riskneutral principal to solve moral hazard problems with respect to a risk-averse and effort-averse agent. The effort aversion of the agent reflects the conflict of interest between him and the principal, which in the classical agency model reflects the trade-off between leisure and work. Critics argue that this classical view of the agency problem is too simplistic and too far away from reality. Indjejikian (1999), for example, states that the agency problem is the conflict to stimulate agents to choose the 'right' action and to take the 'right' decision rather than getting employees to work harder. This view has become popular over the last decade and has resulted in an emphasis on multi-task agency models, especially in accounting 
(e.g." Holmström and Milgrom 1991; Feltham and Xie 1994; Hemmer 1996; Data" et al. 2001). Whereas incentives in singlle-task agency models are used to motivate effort, incentives in multi-task settings serve additionally to allocate effort between the different tasks.

In their seminal paper, Holmström and Milgrom (1991) indicate that inducing a certain effort allocation can become problematic when effort is measurable on one task, but not on the other task. In an agency setting with two substitute tasks of equal importance to the principal and performance measured on one task but not on the other task, agents will shift their effort to the measured task when provided with financial incentives. Given that this effort allocation is inconsistent with the principal's objective, Holmström and Milgrom (1991) conclude that a fixed-wage contract may be optimal in such a multi-task setting in order to avold the distorting effects of financial incentives. This conclusion holds under the assumptions that (1) under a fixed wage contract, the agent is willing to provide some effort and allocate this effort according to the objectives of the firm instead of following a random strategy, and (2) financial incentives are the only force that affect the agent's initial effort choice.

\subsubsection{Social incentives}

The predictions of Holmström and Milgrom (1991) are based on the assumption that the agent's effort choice is solely driven by financial incentives. However, besides financial incentives, other more socially mediated motivations play an important role in individual decision-making. Social incentives lead individuals to act in a way to gain social approval and to avoid reputation losses and social sanctions (Akerlof 1980; Fehr and Gächter 2000). Individuals derive utility from reputation, where reputation effects are a consequence of obeying to social customs (Romer 1984; Naylor 1989). Efforts towards social approval are aimed to lower psychological costs, as non-conformity to group norms can be psychologically costly for individuals due to the social sanctions imposed, where social sanctions often take the form of ridicule, name-calling or social ostracism (Roethlisberger and Dickson 
1939; King 2002). Fischer and Huddart (2004) incorporate the aspect of social norms into an agency model and show that this socially mediated mechanism can even change the optimal design of firms.

Experimental and field study evidence confirms the importance of social incentives in individual decision-making. Roethlisberger and Dickson (1939) find in a field study that production workers establish a performance standard for members of their group and deviating members of the group are socially sanctioned. In an experimental setting, Fehr and Gächter (1999, 2000) show that free-riding decreases in the presence of social incentives, either through sociall approval or punishments. King (2002) finds that the self-serving bias of auditors is neutralized when they are exposed to social pressure to conform to group norms. Finally, Towry (2003) examines the effects of social ties on mutual monitoring contracts and finds that horizontal monitoring systems are effective in case of strong social ties in a group, as individual actions are influenced by group affiliation and group norms.

The impact of financial incentives on the effort choice is driven by monetary concerns, while the impact of social incentives is driven by social concerns. Whereas financial incentives lead to a shift in effort allocation towards the task that is measured precisely, social incentives can create pressure towards social approval and reputation concerns and can lead to a different effort allocation. I therefore expect that social incentives moderate the potential distorting effects of financial incentives on effort allocation in a multi-task setting. More specifically, in the presence of social incentives to allocate effort evenly between two tasks, that is congruent social incentives, the distorting effects of providing financial incentives on only one task should be reduced.

In sum, the above discussion indicates that if the agent needs to perform two tasks that are substitutes, of equal importance to the principal, and of equal difficulty, then the provision of financial incentives on only one task leads to an effort distortion compared to providing a fixed wage, but that congruent social incentives can (partly) moderate this distortion. Panel A of table 4.1 shows my expectation of 
how agents allocate their effort in four different treatments, under the assumption that the principall prefers a $50 / 50$ allocation and the agent is always willing to provide some effort. The effort allocation " $a$ " indicates the percentage of effort allocated to the unmeasured task. Under fixed wages and no congruent social incentives, the agent is indifferent in terms of effort allocation and thus acts in congruence with the principal"s objective, i.e., effort is allocated evenly between the tasks $\left(a=a_{\text {first-best }}=1 / 2\right)$. If the agent receives a fixed wage but is also exposed to congruent social incentives, then his effort allocation is driven by the social norm, i.e, $a=a_{\text {social norm }}=1 / 2$, which implies that there is no difference in effort allocation between the two fixed wage treatments. In contrast, with distorting financial incentives and no congruent social incentives, the agent's effort allocation is solely driven by monetary concerns, which results in $a=0$. If congruent social incentives are present in addition to distorting financial incentives, then the agent"s allocation is affected by both monetary concerns (financial incentives) and social norms (social incentives), i.e., $0<a<1 / 2$. As a result, I state the following hypothesis.

$\mathrm{H}_{1}$ : The effort allocated to an unmeasured task is lowest when individuals receive distorting financial incentives and lack congruent social incentives, higher when they receive distorting financial incentives and face congruent social incentives, and highest when they receive a fixed wage, regardless of whether they face congruent social incentives. 


\section{TABLE 4.1}

\section{Overview of Experilmental Method and Expectations}

Panel A: Expected effort allocation per experimentall treatment ${ }^{a}$

\begin{tabular}{|c|c|c|}
\hline & No Sociall Incentives & Social Incentives ${ }^{b}$ \\
\hline $\begin{array}{l}\text { Fixed } \\
\text { Wage }\end{array}$ & $a=a_{\text {first-best }}=1 / 2$ & $a=a_{\text {social norm }}=1 / 2$ \\
\hline $\begin{array}{l}\text { Financial } \\
\text { Incentives }\end{array}$ & $a=0$ & $0<a<1 / 2$ \\
\hline
\end{tabular}

Panel B: Effort Levels and Cost of Effort ${ }^{\mathrm{d}}$

\begin{tabular}{|l|c|c|c|c|c|c|c|c|c|}
\hline Overall effort level & 1 & 2 & 3 & 4 & 5 & 6 & 7 & 8 & 9 \\
\hline Cost of effort (C) & 0.56 & 1.11 & 1.67 & 2.22 & 3.33 & 4.44 & 5.56 & 6.67 & 8.56 \\
\hline
\end{tabular}

\footnotetext{
a The effort allocation " $a$ " represents the amount of effort allocated to the unmeasured task (Task B) relative to overall effort.

${ }^{b}$ Social incentives relate to the exposure to a social norm of allocating effort evenly among the two tasks.

CFinanciall incentives relate to a piece-rate om task $A$ and no incentives on task $B$.

d Effort levels represent the amount of effort on task A plus task B.
}

\subsubsection{Ethical concerns}

In addition to financial and social incentives, individual decision-making is also affected by individual characteristics of the decision-maker. When exposed to the same situation, different people react differently because of personality differences. For example, recent studies suggest that human subjects have a preference for honesty (Evans et al. 2001), respond reciprocally to acts of kindness (Hannan 2005), and are influenced by ethical concerns (Stevens 2002). Ethical concerns differ from person to person and indicate the importance of a certain norm and code of conduct to an individual. Individuals who have low ethical concerns are motivated by self-interest, l.e., personal gain at the expense of others, while individuals with high ethical concerns are less likely to act purely oppoirtunistically (Stevens 2002; Schatzberg and Stevens 2004). 
Stevens and Thevaranjan (2005) show that an agent who shirks, derives a disutility if the level of shirking is in conflict with his "work ethic". There is thus a tradeoff between gains from opportunistic behavior and losses due to violations of own ethical standards. Further, they suggest that the principal can induce an effort level that is beyond the agent's critical point, i.e., the level of effort that is considered as reasonable and fair. Stevens and Thevaranjan (2005) show that even a first-best solution is possible by simply requesting the first-best effort level from the agent and compensating the agent for the cost of effort. At a certain level of ethical concerns, the agent will deliver the first-best effort level, because the disutility of not meeting the request of the principal can be high when the agent is compensated for costs of effort.

In a multi-task setting this implies that, if individuals are exposed to distorting financial incentives, greater ethical concerns lead to an effort allocation that is more in line with the firm's objective if agents consider distorted effort as unethical. Acting in line with a certain "work ethic" reduces the disutility of violating own ethical preferences. This effect of ethical concerns is reinforced when the individual is exposed to congruent social norms that are consistent with his/her internal values, because in presence of congruent social norms, distorted effort allocation does not only violate own ethical norms but in addition a social norm. Congruent social incentives and ethical concerns thus positively interact to affect behavior. I therefore formulate the following two hypotheses.

$\mathrm{H}_{2}$ : Ethical concerns decrease the negative effect of distorting financial incentives on effort allocation.

$\mathrm{H}_{3}$ : Ethical concerns and social incentives positively interact to decrease the negative effects of distorting financial incentives on effort allocation. 


\subsection{Experimental method}

To test the hypotheses, I conduct a laboratory experiment. The experimental design is a completely randomized $2 \times 2$ factorial design. As shown in Panel $A$ of table 4.1 , there are two independent variables, i.e., congruent social incentives and compensation scheme, resulting in four treatments. In total 77 business students, 36 female and 41 male, participate in the experiment, all of whom are randomly assigned to one of the four treatment groups. The average age of the participants is 22.5 years.

I choose to design a single-period experiment for the following two reasons. First, as mentioned by Bonner et al. (2000), with complex tasks learning and strategy development takes time and requires multiple periods. The experimental task, which will be described below, is simple and does not require any such learning or strategy development to take place. Second, a component of the congruent social incentive manipulation is communicating to participants "what is desirable", and a singleperiod experiment avoids the problem that a social norm will be endogenously determined during the course of the experiment. As the focus of the study is on congruent social incentives, I want to avoid an endogenous development of a social norm over the course of the experiment. Although such developments are interesting, they are also problematic for the purpose of this study, since these are not only uncontrollable by the experimenter, but most likely also unobservable in my setting.

\subsubsection{Experimental task}

1 use a rather abstract task similar to tasks in experiments by Hannan et al. (2002) and Hannan (2005). Participants are asked to choose an overall effort level. To simulate the concept of costs of effort, participants incur personal costs of effort that are subtracted from their final compensation. Panel B of table 4.1 shows the effort levels and the related costs. Minimum effort level is one and the maximum effort level is nine. The economic optimum is an overall effort level of one in the fixed wage treatments, and an overall effort level of nine in the financial incentive 
treatments. The payoff in the economic optima is 69.44. After having chosen an overall effort level participants need to allocate this effort level on two tasks, task $A$ and task $B$, by indicating a percentage on a decision form. Participants are told that they are working for a firm, whose long-term value is maximized if effort is evenly allocated between the two tasks. In contrast to public good experiments, the overall well-being of the firm as well as effort on task $B$ is not contractible in this setting (cf. Holmström and Milgrom 1991). The combination of a very abstract economic type of experiment with a realllife context is in my setting necessary to communicate that an even effort allocation is desired, given that there is no (economic) public good involved. Instructions are found in Appendix A.

\subsubsection{Experimental procedure}

Participants arrive at the setting and draw an experimental code for reasons of anonymity. After having taken a seat at one of the tables in the laboratory, participants receive an envelope with the instructions and the experimental material. I performed pilot tests to practice the procedures and to test the experimentall material.

\subsubsection{No social incentives and fixed wage/distorting financial incentives}

Participants work individually separated from each other by walls. In a fixed wage treatment, participants receive a wage of 610 irrespective of how they allocate their effort. In the financial incentive treatment, participants recelve $€ z$ per allocated "unit" of effort to task $A$, but nothing for effort allocated to task $B$. The costs of effort are subtracted from the compensation in all compensation treatments.

\subsubsection{Social incentives and fixed wage/distorting financial incentives}

The social incentive treatment is similarly done as in King (2002). Before the start of the experiment participants are asked to introduce each other. Given the information that they are working as a team, participants are asked to find a name for their team. After that, participants take a seat and receive the envelope with the 
instructions and the experimental material. Individuals sit at separate tables, but are not separated by walls. Following King (2002) and Towry (2003), the effort allocation of each team member in percentages is posted on a board for all team members to see in order to simulate mutual monitoring. This was communicated to the participants before the start of the experiment. The individual with the strongest effort distortion, $1 . e$. , the one with the lowest percentage of effort allocated to the unmeasured task, needs to explain his/her effort allocation to the others and this was also ex-ante communicated. ${ }^{12}$

At the end of the experiment participants complete an exit questionnaire. Besides demographic information, manipulation checks are included. There is one dichotomous quiestion as manipulation check for the compensation treatment and two statements that participants evaluate based on a 7-point Likert scale (do not agree at all - strongly agree) as manipulation check for the social incentive treatment. Furthermore, ethical concerns are measured by one question similar to Stevens (2002). ${ }^{13}$ Participants receive their compensation after the experiment is over. The experiment lasts about 30 minutes. Average actual pay per participant is €6.94.

\subsubsection{Dependent variable}

Effort allocated to the unmeasured task $B$ is used as dependent variable. In particular, I measure this variable by the percentage of effort allocated to task $B$ by each participant. Effort is a construct of several dimensions: intensity, direction, duration and strategy development (Bonner and Sprinkle 2002). Whereas effort intensity and direction are considered in this experiment by overall effort level and the effort allocation, the dimensions duration and strategy development are not an issue in this experiment due to the short time frame and the simplicity of the experimental task, respectively.

\footnotetext{
${ }^{12}$ In case of more than one participant with equally distorted effort allocation, more than one person has to explain.

${ }^{13}$ The question used is: "Ignoring the goal of the company would be unethical."
} 


\subsection{Results}

\subsubsection{Manipulation checks}

The manipulation checks with respect to the social incentive manipulation indicate that participants perceived themselves significantly more as a team member under the social incentives treatments than in the other treatments $(p<0.01){ }^{14}$ The manipulation check for the compensation system treatment indicates that all but six participants correctly understand the way they are compensated. I exclude these six participants from further analysis, which results in 71 usable observations.

\subsubsection{Descriptive statistics}

Of the 71 participants in total, 20 participated in the distorting financial incentives/no social incentives treatment, 16 in the distorting financial incentives/social incentives treatment, 17 in the fixed wage/no social incentives treatment, and 18 in the fixed wage/social incentives treatment. Overall, subjects allocate $36 \%$ of their effort to task $\mathrm{B}$, ranging from $15 \%$ in the treatment distorting financial incentives/no social incentives to $51 \%$ in the treatment fixed wage/social incentives. The results are shown in Panel A of table 4.2 and indicate that, even in the absence of social incentives, distorting financial incentives do not lead subjects to completely ignore the unmeasured task and act fully opportunistically (cf. Chow et al. 1988; Stevens 2002). The results further show that the economic optimum is on average never reached. In the two fixed wage treatments all participants allocated effort to task $B$, while in the distorting financial incentives/no social incentives treatment $50 \%$ of the participants allocated no effort to task B. This number is significantly reduced in the distorting financial incentives/social incentives treatment, where only $25 \%$ of the participants allocate no effort at all to task $B$. Finally, the average ethical concerns of the participants equals 4.68 (7-point Likert scale) and a one-way ANOVA indicates that there are no significant differences among the four treatments.

${ }^{14}$ To test this, I sum the answers to the following two questions: (1) the others in the room and I form one production team and (2) if I allocated no effort to task $B$, others in the group will find that out for sure. 


\subsubsection{Hypothesis 1}

As shown in Panel A of table 4.2, the pattern of the means over the different treatments is consistent with hypothesis $H_{1}$. That is, the effort allocated to task $B$ is, on average, lowest in the distorting financial incentives/no sacial incentives condition $(15 \%)$, higher in the distorting financia incentives/social incentives condition (29\%), and highest in the two Fixed Wage conditions ( $50 \%$ and $51 \%$ ). Results of an ANOVA with distorting financial incentives and social incentives as factors are given in Panel $B$ of table 2. The results show a significant interaction of distorting fhancial and social incentives $(p<0.1)$. To statistically test the ordinal interaction stated in hypothesis $H_{1}$ further, $I$ use contrast coding (Buckless and Ravenscroft 1990; Rosnow and Rosenthal 1995; Kadous et al. 2003). Following my hypothesis $H_{1}, I$ use the contrast weights $-3,-1$, and 2 for the conditions distorting financial incentives/no social incentives, distorting financial incentives/social incentives, and fixed wage/(no) social Incentives, respectively (cf. Rosnow and Rosenthal 1995; Kadous et al. 2003). The results, presented in Panel C of table 4.2, show that the hypothesized ordinal interaction is statistically significant $\left(x_{1}^{2}=70.66, p<0.01\right)$. The data therefore provide suppot for hypothesis $H_{1}$. 
TABLE 4.2

Results of the Impact of Financial Incentives and Social Incentives on Effort Allocation

Panel A: Average Effort Allocation per Treatment

\begin{tabular}{l|c|c|} 
& No Sociall Incentives & Social Incentives \\
\hline Fixed Wage & $\begin{array}{c}0.50 \\
(n=17)\end{array}$ & $\begin{array}{c}0.51 \\
(n=18)\end{array}$ \\
\hline $\begin{array}{l}\text { Financial } \\
\text { Incentives }\end{array}$ & $\begin{array}{c}0.15 \\
(n=20)\end{array}$ & $\begin{array}{c}0.29 \\
(n=16)\end{array}$ \\
\hline
\end{tabular}

Panel B: ANOVA with treatment as between factor

\begin{tabular}{llllll} 
Variable & Df & SS & MS & F-value & \\
\cline { 2 - 2 } & 1 & 15370.833 & 15370.833 & 64.13 & $<0.01$ \\
Social Incentives & 1 & 934.587 & 934.587 & 3.90 & $<0.1$ \\
Interaction & 1 & 696.212 & 696.212 & 2.90 & $<0.1$ \\
Error & 67 & 16059.832 & 239.699 & &
\end{tabular}

\section{Panel C: Contrast Coding}

\section{Hypothesized contrast}

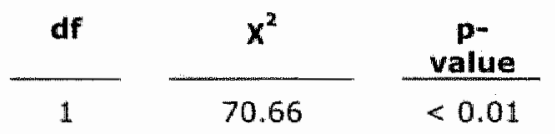

$H_{1}$ : The effort allocated to Task $B$ is lowest in the Financial Incentives/No Social Incentives condition, higher in the Financial Incentives/Social Incentives condition, and highest in the two Fixed Wage conditions (contrast weights are $-3,-1,2$, and 2 respectively).

The dependent variable, effort allocation, is measured by the amount of effort allocated to the unmeasured task (taisk B) relative to overall effort.

\subsubsection{Hypotheses 2 and 3}

To test hypotheses $\mathrm{H}_{2}$ and $\mathrm{H}_{3}$, which respectively state that ethical concerns affect the distorting effects of distorting financial incentives and ethical concerns interact with social incentives to affect this distortion, I apply moderated regression analysis. I use the following empirical specification (Model 1). 
(Modell 1) Effort Allacation $=a_{0}+a_{1} D_{F I}+a_{2} D_{5 I}+a_{3}$ ethic $+a_{4} D_{F I} \times D_{5 I}$

$$
\begin{aligned}
& +a_{5} D_{F I} \times \text { ethic }+a_{6} D_{S I} \times \text { ethic } \\
& +a_{7} D_{F I} \times D_{S I} \times \text { ethic }+\varepsilon_{1}
\end{aligned}
$$

where $D_{F I}\left(D_{S I}\right)$ is a dummy variable that equals 1 if the treatment is Distorting Financial Incentives (Social Incentives) and zero otherwise. The intercept reflects the treatment Fixed Wage/No Social Incentives. ${ }^{15}$ Evidence consistent with $\mathrm{H}_{2}\left(\mathrm{H}_{3}\right)$ is provided when $a_{5}>0\left(a_{>}>0\right)$.

The results for Model 1 are presented in Panel $A$ of table 3. Results show that the interaction stated in $\mathrm{H}_{2}$ is not significant, whereas the hypothesized three-way interaction of $\mathrm{H}_{3}$ is positive and significant $(p<0.10)$. This suggests that ethical concerns only have an effect combined with social incentives, which is consistent with $\mathrm{H}_{3}$, but not with $\mathrm{H}_{2}$. Given the complexity of a three-way interaction (Hartmann and Moers 1999) and the finding that social incentives do not have an effect in the fixed wage treatment, I analyze this three-way interaction further. Specifically, I examine the following model (Model 2):

(Model 2) Effort Allocation $=a_{0}+a_{1} D_{F I S I}+a_{2} D_{F W S I}+a_{3} D_{F W}+a_{4}$ ethic

$$
+a_{5} D_{\text {FISI }} \times \text { ethic }+\varepsilon_{2}
$$

where $D_{F i s I}$ is a dummy variable that equals 1 if the treatment is Distorting Financial Incentives/Sociall Incentives and zero otherwise. $D_{F W S I}\left(D_{F W}\right)$ is a dummy variable that equals 1 if the treatment is fixed wage/social incentives (fixed wage/no social incentives) and zero otherwise. This model tests the influence of ethical concerns on effort allocated to the unmeasured task in the distorting financial incentives/social incentives treatment versus the other treatments. Results of model 2 are shown in Panel $B$ of table 4.3 . The significant result for the interaction term $D_{\text {FISI }} \times$ ethic indicates that ethical concerns have a more positive effect on effort allocated to the unmeasured task in the distorting financial incentives/social incentives treatment

\footnotetext{
${ }^{15}$ Note that the variable ethical concerns is centered, which implies that all lower-order effects are effects at the (sample) average of ethical concerns (Hartmann and Moers 1999).
} 
than in the other treatments $(p<0.05)$. Furthermore, the coefficient for ethic indicates the effect of ethical concerns in the other treatments. This finding provides additional support for $\mathrm{H}_{3}$ and reveals that under distorting financial incentives, the effect of social incentives is stronger with high ethical concerns and leads to more effort allocated to the unmeasured task. 


\section{TABLE 4.3}

OLS Regression of Effort Allocation on Distorting Financial Incentives, Social Incentives, and Ethical Concerms $(n=71)$

\section{Panel A: Results for Model 1}

Independent Variable

Intercept"

Dat

D\$1

Ethical Concerns

$\mathrm{D}_{\mathrm{FI}} \times \mathrm{D}_{51}$

$\mathrm{D}_{\mathrm{FI}} \times$ Ethical Concerns

$D_{\text {SI }} \times$ Ethical Concerns

$D_{\mathrm{FI}} \times \mathrm{D}_{\mathrm{SI}} \times$ Ethical Concerns

Adjusted R-square

Panel B: Results for Model 2

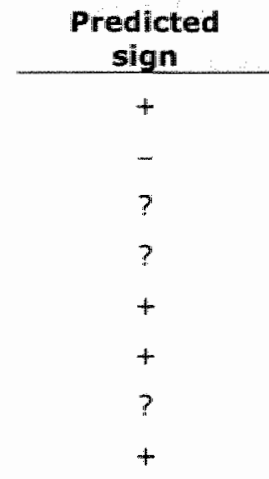

\begin{tabular}{c}
$\begin{array}{c}\text { Predicted } \\
\text { sign }\end{array}$ \\
\hline+ \\
+ \\
+ \\
+ \\
$?$ \\
+
\end{tabular}

Effort Allocation ${ }^{a}$

$50.00^{* * * *}$
$-35.01 * * *$
0.83
0.00
9.01
0.28
-1.76
$7.34 *$
0.49

Intercept ${ }^{c}$

DFISI

$D_{\text {FWSI }}$

DFWnSI

Ethical Concerns

D*tsin $\times$ Ethical Concerns

Adjusted R-square

\begin{tabular}{c} 
Effort Allocation \\
\hline $15.12^{* * * *}$ \\
$9.70^{*}$ \\
$35.80^{* * *}$ \\
$34.62^{* * *}$ \\
-0.33 \\
$6.19^{* *}$ \\
0.51
\end{tabular}

***,**, is statistically significant at the $1 \%, 5 \%$, and $10 \%$ level respectively (two-tailed) based on White-adjusted standard errors.

$D_{F I}\left(D_{S i}\right)$ : indicator variable that equals 1 if the treatment is distorting financial incentives (social incentives) and D otherwise.

$D_{\mathrm{FISI}}, \mathrm{D}_{\mathrm{FWSI}}$, and $\mathrm{D}_{\mathrm{FwnSI}}$ : $\mathrm{D}_{\mathrm{FI}}$ : indicator variable that equals 1 if the treatment is distorting financial incentives/social incentives, fixed wage/social incentives, and fixed wage/no social incentives, respectively and 0 otherwise.

" The dependent variable, effort allocation, is measured by the amount of effort allocated to the unmeasured task (task B) relative to overall effort.

"The intercept reflects the treatment fixed wage/no social incentives, which is used as the benchmark setting.

c The intercept reflects the treatment distorting financial incentives/ino social incentives, which is used as the benchmark setting. 


\subsubsection{Economic significance}

Although my results with respect to the impact of social incentives and ethical concerns are statistically significant, the important question is whether they are economically significant. Whereas in the fixed wage treatments effort allocation roughly equals $50 \%$, effort is strongly distorted in the distorting financial incentives/no social incentives treatment with only $15 \%$ of effort allocated to task $B$. The effort allocated to task B, however, almost doubles to $29 \%$ in the distorting financial incentives/social incentives treatment. In addition to congruent social incentives, ethical concerns seem to play a role in allocating effort to the unmeasured task when confronted with both distorting financial incentives and social incentives. Based on the results of Model 1 and Model 2, 1 find that the estimated effort allocated to task $B$ in the distorting financial incentives/social incentives treatment equals approximately $3 \%$ when subjects score very low on ethical concerns, while it equals approximately $38 \%$ when they score very high on ethical concerns. ${ }^{16}$ These results lead us to conclude that the observed effects of social incentives and ethical concerns are economically significant in addition to being statistically significant.

\subsubsection{Trade-off between total effort and effort allocation}

Although the effort allocated to task $B$ is significantly higher in the distorting financial incentives/sociall incentives treatment compared to the distorting financial incentives/no social incentives treatment, it is still significantly lower than the $50 \%$ observed in the fixed wage treatments. Despite the incongruent effort allocation with distorting financial incentives, such incentives can motivate agents to deliver higher overall levels of effort (Holmström and Milgrom 1991, 34). Consistent with economic theory, I find that there is a significant difference in total effort between the incentives condition and the fixed wage condition $(p<0.01)$. These differences in

\footnotetext{
${ }^{46}$ Very low ethical concerns equals a score of one on the seven-point Likert scale (4.2\% of participants), while very high ethical concerns equals a score of seven on the seven-point Likert scale ( $18.3 \%$ of participants).
} 
effort levels have important implications since high effort levels with a (somewhat) distorted effort allocation may be more beneficial for the principal than very low effort levels that are allocated in congruence with the principal's objective.

To provide some insights into the trade-offs between effort intensity and effort allocation, I use the following example. Given that the preferred effort allocation for the principal is $50 / 50$, I can write the gross-payoff $(\Pi)$ to the principal as

$$
\Pi=\gamma \cdot A \cdot B
$$

where $\gamma$ is a positive production parameter and $A(B)$ is the absolute effort level allocated to task $A$ (B). This specification further indicates that, if $A$ or $B$ equals zero, l.e., the agent provides no effort on task $A$ or on task $B$, the gross-payoff will be zero and the firm will go bankrupt if any payments need to be made to the agent. To create a benchmark solution, I let $\gamma=40$ and write the principall's grosspayoff as

$$
\Pi=40 \cdot A \cdot B
$$

Then under fixed wages of 10 and the optimal economic response of the agent, i.e., effort level of 1 and 50/50 allocation, the actuall net-payoff (Inet) to the principal equals

$$
\Pi_{\text {ner }}=40 \cdot(0.5 \cdot 1) \cdot(0.5 \cdot 1)-10=0
$$

More generally, the net-payoff under fixed wages and under financial incentives can be written as

$$
\begin{aligned}
& \Pi_{\text {HEt }}^{F H F}=40 \cdot\left(1-\alpha_{F W}\right) E_{F W W} \cdot \alpha_{F W} E_{F W}-10 \\
& \Pi_{k g}^{F l}=40 \cdot\left(1-\alpha_{F i}\right) E_{F Y} \cdot \alpha_{F r} E_{F i}-\left(1-\alpha_{F I}\right) E_{F Y} \cdot 2
\end{aligned}
$$


respectively, where $\alpha_{F w}\left(\alpha_{F I}\right)$ is the effort allocated to task $B$ under fixed wages (financial incentives) and $E_{F W}\left(E_{F F}\right)$ is total effort under fixed wages (financiall incentives).

Taking the effort allocations as a given, l.e., using the experimental results, the question is how much higher should $E_{\mathrm{Fl}}$ be relative to $E_{\mathrm{Fw}}$ to prefer distorted financial incentives over fixed wages. For this purpose, I rewrite $E_{F I}$ as

$$
E_{F I}=\kappa \cdot E_{F H}
$$

and answer the following question: for a given $E_{F w}$, how high should $k$ be to set equation (4) equal to equation (5)? To answer this question, I let $\alpha_{F w}=0.50$ (average of Fixed Wage conditions) and $\alpha_{F I}=0.29$ (average of the Distorted Financial Incentives/Social Incentives condition). Using these allocations and equations (4)(6), I can write the difference between $\square_{n v r}^{F W}$ and $\Pi_{w e r}^{F /}$ as

$$
\Pi_{n e t}^{F H}-\Pi_{n e t}^{F E}=\left(10-8.236 \kappa^{2}\right) E_{F \cdot H}^{Z}+\left(1.42 \kappa E_{F H}-10\right)
$$

where the first term reflects differences in the gross-payoff and the second term reflects differences in compensation costs. I subsequently let $E_{F W}$ vary between 2 and 8 (in discrete values) and solve for $k\left(K^{0}\right)$, the results of which are presented in Panel $A$ of Figure $1 .{ }^{17}$ These results indicate that $k^{0}$ varies from $99.8 \% \quad\left(E_{F W}=2\right)$ to $110.4 \%\left(E_{F W}=8\right)$ and levels off at approximately $110 \%$ as $E_{F W}$ gets "large", i.e., $k^{0}$ is an increasing and concave function of $E_{F W}$. This suggests that relatively small increases in total effort are required to prefer distorted financial incentives over fixed wages. ${ }^{18}$ That is, even if financial incentives distort effort allocation, these incentives are preferred over fixed wages if they sufficiently increase total effort. Additional analysis, presented in Panel B of Figure 4.1, indicates that, at lower levels of effort, the "benefits" of distorted financial incentives are driven by lower

\footnotetext{
I7 exclude $E_{F W}=1$ and $E_{F W}=9$, since the solutions in these setting imply that $E_{F I}<1$ and $\mathbb{E}_{\mathrm{FI}}>9$, respectively, a result which is imposstble in the experimental setup.

18 These results are, in a qualitative sense, not sensitive to my choice of $\gamma=40$.
} 
compensation costs (second term in equation (7)), while at higher levels of effort, the "benefits" are driven by a higher gross-payoff (first term in equation (8)).

In sum, my results indicate that a principal may prefer high effort levels with a distorted effort allocation over low effort levels with a congruent allocation. Thus, multi-tasking is not only about adding the issue of effort allocation to the issue of effort intensity, but also, and maybe more importantly, about the trade-off between intensity and allocation. 


\section{FIGURE 4.1.}

Tradeoff Between Effort Allocation and Effort Level

Panel A: Indifference curve between fixed wages and financial incentives when effort $t_{\text {financial incentives }}=\kappa \times$ effor $_{\text {fixed wages }}{ }^{a}, b$

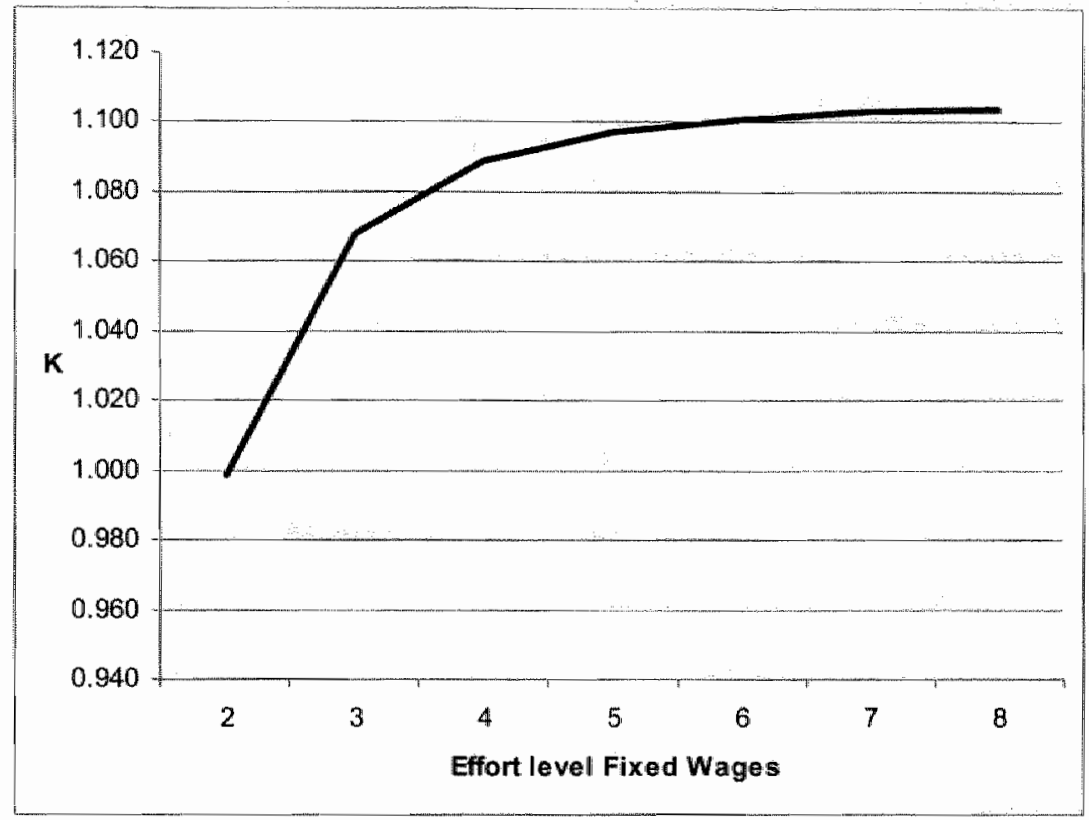

Panel B: Difference in compensation costs and gross payoff between fixed wages and financial incentives at different points on the indifference curve ${ }^{b}$

\begin{tabular}{|c|c|c|c|}
\hline$\frac{\text { Effort Level Fixed }}{\text { Wages }}$ & AGross Pavoff & $\frac{\text { ACompensation }}{\text { Costs }}$ & ANet Pavoff \\
\hline$\frac{\pi}{2}$ & 7.165 & -7.165 & 0 \\
\hline 3 & 5.450 & -5.450 & 0 \\
\hline 4 & 3.816 & -3.816 & 0 \\
\hline 5 & 2.211 & -2.211 & 0 \\
\hline 6 & 0.620 & -0.620 & 0 \\
\hline 7 & -0.963 & 0.963 & 0 \\
\hline 8 & -2.542 & 2.542 & 0 \\
\hline
\end{tabular}

"The value $\kappa$ indicates how productive the effort level of financial incentives must be so that the principal prefers financial incentives over fixed wages. Values of $k>1$ indicate that the effort level under financial incentives must be larger than effort levels under fixed wages. - Values in this figure are based on the effort allocation of the experiment. 


\subsection{Discussion and conclusion}

This study has several implications, both theoretical and managerial. From a theoretical perspective, this study shows the importance of incorporating "noneconomic incentives" into agency models, as is done by, for example, Fischer and Huddart (2004) and Stevens and Thevaranjan (2005). More specifically, my results indicate that, as soon as individuals do not act fully opportunistically, the trade-off between effort intensity and effort allocation becomes crucial. One opportunity for future analytic research is thus to extend the basic multi-tasking model of Holmström and Milgrom (1991) to include these individually and/or socially driven motivations and analyze how the trade-off between effort intensity and effort allocation affects the design of optimal contracts. For example, Stevens and Thevaranjan (2005) incorporate ethics into a single-task agency model to show that fixed wages are preferred over financial incentives when agents are "ethically sensitive" and promise to deliver a predetermined standard level of effort. However, the question is raised whether their results hold in a multi-task setting where ethically sensitive agents promise to deliver a predetermined standard allocation of effort and the trade-off between effort intensity and effort allocation comes into play.

A further extension would be to allow the social norm to be endogenously determined, as in Fischer and Huddart (2004). Fischer and Huddlart (2004) analyze a setting in which a single performance measure is affected by two actions, one of which is subject to an endogenously determined social norm. Their model coull be adjusted to reflect the setting examined in this study, i.e., a contractible performance measure that is affected by one task, a non-contractible performance measures that is affected by another task, and an effort allocation that is subject to an endogenously determined social norm. Analyzing such models could potentially provide more insights into the impact of social incentives on the optimal design of contracts, the selection of agents, or more broadly, the design of firms. 
My results also have managerial implications. In this study, I manipulate the social incentives to be consistent with the principal's objective, i.e., congruent social incentives, and the results provide a plausible explanation for why I observe financial incentives in multi-task settings where parts of the agent's job cannot be measured. The implications of my results, however, extend beyond the experimental setting. The results imply not only that social incentives can mitigate the potential distorting effects of financial incentives, but also the reverse. That is, if social incentives are present within (parts of) a firm that are not consistent with the principal's objective, then financial incentives can mitigate the distorting effects of these non-congruent social incentives. The typical example in this respect is holding scientists in R\&D responsible for financial results because they are in the pursuit of knowledge, while the firm is in the pursuit of marketable products and making a profit (see e.g., Monsanto Company, HBS No. 189-091). Paying these scientists a fixed wage will lead them to allocate too much effort to research for the sake of research and not enough to the development of profitable products. In these circumstances, financial incentives can lead to a more balanced effort allocation that is consistent with the firm's objectives.

My results further imply that if financial incentives and social incentives go in the same direction, then this can be problematic. For example, if financial incentives are provided to meet or beat a performance target and the social norm is that you should live up to expectations, i.e., meet or beat the target, then the focus will be solely on the quantitative aspects of the job to the detriment of the qualitative aspects. As soon as these qualitative aspects are very important ${ }_{i}$ as in the model of Holmström and Milgrom (1991), then this will deteriorate performance and ultimately lead to bankruptcy.

Finally, my results have implication for the selection of employees by firms. Financial incentives are not only used to increase effort but also to attract the 'right' people for the 'right' job, especially at higher hierarchical levels characterized by multi-tasking. At these higher hierarchical levels, incentive contracts are unlikely to 
The Role of Social Incentives in Multi-Task Agency Settings

be complete and social incentives and ethical concerns thus become important issues of management control. 


\section{CHAPTER 5}

\section{The Role of Career Concerns in Multi-Task Agency Settings}

\subsection{Introduction}

The purpose of the study of this chapter is to examine the role of implicit financial incentives in form of career concerns and explicit financial incentives in a multi-task setting. I argue that, in a multi-task setting, career concerns and explicit financial incentives can complement each other, which has important implications for two main findings that have been put forward in the analytical literature. First, analytical research on the use of multiple performance measures indicates that there is a negative relationship between the level of noise in a performance measure and the incentive weight (Banker and Datar 1989). Second, in a setting with not only multiple performance measures but also multiple tasks, Holmström and Milgrom (1991) show that a fixed wage can be optimal when performance on one task is measurable but not at all or only with high levels of noise on another one. By means of an experimental labor market, I provide experimental evidence that suggests that these conclusions may not hold in the presence of career concerns.

Agents with career concerns consider in their action choice that performance in the current period may have an influence on compensation in future periods. ${ }^{19}$ Gibbons and Murphy (1992) argue that in early career stages, an agent is still interested in "making a career", so that the reputation of the agent in the labor market forms an implicit incentive to work. This reduces the need for explicit financial incentives. The

${ }^{19}$ I consider career concerns as mainly financially oriented career concerns and ignore in this study additional aspects of career concerns, such as social status and reputation. 
closer an agent gets to retirement the weaker become implicit incentives due to career concerns. In such a situation, explicit financial incentives become important to motivate the agent. Whereas such substitute effects of career concerns and explicit financial incentives are important in single-task settings, the situation can be different in multi-task settings. The conclusion of Holmström and Milgrom (1991) that a fixed wage can be optimal is drawn in a model without implicit financial incentives of an agent (e.g., career concerns). Given that an agent has career concerns, his action choice is not only influenced by explicit financial incentives, but also by implicit incentives due to career concerns. More specific, the agent will allocate his effort to tasks where his effort is measured more precisely to be able to signal his ability to the labor market. The labor market favors precise performance measures to infer the ability of an agent, so that in presence of career concerns the implicit incentive weight on the precise measure is added to the explicit financial incentive weight on that measure. Banker and Datar (1989) show that explicit incentive weights in contracts with multiple measures should be high on precise measures and should decrease with higher levels of noise. Applying the results of Banker and Datar (1989) leads to an overweighting of precise measures in presence of career concerns, because there are also implicit incentives on the precisely measured task. To counteract a strong preference of the agent with career concerns towards the precisely measured task it may be necessary to increase the explicit incentive weight on a measure with higher noise (Prendergast 2002b). In contrast to a single-task setting where weights on explicit financial incentives and career concerns are substitutes (Gibbons and Murphy 1992), they complement each other in a multi-task setting.

To investigate the rolle of career concerns in multi-task settings, I run a $2 \times 3$ experiment. Participants have to work on two tasks per experimental period that are of equal complexity and character. There are five periods in total. Performance on one task is measured precisely, and on another one with noise. Participants are randomly assigned to one of the following six treatments: (1) equally weighted financial incentives/no career concerns, (2) equally weighted financial incentives/career concerns, (3) fixed wage/no career concerns, (4) fixed 
wage/career concerns, (5) unequally weighted financial incentives/no career concerns and (6) unequally weighted financial incentives/career concerns. ${ }^{20}$ In the career concerns treatments participants are in the first period assigned to one of two principals. These two principals evaluate after every period the performance of the agents and compete with each other for skilled agents by offering agents a transitory wage increase. Agents are automatically assigned in the subsequent period to the principal offering the highest wage for that subsequent period. In case of equal offers of the two principals, the agent stays in the subsequent period assigned as in the previous period.

I find that under a contract with equal incentive weights on both tasks, effort is strongly allocated toward the precisely measured task, both with and without career concerns. In the absence of career concerns and with fixed wages, agents are indifferent between tasks, which supports theoretical predictions by Holmström and Milgrom (1991). The presence of career concerns, however, leads agents to allocate more effort on the precisely measured task, indicating that agents are not indifferent between tasks anymore. Under an incentive contract with a higher explicit financial incentive weight on the task measured with noise, participants allocate most of their effort to that particular task. In the presence of career concerns, however, participants show an almost even effort allocation between tasks, suggesting that explicit financial incentive weights and career concerns are thus complements, and a high explicit incentive weight can help to counterbalance the possibly harmful effects of career concerns.

This study contributes to the literature in several ways. First, there is evidence that in a multi-task setting with career concerns the relationship between noise in performance measures and incentive weights can be positive, which is at odds with

\footnotetext{
${ }^{20}$ Unequally weighted financiall incentives have a higher weight on the noisy measure, and a reduced weight on the precise measure. Equally weighted financial incentives are chosen for two reasons. First, a contract with equal weights serves as a benchmark to compare effort allocation in the different compensation treatments. Second, if effort allocation is distorted under financial incentives with equal weights with and without career concerns, effort allocation should be even more distorted when incentive weights decrease with increases in noise, as suggested by Banker and Datar (1989).
} 
"standard" arguments. Financial incentives can be beneficiall to counterbalance effort distortions due to career concerns so that explicit incentive weights are increased on noisy measures that are less considered by a labor market and thus are less relevant for career concerns. Second, it appears that financial incentives and career concerns complement each other in multi-task settings. Third, in the presence of career concerns, fixed wages are not necessarily optimal if there are multiple performance measures with different levels of noise, because long-term implicit incentives in form of career concerns are not considered. Given that career concerns are frequently present, this study underlines the importance of explicit financial incentives.

This chapter proceeds as follows. In the next section I discuss the theory and develop hypotheses. After that, I describe the experimental design that is chosen for this study. I discuss the results in section 5.4, and finish this chapter with a discussion and conclusion of this study.

\subsection{Theory and hypotheses}

\subsubsection{Explicit financial incentives}

Organizations, whose employees are faced with several tasks, are confronted with the problem of inducing not only high levels of effort, but also an effort allocation that is in line with the overall organizational objectives. As mentioned by Indjejikian (1999), the agency problem is less of inducing effort at all, but rather to induce the "right" effort. A frequently observed problem in multi-task settings is that performance of agents on one task can be measured better than on another task (Banker and Datar 1989, Feltham and Xie 1994), i.e., one performance measure can be noisier than another one. Under the assumption of economic theory that agents are risk-averse, an incentive scheme with equal weights on different tasks can lead to problems. In particular, agents with equally weighted financial incentives on tasks that are measured with different levels of noise prefer to deliver effort on the more precisely measured task, because the risk of delivering effort on that task 
is lower. Such an effort allocation of agents, however, can be in conflict with the objectives of the firm. Fehr and Schmidt (2004) show that individuals in multi-task settings are strongly motivated by explicit financial incentives even if their action reduces the payoff of the principal. More specific, the authors run an experiment where one task is contractible and a second task is not, but an even allocation is value-maximizing for the principal. Agents basically ignore the second task even if this behavior costs the principal his payoff.

Holmström and Milgrom (1991) analyze the role of financial incentives in multi-task settings and show that in the extreme case when performance on one task is precisely measured, and performance on another task measured with high levels of noise or even immeasurable, a fixed wage is optimal. Under a fixed wage, an agent is assumed to be indifferent between tasks and will act therefore in line with the preferences of the principal. This assumption holds when the agent is willing to provide effort and is not following a random strategy.

In sum, when performance on different tasks is measured with very different levels of noise, a fixed wage can be a solution to avoid a preference of the agent for one task over another one.

\subsubsection{Explicit and implicit financial incentives}

Performance in the current period is a signal of the ability of the agent and can have an influence on future compensation. The concern that current performance has an impact on compensation in later periods is a form of career concern (Gibbons and Murphy 1992). An important condition for career concerns to work is that performance signals of an agent to the labor market allow an inference on the agent's ability. In case performance is not measured at all or with high levels of noise, the incentive effects of career concerns diminish, because the labor market will not consider very noisy performance measures to select "good" employees (Prendergast 1999). Signaling activities of agents due to career concerns are not only relevant when the labor market does not know the true ability of the agent. 
Irlenbusch and Sliwka (2003) show in an experiment, that the sigmaling activity of agents is even stronger when true ability of agents is known to the labor market. Irlenbusch and Sliwka argue that full transparency of abilities can help agents to signal the labor market their willingness to work hard and to build a reputation of rewarding the principal with high effort ("homo reciprocans").

The presence of implicit financial incentives in form of career concerns is important for the design of compensation contracts in multi-task settings. In a multi-task setting where performance on one task is measured more precisely than on another task, career concerns can induce a preference of agents to deliver more effort on the precisely measured task, because a noisy performance measure is considered less by the labor market than a more precise measure. One implication of the existence of career concerns is thus that a fixed wage is nat necessarily optimal in multi-task settings, because an agent with career concerns prefers effort on a precisely measured task over effort on a task measured with noise.

To avoid an agent's potentially harmful preference of one task over another one, it may be necessary to adapt the explicit incentive weights on the performance measures of the tasks. Banker and Datar (1989) analyze the use of multiple performance measures for performance evaluation. They show that it is necessary to balance the incentive weights on performance measures that are different in noise. More specific, they show that in an optimal contract the incentive weight on a performance measure decreases with an increase in noise of that measure. However, implicit financial incentives in form of career concerns work in the same direction, i.e., to assess the ability of an agent the labor market puts a higher weight on a precise measure than on an imprecise performance measure. Applying the findings of Banker and Datar (1989) to a multi-task setting with career concerns, agents would strongly prefer to deliver effort on the task measured precisely, because the combination of explicit and implicit incentives leads to an overweighting of the precise measure. To reduce the strong preference of the agent for the precisely measured task, it may be necessary for the firm to increase the explicit incentive weights on noisy measures to counteract the incentive effects of 
career concerns (Prendergast 2002b). With an increased explicit incentive weight on the noisy task, effort on this task becomes more attractive and consequently, effort may be less driven towards the precise measure. So, in contrast to traditional arguments that an incentive weight should be lowered when noise of a performance measure is high, the opposite can be necessary. An increased incentive weight on a noisy measure can help to reduce a preference of an agent for a precisely measured task due to career concerns. Although compensation costs may be higher "potential costs due to a possibly incongruent effort allocation may be lowered. There can thus be a setting where the relationship between noise in a performance measure and explicit incentive weights is positive rather than negative as suggested by traditional agency models.

A positive relationship between explicit incentive weights and noise in a performance measure thas important implications for the role of career concerns of agents and the use of explicit financial incentives. Gibbons and Murphy (1992) investigate the role of career concerns for CEOs and find that explicit financial incentives are lower in early stages of a career, but higher when a CEO is close to retirement. This finding suggests that the weights of explicit financial incentive and implicit financial incentives in form of career concerns are substitutes, where either explicit financial incentives or career concerns are the major source of motivation, depending on the relevance of career concerns for a CEO in different stages of a career. However, when explicit financial incentives are used to balance effort allocation between tasks, the weights of explicit financial incentives and career concerns are not substitutes, but complements.

In sum, implicit financial incentives due to career concerns lead an agent to prefer to deliver effort on a precisely measured task. This can be a setting where it is necessary to increase the explicit incentive weight on a task measured with noise to balance the implicit incentive weight of a labor market. This implies that the relationship between explicit financial incentive weights and noise in a performance measure can be positive, and further, that the weights of explicit financial incentives and implicit financial incentives are complements, not substitutes. 
Based on the discussion above, I expect that agents in a multi-task setting who are paid a fixed wage are indifferent between tasks in absence of career concerns, but prefer effort on the precisely measured task in presence of career concerns. To counteract this behavior it is necessary to increase the explicit financial incentive weight on the task measured with noise. I therefore expect that financial incentives with a higher weight on the task measured with noise reduce the preference for the precisely measured task in presence of career concerns. This leads to the following hypotheses:

$\mathrm{H}_{1}$ : Career concerns shift the effort allocation of agents from the task measured with noise to the task that is measured precisely.

$\mathrm{H}_{2}$ : Agents with fixed wages are indifferent between tasks in absence of career concerns, but prefer effort on the precisely measured task in presence of career concerns. ${ }^{21}$

$\mathrm{H}_{3}$ : Agents with unequally weighted financial incentives are indifferent between tasks in presence of career concerns, but prefer effort on the task measured with noise in absence of career concerns. ${ }^{22}$

Table 5.1 summarizes my expectations for the setting analyzed in this study. Effort allocation $a_{1}\left(a_{1}, \ldots, a_{6}\right)$ represents the effort allocated to the task measured with noise in the six treatments: (1) equally welighted financial incentives/no career concerns $\left(a_{1}\right),(2)$ equally weighted financial incentives/career concerns $\left(a_{2}\right)^{23}$, flixed wage/no career concerns $\left(a_{3}\right)$, (4) fixed wage/career concerns $\left(a_{4}\right)$, (5)

\footnotetext{
${ }^{21}$ This hypothesis assumes that agents are willing to provide effort in the absence of career concerns.

22 I use the term "indifferent" here to demonstrate that fixed wages without career concerns and unequally weighted financial incentives in the presence of career concerns can lead to similar results. Strictly speaking, agents are not indifferent between tasks when exposed to unequally weighted financial incentives and career concerns, but balance their efforts more between tasks.

${ }^{23}$ The treatments with equally weighted financial incentives are used as benchmark setting in this study.
} 
unequally weighted financial incentives/no career concerns $\left(a_{5}\right)$ and $(6)$ unequally weighted financial incentives/career concerns $\left(a_{6}\right)$.

When the agent is exposed to financial incentives with equal weights, he will prefer to shift his attention to the precisely measured task. This preference is strengthened in case of career concerns, so that $0<a_{2}<a_{1}<1 / 2$. An agent with fixed wages in absence of career concerns is indifferent with respect to effort allocation between tasks under the assumption that he is willing to provide effort and not following a randam strategy, i.e., $a_{3}=1 / 2 .{ }^{24}$ However, when exposed to career concerns, he will prefer to deliver effort on the precisely measured task, i.e., $0<a_{4}<a_{3}=1 / 2$. When the agent receives unequally weighted financial incentives, he will prefer to allocate more effort on the noisy task, i.e., $1 / 2<a_{5}<1$. When the agent is also exposed to career concerns, the precisely measured task increases in importance to the agent, so that unequally weighted financial incentives in combination with career concerns lead to a rather balanced allocation of effort, i.e., $1 / 2 \leq a_{6}<a_{5}<1$. Further, I expect the difference between $a_{1}$ and $a_{2}$ to be smaller than the difference between $a_{3}$ and $a_{4}$ and the difference between $a_{5}$ and $a_{5}$, i.e., career concerns have a stronger effect when the agent is exposed to fixed wages or unequally weighted financial incentives compared to the effect of career concerns under equally weighted financial incentives. Reason for this expectation is the fact that in the presence of equally weighted financial incentives, incentives due to career concerns add little more to inducing effort on the precisely measured task.

${ }^{24}$ See section 5.3.1. for details on the experimental setting. 


\begin{tabular}{|c|c|c|}
\hline \multicolumn{3}{|c|}{$\begin{array}{c}\text { TABLE } 5.1 \\
\text { Expected Effort Allocation per Experimental Treatment }{ }^{\mathrm{a}}\end{array}$} \\
\hline \multirow{2}{*}{$\begin{array}{l}\text { Equally weighted } \\
\text { financial incentives }\end{array}$} & No career concerns & Career concerns \\
\hline & $\begin{array}{c}(\mathbb{1}) \\
0<a_{1}<1 / 2\end{array}$ & $\begin{array}{c}(2) \\
a_{2}<a_{1}\end{array}$ \\
\hline Fixed wage & $\begin{array}{c}(3) \\
a_{3}=1 / 2\end{array}$ & $\begin{array}{c}(4) \\
0<a_{4}<a_{3}\end{array}$ \\
\hline $\begin{array}{l}\text { Unequally weighted } \\
\text { financial incentives }\end{array}$ & $\begin{array}{c}(5) \\
1 / 2<a_{5}<1\end{array}$ & $\begin{array}{c}(6) \\
1 / 2 \leq a_{6}<a_{5}<1\end{array}$ \\
\hline \multicolumn{3}{|c|}{$\begin{array}{l}\text { The effort allocation } a_{1}\left(a_{1}, \ldots, a_{6}\right) \text { represents the effort allocated to the task measured wit } \\
\text { high levels of noise. }\end{array}$} \\
\hline
\end{tabular}

\subsection{Experimental method}

The hypotheses are tested in an experiment with 121 business students. I conduct a $2 \times 3$ laboratory experiment. Manipulations of career concerns and three types of compensation schemes lead to six different treatment groups. The 121 students are randomly assigned to one of the following six treatments: (1) equally weighted financial incentives/no career concerns, (2) equally weighted financial incentives/career concerns, (3) fixed wage/no career concerns, (4) fixed wage/career concerns, (5) unequally weighted financial incentives/no career concerns and (6) unequally weighted financial incentives/career concerns. 


\subsubsection{Experimental task}

Similar to studies by Chow (1983), Chow et al. (1988), Sillamaa (1999), Fisher et al. (2002), and Stevens (2002), the experimental tasks are simple decoding tasks. There are different decoding schemes for each task, but both task $A$ and task $B$ do not differ in complexity. However, performance on task $A$ is measured precisely and performance on task $B$ is measured with noise. To avoid a random effort allocation under fixed wages, participants in all treatments of the experiment are told that an even effort allocation is desirable. Instructions are found in Appendix B.

\subsubsection{Experimental procedure}

The experiment starts with a training session to familiarize participants with the experimental task. After this, five experimental periods follow of 120 seconds each. Participants are informed when 60 seconds are over and when 10 seconds are left in a period. In the experiment, participants decode on average 44.3 numbers per period. The average number of correctly decoded numbers amounts to 39.3 in the first period and increases to 47.9 in the last period, which demonstrates a learning effect in the sense that participants develop a routine in decoding tasks. This effect does not differ significantly between treatments $(p>0.1)$. Performance of participants is measured as follows:

result task $A$ : $r_{A}=30+$ amount of correctly decoded numbers of task $A$ result task $B$ : $r_{B}=30+$ amount of correctly decoded numbers of task $B+e$

At the beginning of each period, participants always receive 30 points. ${ }^{25}$ Per correctly decoded number of $A$ and $B$ they receive one additional point. Whereas performance for task $A$ is measured precisely, performance on task $B$ is measured imprecisely. The performance measure on task $B$ includes a random number e between -20 and 20 (all numbers with an equal probability) that is added to the amount of correctly decoded numbers of B (cf. Fisher et al. 2005). This means that

\footnotetext{
25 I chose 30 to avoid negative numbers or a zero. A negative number or a zero can lead to a biased judgment and may even distort performance evaluation. All values larger than 20 also serve this purpose, but 30 is a more conventient number.
} 
the actual "decoding ability" cannot be assessed precisely on $r_{\mathrm{B}}$, the measure for task B. How performance on the two tasks is measured is known to all participants of the experiment.

\subsubsection{Compensation}

I performed two pilot tests to derive performance standards on which the compensation schemes are developed. There are three different compensation schemes. In the equally weighted financial incentives treatments, participants receive 60.06 per point above 30 of $r_{A}$ and $r_{B}$, respectively. This treatment is mainly used as a benchmark treatment. In the fixed wage treatments, participants are paid $€ 10$ irrespective of their performance. In the unequally weighted financial incentives treatments, incentive weights on the two performance measures differ. More specific, I specify the incentive weight on the noisy performance measure as $€ 0.08$ per point above 30 of $r_{B}$, and on the precisely measured task as $€ 0.04$ per point above 30 of $r_{A}$. This is a simplified way of specifying incentive weights, but serves the purpose of this study, i.e., to investigate the effort allocation of agents when the incentive on the noisy performance measure is higher than on the other one. On average, participants earn $€ 14.81$ during the experiment. ${ }^{26}$

\subsubsection{Career concerns}

To manipulate career concerns, it is necessary that there is a labor market looking for individuals who are good in the experimental task. For this reason there are three different roles for participants in the career concerns treatments: X-players, who have the same role as the participants in the no-career concerns treatments, $Y$ players and Z-players. $Y$ - and Z-players act as a labor market and compete with

\footnotetext{
26 The incentives are determined based on average performance of participants in pilot tests. Particlpants of pilot tests decoded 38 numbers in 2 minutes on average. In the actual experiment, however, performance of participants is on average higher in all treatments compared to the pllot tests, so that average compensation of participants is higher under the two different incentive schemes than under fixed wages. Nevertheless, I do not expect that the difference between the incentive pay and the fixed wage has an influence on the results of this study.
} 
each other for X-players with good decoding abilities. $Y$ - and $Z$-players are only present in the career concerns treatments. The roles are randomly assigned at the beginning of the experiment. Eight or ten $X$-players are assigned to one $Y$-player and one $Z$-player, so that the number of $X$-players is not too large for the $Y-(Z-)$ player. In the first period the $X$-players are equally assigned to the $Y-(Z-)$ player, so that $Y$ - and $Z$ - players have equal numbers of $X$-players at the beginning of the experiment. After every period, the $Y_{-}\left(Z_{-}\right)$player receives a list with the performance measures $r_{A}$ and $r_{B}$ for every $X$-player and evaluate the $X$-players. The construction of the performance measures is common knowledge. The $Y-(Z-)$ player can make wage offers of $€ 0, € 1$, or $€ 2$ for the next period (as a fixed extra wage) to $X$-pllayers in order to keep good $X$-players or to attract good $X$-players from the $Z$ $(Y-)$ player. The $Y-/ Z$ - player, who makes the highest offer, is the employer for the relevant $X$-player in the next period. In case of equal offers of the two principals, the agent stays in the subsequent period assigned as in the previous period. Wage offers are deducted from the payoff of the $\gamma$ - and the $Z$-player to ensure that extra wage offers are made only to those $X$-players who are considered as being highly tallented. The $Y-(Z-)$ player can only earn money with an $X$-player assigned to them. Per assigned $X$-player per period, the $Y-(Z-)$ player is compensated based on the following formula:

$$
\text { Compensation } n_{Y, Z}=\left[\left(r_{A}-30\right)+\left(r_{B}-30\right)\right] \cdot € 0.03-\text { bonus wage }^{27}
$$

The $Y$ - and $Z$-players thus compete for $X$-players with good decoding abilities. $Y$ $(Z-)$ players receive on average $€ 9.99$.

I performed pilot tests to practice the procedures of the experiment and to test the manipulations. Interviews with participants after the pilot test revealed that the manipulation of career concerns was successful. Participants were concerned about the noise in the performance measure of task $B$, and considered the precise measure of task $A$ to be of more value in evaluating own abillity. $Y$ - $(Z$-) players also

27 Similar to the compensation for $X$-players with incentives schemes, vallues for $r_{B}<30$ are not considered for compensation purposes to avoid losses to the $Y^{-}\left(Z^{-}\right)$players due to the random number $e$. 
understood their tasks and the nature of the performance measures. In sum, the pilot tests indicated that participants understood the instructions and their task, and that the manipulation of the different compensation schemes and the career concerns manipulation work appropriately.

\subsubsection{Dependent variable}

Due to the simplicity of the tasks, I consider the amount of correctly decoded numbers as a sufficient proxy for effort, and decoded numbers of task $B$ relative to the sum of decoded number of task $A$ and task $B$ as a proxy for effort allocation. The simplicity of the task does not allow much strategic thinking other than effort allocation. Furthermore, the pre-specified duration of the periods excludes variations in effort duration, which can be considered as part of an effort construct (Sprinkle 2003).

\subsubsection{Exit questionnaire}

In questionnaires distributed to participants between every period, several variables are measured. In particular, the questionnaires between the different periods serve mainly as a filler task. Participants are asked to respond on a 7-point Likert scale anchored by 'strongly disagree" and 'strongly agree' to statements measuring personality traits. The questionnaire items are presented in five different short questionnaires that are handed out to participants of the experiment after every period. The last questionnaire handed out to participants includes demographic questions and manipulation checks with respect to the compensation schemes and the career concerns manipulation. 


\subsection{Resuits}

\subsubsection{Manipulation checks}

The manipulation checks indicate that a total of 6 participants did not understand how they are compensated. ${ }^{28}$ These participants as well as $Y-(Z-)$ players, who serve only to create an implicit financial incentive in form of a labor market in search for a certain skill, are excluded from the analysis which leaves usable data of 103 subjects (68 male and 35 female). The role of the different players in the experiment and the fact that participants could increase their compensation due to a labor market is understood by all participants in the relevant treatment group. ${ }^{29}$

\subsubsection{Descriptive statistics}

The experiment lasts about one hour. The effort allocation of subjects in the six different treatment groups as an average over periods one through four is presented in table 5.2. The last period is left out of the analysis to avoid any problems of potentiall end-game effects. Effort allocation of participants varies from only $19 \%$ of total effort allocated to task $B$ in the equally weighted financial incentives treatments up to $76 \%$ in the unequally weighted financial incentives/no career concerns treatment. Furthermore, there is a learning effect across all treatments. Average total amount of correctly decoded numbers over all treatments is 43.37 , and there is no statistically significant difference between the treatments with respect to total effort. This seems to be in contrast with economic theory, and it appears that participants prefer delivering effort over doing nothing. I argue that the fact that participants could not leave during the experiment (and choose "leisure" instead of "work") is the main reason for this finding of almost equal levels of overall effort across compensation treatments.

Wage offers of $Y$ - (Z-) players range on average from $€ 0.93$ after the first period to $€ 1.17$ after the fourth period, although there is no statistically significant difference

\footnotetext{
${ }^{28}$ Participants are asked to indicate in a multiple choice question their form of compensation.

29 In this manipulation check participants have to verify the statement: "During the experiment $\gamma$ - and $Z$-pllayers evaluated me and could make wage offers to me."
} 
of wage offers between periods ( $p>0.3$ ). Between treatments, average offers of $Y$ (Z-) players range from $€ 0.86$ in the treatments with equally weighted financial incentives to $€ 1.35$ in the unequally weighted financial incentives treatments. Average offers of $Y$ - ( $Z$-) players in the fixed wage treatment are $€ 1.04$. Differences between the means in the three treatments are significant $(p<0.01)$.

\begin{tabular}{|c|c|c|}
\hline \multicolumn{3}{|c|}{$\begin{array}{l}\text { TABLE } 5.2 \\
\text { Allocation per Treatment }{ }^{\text {abc }}\end{array}$} \\
\hline \multirow[b]{2}{*}{$\begin{array}{l}\text { Equally weighted } \\
\text { financial incentives }\end{array}$} & No career concerns & Career concerns \\
\hline & $\begin{array}{c}0.19 \\
(44.0) \\
n=20\end{array}$ & $\begin{array}{c}0.19 \\
(45.6) \\
n=15\end{array}$ \\
\hline Fixed wage & $\begin{array}{c}0.45 \\
(42.6) \\
n=15\end{array}$ & $\begin{array}{c}0.30 \\
(43.0) \\
n=17\end{array}$ \\
\hline $\begin{array}{l}\text { Unequally weighted } \\
\text { financial incentives }\end{array}$ & $\begin{array}{c}0.76 \\
(42.6) \\
n=18\end{array}$ & $\begin{array}{c}0.55 \\
(42.7) \\
n=18\end{array}$ \\
\hline \multicolumn{3}{|c|}{$\begin{array}{l}\text { The dependent variable, effort allocation, is measured by the total number of correctly } \\
\text { decoded numbers of Task } B \text { divided by the total number of correctly decoded numbers of } \\
\text { both task } A \text { and task } B \text {. } \\
\text { "The values in this tablle are the average effort allocation over } 4 \text { periods excluding the last } \\
\text { one. } \\
\text { "The values in brackets are the total amount of correctly decoded numbers per participant } \\
\text { as average over perlod } 1-4 \text {. }\end{array}$} \\
\hline
\end{tabular}




\subsubsection{Hypothesis testing}

\subsubsection{Hypothesis 1}

To test Hypothesis 1, I apply moderated regression analysis. In particular, I specify the following empirical model:

(Model 1) effort allocation $=a_{0}+a_{1} D_{F W}+a_{2} D_{i n c 2}+a_{3} D_{c c}+a_{4} D_{F W} \times D_{c c}$ $+a_{5} D_{\text {inc2 }} \times D_{c c}+\varepsilon_{1}$

where $D_{\mathrm{FW}}$ is a dummy variable that equals 1 if the treatment is a fixed wage treatment and zero otherwise, $D_{\text {incz }}$ is a dummy variable that equals 1 in the unequally weighted financial incentives treatment and zero otherwise, and $D_{c c}$ is a dummy variable that equals 1 if the treatment is a career concerns treatment and zero otherwise. The intercept $a_{0}$ indicates the effort allocation on Task $B$ in the equally weighted financial incentives/no career concerns treatment. The impact of career concerns on effort allocation under equally weighted financial incentives is given by $a_{3} . a_{4}\left(a_{5}\right)$ indicates how this impact is different under fixed wages (unequally weighted financial incentives).

The results of model 1 are given in Panel A of table 5.3. The results indicate that career concerns have no statistically significant influence under equally weighted financial incentives $\left(a_{3}=-0.01, p>0.5\right)$. Results for $a_{4}$ and $a_{5}$ indicate that the impact of career concerns is significantly different with unequally weighted finanicial incentives $\left(a_{5}=-0.20, p<0.1\right)$, and only marginally different in the fixed wage treatment $\left(a_{4}=-0.13, p=0.15\right)$. The impact of career concerns on effort allocation in the fixed wage treatment is given by the sum of $a_{3}$ and $a_{4}\left(a_{3}+a_{4}=-0.14, p<0.05\right)$, and the impact of career concerns on effort allocation under unequally weighted financial incentives is given by the sum of $a_{3}$ and $a_{5}\left(a_{3}+a_{5}=-0.21, p<0.05\right)$. Both impacts are significant and support $H_{1}$ in the fixed wage and the unequally weighted financial incentives treatments. In these two compensation treatments, agents thus allocate more effort to the precisely measured task when career concerns are present compared to a setting without career concerns. In the equally weighted 
financial incentives treatments, however, career concerns do not seem to have a significant impact on effort allocated to task B. Equally weighted financial incentives go in the same direction as motivation due to career concerns, so that there is no support for $\mathrm{H}_{1}$ in the treatment with equally weighted financial incentives.

\subsubsection{Hypotheses 2 and 3}

Hypothesis 2 states that agents are indifferent between tasks under fixed wages in absence of career concerns but prefer to allocate effort on the precisely measured task in presence of career concerns. Hypothesis 3 predicts that agents with unequally weighted financial incentives shift their effort to the task measured with noise in absence of career concerns, but show a rather balanced effort allocation in presence of career concerns. As can be seen in table 5.2, the pattern of mean effort devoted to task $B$, the task measured with noise, is in line with $\mathrm{H}_{2}$ and $\mathrm{H}_{3}$. More specific, effort on task $B$ decreases from $45 \%$ to $30 \%$ in the fixed wage treatments when participants are exposed to career concerns. Under unequally weighted financial incentives, individuals balance their effort between tasks when career concerns are present, that is, effort allocated to task B decreases from $76 \%$ to $55 \%$.

To test the hypotheses 2 and 3,1 apply an ANOVA test and use contrast coding (Buckless and Ravenscroft 1990; Rosnow and Rosenthal 1995; Kadous et al. 2003), I exclude the equally weighted financial incentive treatments and specify for the treatments fixed wages/no career concerns, fixed wages career concerns, unequally weighted financial incentives/no career concerns, and unequally weighted financial incentives/no career concerns the contrast weights in line with the hypotheses as 0 , $-2,2$, and 0 , respectively. More specific, the weights specified as 0 for the treatments fixed wages/no career concerns and unequally weighted financial incentives and career concerns indicate that different compensation contracts lead to similar behavior in different settings. Results of this ANOVA (Panel B of table 5.3) show that the specified contrasts are significant $(p<0.01)$. The difference in effort allocated to task $B$ is not significantly different between the treatments fixed 
wages/no career concerns and unequally weighted financial incentives and career concerns $(p>0.5)$.

There is thus support for both hypotheses 2 and 3 , indicating that individuals are indifferent between tasks under fixed wages without career concerns, but prefer to deliver effort on task B when exposed to career concerns. Further, increased explicit financial incentives on the noisy task induces participants to prefer effort on that: noisy task in absence of career concerns, but balance the preference of agents when career concerns are present. 


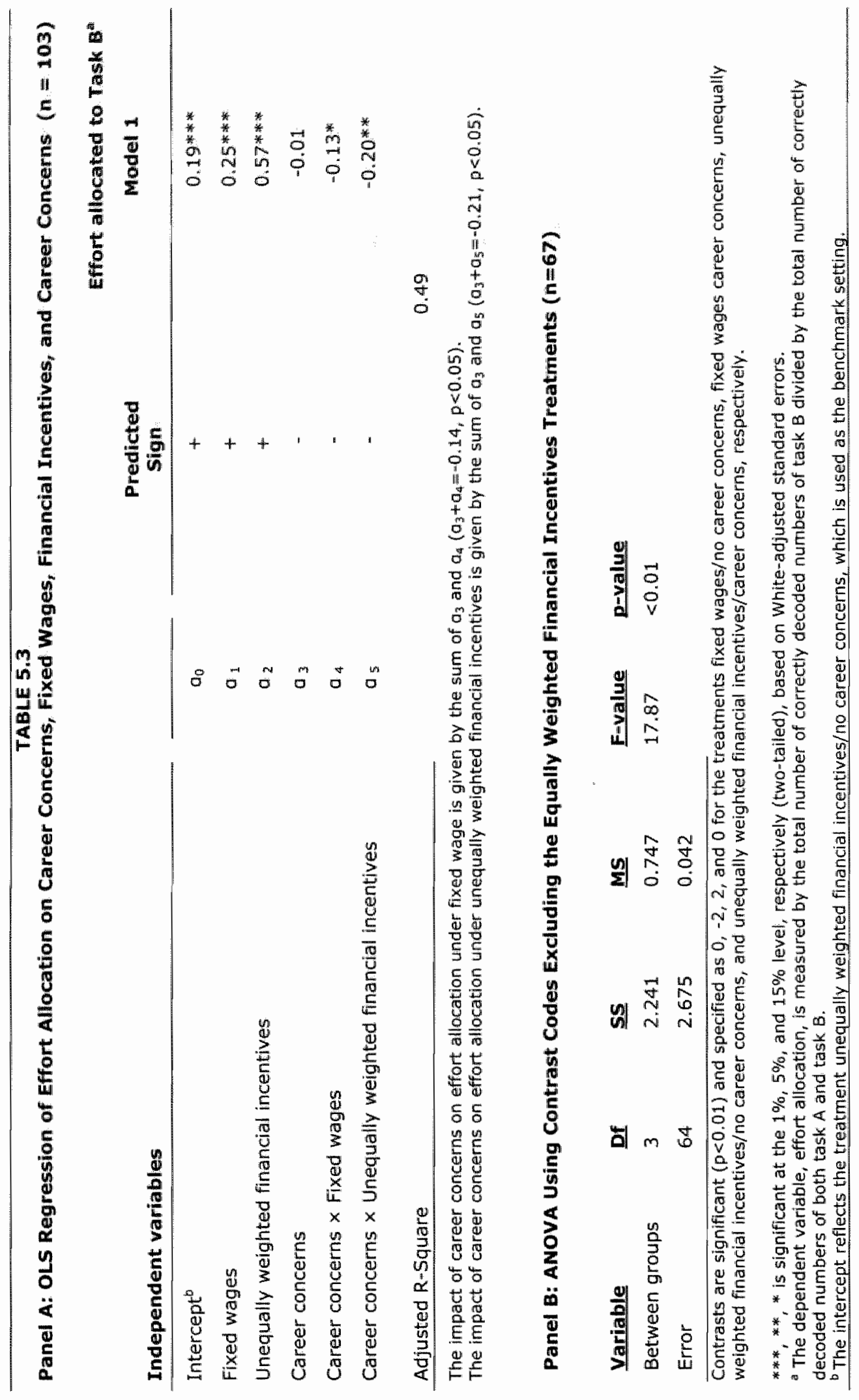




\subsection{Discussion and conclusion}

In thils study, I examine the effects of explicit financial incentives and implicit financial incentives in form of career concerns in a multi-task setting. This study contributes to the literature in several ways. First, results of this study underline that explicit financial incentives can cause problems in multi-task settings where performance on one task is measured precisely and with noise on another task. Individuals strongly prefer to allocate effort on the task measured precisely. Second, this study confirms theoretical predictions that fixed wages can be optimal for effort allocation in absence of career concerns (c.f. Holmström and Milgrom 1991), but shows that fixed wages are not necessarily optimal in multi-task settings in presence of career concerns. More specific, individuals under a fixed wage and with career concerns allocate more effort on the precisely measured task, because the performance measure of this task is considered as an important indicator of own ability by the labor market and therefore important for career concerns. Third, this study presents a setting where the relationship between noise in performance measures and explicit incentive weights is not negative but positive. Under financial incentives with a higher weight on the task measured with noise, individuals allocate most of their effort to the noisy task. In presence of career concerns, however, a higher explicit incentive weight on the task measured with noise counterbalances an allocation preference due to career concerns. As a result, effort is rather balanced between the tasks when there are implicit incentives in form of career concerns and a higher incentive weight on the task measured with noise. Hence, despite the prediction of economic theory of a negative relationship between nolise in performance measures and explicit incentive weights, this study shows a scenario where this relationship is reversed, supporting a view raised by Prendergast (1999, 2002 b). Fourth, whereas previous research indicates that financial incentives and career concerns are substitutes (Gibbons and Murphy 1992) this study reveals that the two complement each other in a multi-task setting. Financial incentives are used to counteract the distorting effects of career concerns in multi-task settings, where one task is measured precisely and another task measured with noise. 
Findings of this study have important managerial implications. Career concerns have a motivational effect that must be considered in the design of an incentive scheme. Financial incentives are not only useful to attract the "right" employees for the "right" job, but in addition to deal with motivational effects of career concerns. An almost omnipresence of career concerns for employees underlines the importance of finaricial incentives as a balancing device. So, despite the fact that performance on one task is measured very noisy, this study shows that it can be important to increase the explicit incentive weight on that task to avoid a strong preference of one task over another one, which could be harmful for an organization.

The setting of this study is related to agents who are active in a labor market. However, the findings could extend beyond a labor market to other settings. For example, CEO performance is strongly monitored by investors. A CEO may thus be inclined to focus his attention on signals that reflect his ability to investors in order to gain from a good reputation by means of better valuation of the firm and better stock performance. At the same time, other actions that may be important for the firm but are not observable by the stock market, are neglected. Findings coulld thus extend to CEO behavior in response to stock markets.

This study is subject to a number of limitations. As with most experiments the external validity is low. Participants work in a laboratory setting and the tasks are simplified in order to increase the internal validity. In addition, communication between subjects was not allowed and group dynamics and social norms cannot develop. Future research might address these limitations of the study. Allowing for different forms of group dynamics and communication between participants of an experiment could be an interesting avenue for future research. Reputation and social status are influenced by careers and future research could include such nonfinancial components of career concerns. Further, future research could investigate how far the implications of this study hold in other settings, for example in a setting with CEO and stock markets, where a stock market cannot measure all actions of a CEO precisely. 


\section{CHAPTER 6}

\section{Summary and Conclusion}

\subsection{Introduction}

In this final chapter I summarize the dissertation. In addition to a discussion of the implications of the findings, I provide some directions for future research in the area of multi-task principal-agent models and incentive schemes.

\subsection{Summary}

Economic theory suggests that financial incentives are optimal for agents to induce effort in single-task settings. However, theory predicts that in multi-task settings where performance on different tasks are measured with different levels of precision, financial incentives can lead to an effort allocation between tasks that is not necessarily in line with the objectives of the principal. Risk-averse agents tend to prefer effort on a precisely measured task over effort on a task measured with noise. A solution put forward in the literature is to offer agents a fixed wage, so that effort can be allocated in line with organizational objectives - assuming that agents are willing to deliver effort at all and do not follow a random strategy. Empirical findings put forward that individuals are not only motivated by means of explicit financial incentives, as frequently argued by economic theory. Rather, individuals are also motivated by implicit financial incentives, like career concerns, and nonfinancial incentives, like reputation and social status. Total incentives of an 
individual are thus a combination of explicit financial incentives and implicit financial and non-financiall incentives.

The purpose of this dissertation is to give answers to the following two research questions:

- How do explicit financial incentives influence effort allocation in multi-task agency settings?

- What role do other forms of incentives, such as social incentives and career concerns, play?

The focus in this dissertation is thus on how financial incentives and other forms of motivation influence effort allocation of agents in a multi-task setting. I have examined the two research questions by means of two experimental studies with business students from Maastricht University.

\subsubsection{The role of financial and social incentives}

The objective of the study described in chapter 4 is to examine the influence of social incentives (group norms) and ethical concerns (individual norms) on effort allocation of agents who are exposed to distorting financial incentives in a multi-task setting. Participants work for an experimental firm on two independent tasks and are informed that an equal output on both tasks is optimal for the firm. Participants are randomly assigned to one of the following four treatments: (1) fixed wage/no social incentives, (2) fixed wage/social incentives, (3) financial incentives/no social incentives, and (4) financial incentives/social incentives. I find that subjects who receive financial incentives on one task significantly reduce their effort on the other task, which is consistent with agency theory. Contrary to agency theory, however, I find that subjects do not purely act in self-interest when exposed to congruent social incentives. In particular, results of this study show that the 
distorted effort allocation caused by financial incentives is significantly reduced, both in statistical and economic terms, by social incentives and ethical concerns.

Results thus indicate that the effort allocation of subjects is not solely driven by financial incentives, but also by the desire for social approval and internalized values. This finding has important managerial implications given that managerial chaices affect the social incentives within an organization. Results of this study are summarized in table 6.1 .

\section{TABLE 6.1}

The Role of Financial Incentives and Social Incentives in Multi-Task Settings

\section{Hypothesis}

Effort allocation lowest with $\mathrm{FI}^{\mathrm{a}}$, higher with $\mathrm{FI}$ and $\mathrm{SI}^{\mathrm{b}}, 1$ - supported and highest with fixed wages

\begin{tabular}{l}
\hline Ethical concerns lower distoring effect of FI \\
\hline Ethical concerns positively interact with SI to decrease $3-$ supported \\
distorting effect of FI \\
\hline Financial incentives
\end{tabular}

\footnotetext{
${ }^{a}$ Financial incentives

Social incentives
}

Findings of this study contribute to the literature in many ways. This study is one of the first to investigate the role of financial and social incentives in a multi-task agency setting. The important roles of social incentives as well as internalized values, such as ethical concerns, are underlined. Further, this study shows that there are settings where financial incentives are preferred over fixed wages despite being distorted and although performance of the agent on one task is not measured. Finally, results suggest that the agency problem is not only about inducing effort, but also about inducing the 'right' effort, because there is a tradeoff between effort allocation and the overall effort levels desired by the principal. 


\subsubsection{The role of career concerns in multi-task settings}

The purpose of the study described in chapter 5 is to investigate three issues. In a multi-task agency setting with career concerns, I examine whether fixed wages are still optimal for the effort allocation of agents. Furthermore, this study investigates whether the negative relationship between noisy performance measures and incentive weights holds in presence of career concerns. A further objective of this study is to find out whether career concerns of agents and financial incentives are substitutes or complement each other.

To investigate the role of career concerns in multi-task settings, I run a $2 \times 3$ experiment. Participants work on two tasks per experimental period that are of equal complexity and character. However, effort on one task is measured precisely and effort on another task is measured with noise. Subjects are randomly assigned to one of the following six treatments: (1) fixed wage/no career concerns, (2) fixed wage/career concerns, (3) equally weighted financial incentives/no career concerns, (4) equally weighted financial incentives/career concerns, (5) unequally weighted financial incentives/no career concerns and (6) unequally weighted financial incentives/career concerns.

Findings of this study indicate that under incentives with equal weights on both tasks, effort is strongly allocated to the task that is measured precisely. However, participants are indifferent between tasks under a fixed wage, which is in line with theoretical predictions. Results further show that in presence of career concerns, participants prefer to allocate their effort to the precisely measured task also under fixed wages, because this signal is favored by the labor market. Agents with fixed wages and career concerns are thus not indifferent between tasks. Whereas in presence of career concerns, effort is mostly allocated to the precisely measured task both with fixed wages and with equally weighted financial incentives, increased explicit incentive weight on the task measured with noise helps to counterbalance this possibly harmful allocation. More specific, to avoid that agents with career concerns prefer effort on the precisely measured task, it can be necessary to increase the explicit incentive weight on the task measured with noise (unequally 
weighted financial incentives), which is at odds with standard arguments in the literature. Results indicate that effort is aimost evenly balanced between tasks when there are career concerns and a higher financial incentive weight on the task measured with noise, suggesting that career concerns and explicit incentive weights are not substitutes but complements.

This study contributes to the literature in several ways. It is one of the first empirical studies examining the role of career concerns in a multi-task setting. There is evidence that fixed wages are not necessarily optimal, because agents have an economic incentive to prefer effort on a precisely measured task when there are career concerns. Further, the relationship between risk and incentives can be positive. In presence of career concerns, financial incentives with a higher weight on a noisy task can help to mitigate effects of implicit incentives due to career concerns. Explicit financial incentives thus counterbalance these effects. Results indicate that financial incentive weights and career concerns complement each other. Table 6.2 summarizes the findings of this study.

\section{TABLE 6.2}

The Role of Career Concerns in Multi-Task Settings on Effort Allocation of Agents

\begin{tabular}{ll}
\hline Career concerns $\rightarrow$ effort on precise task & Hypothesis \\
\hline No career concerns $\rightarrow$ fixed wage "optimal" & 1 - supported \\
\hline With career concerns $\rightarrow$ Unequally weighted financial & $3-$ supported \\
Incentives "optimal"
\end{tabular}

\subsection{Implications}

Findings of this dissertation have both theoretical and managerial implications. Whereas theory predicts that fixed wages may be optimal in multi-task settings for 
effort allocation purposes, it seems that many multi-task jobs are not compensated with fixed wages. Especially managerial jobs in higher levels of an organization are characterized by multi-tasking, and are frequently compensated with performancebased financial incentives. Incentive compensation is, however, not only used to motivate employees to work, but is also used to attract the 'right' people for certain jobs. This holds especially for higher levels in an organization, where financial incentives are simply expected as standard compensation practice. The wide use of financial incentives and the apparent lack of alternatives for various reasons stress the importance of the findings and implications of this dissertation.

First, financial incentives have a strong impact on effort allocation. However, in addition to the effects of financial incentives, individuals are motivated also by other mechanisms, such as implicit financial incentives as well as group and individual norms (i. $e_{2,}$ social incentives and ethical concerns). Non-financial motivations are thus important for individuals in their action choice and can have implications for organizational values and principles and can be an issue for recruiting and selection of individuals for certain jobs.

Second, it may not be beneficial for a principal to offer fixed wages, because fixed wages can lead to lower overall effort. Further, in presence of career concerns, effort under fixed wages is not necessarily in line with the objectives of the principal, because the agent's allocation is influenced by career concerns and signals to a labor market. It is necessary to understand motivational mechanisms for individual action choice in order to determine the appropriateness of fixed wages.

Third, whereas the literature suggests that explicit financial incentives and career concerns are substitutes, results of this dissertation put forward that the two are not substitutes, but even complement each other. For compensation practice it may be necessary to use explicit financial incentives in order to counter motivational effects due to career concerns. Given an almost omnipresence of career concerns, it is thus necessary to consider such concerns in the design of an incentive scheme. 
Fourth, theory predicts that there is a negative relationship between risk and incentives. However, this dissertation shows a situation where the relationship is not negative but positive. To counterbalance the effects of career concerns it may be necessary to increase the incentive weights on tasks that are measured with high levels of noise, because these tasks are ignored by the labor market.

Contracts between a principal and an agent are a trade-off between the level of financial incentives and the risk imposed on an agent. Higher risk needs to be compensated with a risk premium, with the result that financial incentives are muted in very risky environments because compensation cost is too high. Prendergast (2002a) argues that this trade-off between risk and incentives is rather difficult to detect empirically, and mixed evidence on this trade-off may even suggest that the relationship is not negative. Bonus and incentive schemes are common for managers not only in very stable industries, but also in highly volatile and risky industries, such as the high-tech industry. More specific, Prendergast (2002A) gives four arguments why one would not see a negative relationship between risk and incentive weights. First, monitoring of managerial inputs is less effective in uncertain environments. The principal is more likely to offer an outcomebased incentive contract in very uncertain environments as he does not have a clear idea what exactly the agent should spend his time on. Second, sorting and truthful performance appraisals are less effective in uncertain environments. In particular, if reports of supervisors are less reliable, a firm may choose to increase financial incentives to induce effort of the agent, because performance appraisals become more noisy and incorrect. Third, sporadic investigations on the agent's performance are less effective in uncertain environments. Agents suffer less from investigations in risky environments because they can easier "get away" with bad performance in noisy environments than in stable environments. To motivate the agent, however, a firm may choose to increase financial incentives based on the performance of the agent. Fourth, agents have reputation and career concerns. These concerns, however, are less effective in noisy environments, where results of individual agents are difficult to assess by others. In such settings financial incentives are needed to induce effort of the agent to overcome shortcomings of evaluations of a labor 
market (career concerns) or others. As mentioned by Prendergast (2002a), these reasons are not meant to claim that agency theory is "wrong" in the assumption of a negative relationship between risk and incentives. But the reasons above can be instances where the relationship between risk and incentives may be different.

\subsection{Limitations}

The studies of this dissertation are both experimental studies. The use of experiments in accounting research is increasing for various reasons. By means of laboratory experiments, one can investigate issues that are difficult to detect with fleld data. The main reason for choosing an experiment is to control everything except for the variables of interest. By keeping everything else constant one can infer a clear relationship that is not distracted by noise. Even further, experiments are the most suitable method to detect causal relationships (Shadish et al. 2002). Experimental research is subject to several specific limitations that I will discuss in detaill in this section.

First, high internal validity often leads to rather abstract experiments. Lack of realism is one of the most frequently raised concerns with experiments. The question is how far results form experimental research can be generalized. How high is the external validity, l.e., do results generalize over different populations and different situations. Experiments cannot be a mirror of real-life. If they were, one could also use field data for research. The strength of experimental research is that one can investigate certain selected variables without noise. Usually, the variables of interest are embedded in the environment together with many other variables, so that it is impossible to draw conclusions on these variables alone. The fact that laboratory experiments are not very realistic is thus a limitation but is at the same time a strength and even a necessity.

Second, a limitation of the studies of this dissertation is the use of very simplified tasks. For the first study participants are asked to indicate their effort level. There is 
thus no "real" effort of performing a certain task. In the second experiment, participants are asked to decode numbers based on a decoding key. The tasks are thus no typical managerial tasks, but serve the purpose to rule out any intrinsic motivation because of the tasks, to rule out certain skills and talents, and to keep necessary pre-knowledge as low as possible. Nevertheless, results of the studies here could be different with other types of tasks, for example problem-solving or memory tasks.

Third, the short duration of the experiments may pose another limitation. Due to the short duration, endogenous reputation building and other dynamic factors are excluded. However, such aspects could play an important role and lead to different results. The design of the experiments and the fact that they are laboratory experiments and no field experiments, do not allow longitudinal studies of the relevant variables.

A final remark concerns the use of student participants in experiments. There is a continuous debate on whether students behave differently than managers or other employees. Until now, there is no consensus on this issue. I cannot find a reasonable argument that students behave differently than employees of a firm. With respect to the incentives provided in the experiments, it may be a question on the level of financial incentives, but there is hardly any reason why students would behave in an opposite direction than employees in any of the two studies.

\subsection{Future research}

Results of this dissertation open several interesting avenues for future research. First, the financial incentive schemes examined in the studies are piece-rate schemes. There are many other forms of financial incentives that can possibly lead to different results in multi-task settings. Bonus schemes or stock options, for example, can induce agents to behave less short-term oriented and myopic, but: consider the long-term value of a firm. 
Second, the study on the role of social incentives has indicated the strong effects of such incentives. Nevertheless, communication between subjects was not allowed and the group norm was exogenous. Communication between participants and extending the time frame of the experiment allows a group norm to develop or change over time. It could be interesting to find out how a norm endogenously develops over time, and how and why al group norm changes. Research in this direction can help to understand group behavior better, and can mitigate social incentive problems and incongruent behavior due to group dynamics.

Third, findings of the study on social incentives indicate that there is a tradeoff between effort allocation and overall effort level. Analytical research could tackle this tradeoff and analyze this tradeoff. Incorporating the dilemma of effort allocation and effort level in agency models could extend theory further and help to understand multi-task settings better.

Fourth, the study on career concerns allowed signaling of one type of ability. However, in a more complex situation employees with different abilities can signal these different abilities to the labor market. It is thus possible that employees compete not necessarily with the same (signaled) abilities but with different abilities and a labor market needs to trade-off an employee with different abilities. Given the simplicity of the task, agents could not signal different abilities to the labor market. This may change with increasingly complex tasks. It may be interesting to investigate whether and how results hold in a similar setting but with different abilities and more complex experimental tasks.

Finally, comparing the two studies of this dissertation, one can see an interesting finding with respect to total effort under fixed wages. Participants of the first study hardly delivered any effort with fixed wages, but participants of the second study delivered almost equal levels of total effort with fixed wages than their colleagues with financial incentives. This seems to contradict economic theory. Economic theory predicts that individuals do not deliver any effort at all when not given a performance-based compensation. The predictions of economic theory are to some 
extent satisfied in the first study under fixed wages but not on the second one. I argue that given the fact that participants of the experiment could not leave and directly exchange effort for leisure, participants derived some utility from work. An interesting avenue for future research can be to investigate the influence of fixed wages on effort of individuals using different experimental methodologies. There are thus situations where fixed wages lead to effort, and there are situations where this is not the case. Future research could investigate the determinants that induce individuals to deliver effort under fixed wages. 


\section{References}

Akerlof G.A. 1980. A theory of social custom of which unemployment can be one consequence. Quarterly Journal of Economics 94: 749-775.

Andersson F. 2002. Career concerns, contracts and effort distortions. Journal of Labor Economics 20: 42-58.

Ashton, R.H. 1990. Pressure and performance in accounting decision settings: paradoxical effects of incentives, feedback, and justification. Journal of Accounting Research 28: 148-180.

Autrey R.L., S.S. Dikolli, and P. Newman. 2003. The effect of career concerns on the contracting use of public and private performance measures. University of Texas at Austin. Working paper.

Awasthi, $V_{.}$, and J. Pratt. 1990. The effects of monetary incentives on effort and decision performance: the role of cognitive characteristics. The Accounting Review 65: 797-811.

Bailey C., L. Brown, A. Cocco. 1998. The effects of monetary incentives on worker learning and performance in an assembly task, Journal of Management Accounting Research 10

Baiman, S. 1990. Agency research in managerial accounting: a second look. Accounting, Organizations \& Society 15: 341-371.

Banker R., S. Datar. 1989. Sensitivity, precision, and linear aggregation of signals for performance evaluation. Journal of Accounting Research 27: 21-39.

Banker R.D., S, -Y. Lee, G. Potter. 1996a. A field study of the impact of a performance-based incentive plan, Journal of Accounting and Economics 21: 195-226.

Banker R.D., S.-Y. Lee, G. Potter, D. Srinivasan. 1996b. Contextual analysis of performance impacts of outcome-based incentive compensation, Academy of Management Journal 39: 920-948.

Banker R.D., S.-Y. Lee, G. Potter, D. Srinivasan. 2001. An empirical analysis of continuing improvements following the implementation of a performance-based compensation plan. Journal of Accounting and Economics 30: $315-350$ 
Bonner, S.E., and G.B. Sprinkle. 2002. The effects of monetary incentives on effort and task performance: theories, evidence, and a framework for research. Accounting, Organizations and Society 27: 303-345.

Bonner, S.E., R. Hastie, G.B. Sprinkle, S.M. Young. 2000. A review on the effects of financial incentives on performance in laboratory tasks: implications for management accounting. Journal of Management Accounting Research 12: 19-64.

Buckless, F.A., and S.P. Ravenscroft. 1990. Contrast coding: a refinement of ANOVA in behavioral analysis. The Accounting Review 65: 933-945.

Chow C. 1983. The effects of job standard tightness and compensation scheme on performance: an exploration of linkages. The Accounting Review 58: 667-685.

Chow C., Cooper J., Waller W. 1988. Participative budgeting: effects of a truth-inducing pay scheme and information asymmetry on slack and performance. The Accounting Review 63: 111-122.

Coletti A., K. Sedatole, K. Towry. 2004. The effect of control systems on teams and alliances: trust and cooperation in collaborative environments. Emory University working paper.

Datar, S., S. Cohen Kulp, and R.A. Lambert. 2001. Balancing performance measures. Journal of Accounting Research 39: 75-92.

Dikolli S.S., S.C. Kulp. 2003. Interrelated performance measures, interactive effort, and optimal incentives. University of Texas at Austin working paper.

Evans III J., L. Hannan, R. Krishnan. 2001. Moser D., Honesty in managerial reporting, The Accounting Review 76: 537-559.

Fama E. 1980. Agency Problems and the theory of the firm. Journal of Political Economy 88: 288-307.

Fehr E., S. Gächter. 1998. Reciprocity and economics: The economic implications of homo reciprocans, European Economic Review 42: 845859.

and 1999 . Collective action as a social exchange. Journal of Economic Behavior and Organization 39: 341-369. 
- and 2000. Cooperation and punishment in public goods experiments. American Economic Review 90: 980-994.

- G. Kirchsteiger, A. Riedl. 1993. Does fairness prevent market clearing? An experimental investigation. Quarterly Journal of Economics 108: 437-459.

- E. Kirchler, S. Gächter, G. Kirchsteiger. 1997. Reciprocity as a contract enforement device: experimental evidence. Econometrica 65: 833860.

E. Kirchler, A. Weichbold, S. Gächter.1998. When social norms overpower competition: gift exchange in experimental labor markets, Journal of Labor Economics 16: 324-351.

, K.M. Schmidt. 2004. Fairness and incentives in a multi-task principalagent model. Scandinavian Journal of Economics 106: 453-475.

Feltham G.A., and J. Xie. 1994. Performance measure congruity and diversity in multi-task principal-agent relations. The Accounting Review 69: 429-453.

Fischer P., Huddart 5., 2004, Optimal contracting with endogenous reporting norms. Pennsylvania State University, Working Paper.

Fisher J., Maines L., Peffer S., Sprinkle G. 2002. Using budgets for performance evaluation: effects of resource allocation and horizontal information asymmetry on budget proposals, budget slack, and performance. The Accounting Review 77: 847-865.

__., Maines L., Peffer S., Sprinkle G. 2005. An experimental investigation of employer discretion in employee performance evaluation and compensation. The Accounting Review 80: 563-583.

Gibbons R., Murphy K. 1992. Optimal incentive contracts in the presence of career concerns: theory and evidence. Journal of Political Economy 100: 468-505.

Hannan, R.L., 2005. The combined effect of wages and firm profit on employee effort. The Accounting Review 80: 167-188.

- J.H. Kagel, and D.V. Moser. 2002. Partial gift exchange in an experimental labor market: Impact of subject population differences, 
productivity differences, and effort requests on behaviour. Journal of Labor Economics 20: 923-952.

Hartmann, F.G.H., and F. Moers. 1999. Testing contingency hypotheses in budgetary research: an evaluation of the use of moderated regression analysis. Accounting, Organizations and Society 24: 291-315.

Monsanto company: control of R\&D at the animal science division. HBS Case No. 189-091 Boston, MA: Harvard Business School Publishing.

Hemmer, T. 1996. On the design and choice of "modern" management accounting measures. Journal of Management Accounting Research 8: 87- 116.

Holmström B. 1979. Moral hazard and observability. Bell Journal of Economics 10: 74-91.

Milgrom P. 1991. Multitask principal agent analyses: Incentive contracts, asset ownership and job design. Journal of Law, Economics and Organizations 7 (special issue): 24-52.

1999. Managerial incentive problems: a dynamic perspective, Review of Economic Studies 66: 169-182.

Indjejikian R. 1999. Performance evaluation and compensation research: an agency perspective. Accounting Horizons 13: 147-157.

Irlenbusch B., D. Sliwka. 1993. Career concerns in a simple experimental labor market. University of Bonn Working paper No. 855.

Ittner, C.D., D.F. Larcker and M.W. Meyer. 2003. Subjectivity and the weighting of performance measures: evidence from a balanced scorecard. The Accounting Review 78: 725-758.

Kadous, K., S.J. Kennedy, and M.E. Peecher. 2003. The effect of quality assessment and directional goal commitment on auditors' acceptance of client-preferred accounting methods. The Accounting Review 78: 759-778.

King, R.R. 2002. An experimental investigation of self-serving biases in an auditing trust game: the effect of group affiliation. The Accounting Review 77: 265-284.

Lambert, R. A. 2001. Contracting theory and accounting. Journal of 
Accounting and Economics32: 3-87.

Larcker D. 1983. The association between performance plans and corporate capital investment, Journal of Accounting and Economics40: 711-726.

Lipe, M.G., S.E. Salterio. 2000. The balanced scorecard: judlgmental effects of common and unique performance measures. The Accounting Review 75: 283-298.

Naylor, R. 1989. Strikes, free-riders, and social customs. Quarterly Journal of Economics 104: 771-785.

Prendergast C. 1999. The provision of incentives in firms. Journal of Economic Literature 37: 7-63.

- 2002a. The tenuous trade-off between risk and incentives. Journal of Political Economy 110: 1071-1102.

- 2002b. Uncertainty and incentives. Journal of Labor Economics 20: 115-138.

Roethlisberger, F.J., and W.J. Dickson. 1939. Management and the Worker. Cambridge, MA: Harvard University Press.

Romer, D. 1984. A theory of social custom: a modification and some extensions. Quarterly Journal of Economics 99: 717-727.

Rosnow, R.L., and R. Rosenthal. 1995. "Some things you learn aren"t so": Cohen's paradox, Asch's paradigm, and the interpretation of interaction. Psychological Science 6: 3-9.

Schatzberg, J.W., and D.E. Stevens. 2004. The realism of self-interested opportunism: an experimental investigation of learning, fairness, and ethics. University of Arizona / Syracuse University, Working Paper.

Shadish W.R., T.D. Cook, D.T. Campbell, 2001. Experimental and quasiexperimental designs for generalized causal inference. Houghton Mifflin Company.

Sillamaa, M.A. 1999. How work effort responds to wage taxation: A nonlinear versus a linear tax experiment. Journal of Economic Behavior and Organization 39: 219-233.

Sprinkle G. 2000. The effect of incentive contracts on learning and 
performance, The Accounting Review 75: 299-326.

2003. Perspectives on experimental research in managerial accounting. Accounting, Organizations and Society 28: 287-318.

Stevens, D.E. 2002. The effects of reputation and ethics on budgetary slack. Journal of Management Accounting Research 14: 153-171.

- , and A. Thevaranjan. 2003. Ethics and agency theory: incorporating a standard for effort and an ethically sensitive agent. Syracuse University Working Paper.

Towry, K.L. 2003. Control in a teamwork environment - the impact of social ties on the effectiveness of mutual monitoring contracts. The Accounting Review 4: 1069-1095.

Wallace, Adopting residual income-based compensation plans: Do you get what you pay for? Journal of Accounting and Economics 24: 275-300. 


\section{Appendix A}

This appendix includes the experimental material for the study described in chapter 4 on social incentives in multi-task settings. For reasons of clarity, I have titled the instructions with the relevant treatment. Further, this appendix includes "decision form" where participants filled in their decision, and the exit questionnaire, which is equal for all treatments. 


\section{Instructions "Fixed Wage/No Social Incentives"}

Welcome to this study.

Thank you for participating in this study. You will assume the role of an employee working for XYZ Company. Your decision will be to choose how much effort to spend on 2 tasks in order to increase the performance of the company. Depending on your choices you will earn between $€ 1.44$ and $€ 9.44$. Details on how you are compensated are specified below. Please read all information carefully.

Your decision consists of 2 separate choices. First, you need to choose an overall effort level from 1 to 9. After that, you are asked to decide how to allocate your chosen effort level on 2 tasks, Task A and Task B. You indicate your choice by circling your overall effort level and indicating your allocation on the decision form.

Note that your decisions stay anonymous to the experimenter and you are free to make any choice.

Instead of your name, you have received an ID number. When starting with the study you will be asked to fill in this number on the decision form. You will need this number later in order to receive your compensation.

\section{Company information}

$X Y Z$ Company's goal is to maximize long-term value. The only way to achieve this is when employees of this firm allocate their efforts evenly between tasks A and B, thus $50 \%$ of their effort on task $A$ and the other $50 \%$ on task $B$.

\section{Compensation}

You recelve a fixed wage of $€ 10$ irrespective how you allocate your effort between the tasks. However, each overall effort level has a certain cost that will be subtracted from your wage: The effort levels and the relevant costs for each effort level are speclfied in the table below.

\begin{tabular}{|l|c|c|c|c|c|c|c|c|c|}
\hline Overall effort level & 1 & 2 & 3 & 4 & 5 & 6 & 7 & 8 & 9 \\
\hline Cost of effort $(\epsilon)$ & 0.56 & 1.11 & 1.67 & 2.22 & 3.33 & 4.44 & 5.56 & 6.67 & 8.56 \\
\hline
\end{tabular}


To calculate your income you thus follow this procedure:

[e10] $-[$ costs of overall effort] $=$ income

\section{EXAMPLE 1}

You choose an effort level of 7 and allocate $60 \%$ on Task A and the other $40 \%$ on Task B. Choosing an effort level of 7 costs you $\in 5.56$. Subtracting this from your fixed wage, your income for this decision would be 64.44 .

\section{EXAMPLE 2}

You choose an effort level of 4 and allocate $50 \%$ on Task $A$ and the other $50 \%$ on Task B. Choosing an effort level of 4 costs you $€ 2.22$. Subtracting this from your fixed wage, your income for this decision would be $€ 7.78$. 


\section{Instructions "Fixed Wage/Social Incentives"}

Welcome to this study.

Thank you for participating in this study. You will assume the role of an employee working for $X Y Z$ Company. The participants in this room form one production team of $X Y Z$ Company. Your decision will be to choose how much effort to spend on 2 tasks in order to increase the performance of the company. Depending on your choices you will earn between $€ 1.44$ and 69.44. Details on how you are compensated are specified below. Please read allinformation carefully.

Your decision consists of 2 separate choices. First, you need to choose an overall effort level from 1 to 9 . After that, you are asked to decide how to allocate your chosen effort level on 2 tasks, Task A and Task B. You indicate your choice by circling your overall effort level and indicating your allocation on the decision form.

Note that your decisions stay anonymous to the experimenter and you are free to make any choice.

Instead of your name, you have received an ID number. When starting with the study you will be asked to fill in this number on the decision form. You will need this number later in order to receive your compensation.

\section{Company information}

$X Y Z$ Company's goal is to maximize long-term value. The only way to achieve this is when you and your team members allocate your efforts evenly between tasks $A$ and $B$, thus $50 \%$ of their effort on task $A$ and the other $50 \%$ on task $B$.

\section{Compensation}

You receive a fixed wage of $€ 10$ irrespective how you allocate your effort between the tasks. However, each overall effort level has a certain cost that will be subtracted from your wage! The effort levels and the relevant costs for each effort level are specified in the table below.

\begin{tabular}{|l|c|c|c|c|c|c|c|c|c|}
\hline Overall effort level & 1 & 2 & 3 & 4 & 5 & 6 & 7 & 8 & 9 \\
\hline Cost of effort $(\epsilon)$ & 0.56 & 1.11 & 1.67 & 2.22 & 3.33 & 4.44 & 5.56 & 6.67 & 8.56 \\
\hline
\end{tabular}


To calculate your income you thus follow this procedure:

$[$ [10] $-[$ costs of overall effort $]=$ income

\section{EXAMPLE 1}

You choose an effort level of 7 and allocate $60 \%$ on Task A and the other $40 \%$ on Task B. Choosing an effort level of 7 costs you $€ 5.56$. Subtracting this from your fixed wage, your income for this decision would be 64.44 .

\section{EXAMPLE 2}

You choose an effort level of 4 and allocate $50 \%$ on Task $\mathrm{A}$ and the other $50 \%$ on Task $\mathrm{B}$. Choosing an effort level of 4 costs you $\in 2.22$. Subtracting this from your fixed wage, your income for this decision would be 67.78 .

\section{Important note:}

After every member of your team has made his/her decision, the decisions of all team members will be posted on the whiteboard. The team member who has the least equal (most distorted) effort allocation between Task A and Task B will be pointed out. In particular, this person who failed to contribute to the objectives of the firm and the team has to stand up and explain his/her behaviour to the team. 


\section{Instructions "Distorting Financial Incentives/No Sociall Incentivies"}

Welcome to this study.

Thank you for participating in this study. You will assume the role of an employee working for XYZ Company. Your decision will be to choose how much effort to spend on 2 tasks in order to increase the performance of the company. Depending on your choices you will earn between $€ 1.44$ and $€ 9.44$. Details on how you are compensated are specified below. Please read all information carefully.

Your decision consists of 2 separate choices. First, you need to choose an overall elfort level from 1 to 9 . After that, you are asked to decide how to allocate your chosen effort level on 2 tasks, Task A and Task B. You indicate your choice by circling your overall effort level and indicating your allocation on the decision form.

Note that your decisions stay anonymous to the experimenter and you are free to make any choice.

Instead of your name, you have received an ID number. When starting with the study you will be asked to fill in this number on the decision form. You will need this number later in order to receive your compensation.

\section{Company information}

$X Y Z$ Company's goall is to maximize long-term value. The only way to achieve this is when employees of this firm allocate their efforts evenly between tasks $A$ and $B$, thus $50 \%$ of their effort on task A and the other $50 \%$ on task B.

\section{Compensation}

Your effort allocated to Task $A$ is compensated with 62 per "unit" of effort. This means, of the overall effort you chose, you allocate a certain percentage to Task $A$. This part is then compensated with $€ 2$ per "unit" of effort. The examples below lilustrate this. Despite the importance for the experimental firm, effort al located to Task B is not compensated!

Furthermore, each overall effort level has a certain cost that will be subtracted from your compensation! The effort levels and the relevant costs for each effort level are specified in the table below.

\begin{tabular}{|l|c|c|c|c|c|c|c|c|c|}
\hline Overall effort level & 1 & 2 & 3 & 4 & 5 & 6 & 7 & 8 & 9 \\
\hline Cost of effort $(\epsilon)$ & 0.56 & 1.11 & 1.67 & 2.22 & 3.33 & 4.44 & 5.56 & 6.67 & 8.56 \\
\hline
\end{tabular}


Appendix A

To callculate your income you thus follow this procedure:

[overall effort $] \times[\%$ allocated to Task $A] \times[\in 2]-[$ costs of overall effort $]=$ income

\section{EXAMPLE 1}

You choose an effort level of 7 and allocate $60 \%$ on Task $A$ and the other $40 \%$ on Task $B$. You will then earn $7 \times 0.6 \times € 2=€ 8.40$. Choosing an effort level of 7 , however, costs you 65.56. Subtracting this, your income for this decision would be $€ 2.84$.

\section{EXAMPLE 2}

You choose an effort level of 4 and allocate $50 \%$ on Task A and the other $50 \%$ on Task B. You will then earn $4 \times 0.5 \times € 2=€ 4$. Choosing an effort level of 4 , however, costs you $€ 2.22$. Subtracting this, your income for this decision would be $€ 1.78$. 


\section{Instructions "Distorting Financial Incentives/Social Incentives"}

Welcome to this study.

Thank you for participating in this study. You will assume the role of an employee working for $X Y Z$ Company. The participants in this room form one production team of $X Y Z$ Company. Your decision will be to choose how much effort to spend on 2 tasks in order to increase the performance of the company. Depending on your choices you will earn between 61.44 and 69.44. Details on how you are compensated are specified below. Please read all information carefully.

Your decision consists of 2 separate choices. First, you need to choose an overall effort level from 1 to 9. After that, you are asked to decide how to allocate your chosen effort level on 2 tasks, Task A and Task B. You indicate your choice by circling your overall effort level and indicating your allocation on the decision form.

Note that your decisions stay anonymous to the experimenter and you are free to make any cholce.

Instead of your name, you have received an ID number. When starting with the study you will be asked to fill in this number on the decision form. You will need this number later in order to receive your compensation.

\section{Company information}

$X Y Z$ Company's goal is to maximize long-term value. The only way to achieve this is when you and your team members allocate your efforts evenly between tasks A and B, thus $50 \%$ of their effort on task $A$ and the other $50 \%$ on task $B$.

\section{Compensation}

Your effort allocated to Task $A$ is compensated with $€ 2$ per "unit" of effort. This means, of the overall effort you chose, you allocate a certain percentage to Task A. This part is then compensated with $€ 2$ per "unit" of effort. The examples below illustrate thls. Despite the importance for the experimental firm, effort allocated to Task B is not compensated!

Furthermore, each overall effort level has a certain cost that will be subtracted from your compensation! The effort levels and the relevant costs for each effort level are specifled in the table below.

\begin{tabular}{|l|c|c|c|c|c|c|c|c|c|}
\hline Overall effort level & 1 & 2 & 3 & 4 & 5 & 6 & 7 & 8 & 9 \\
\hline Cost of effort $(\epsilon)$ & 0.56 & 1.11 & 1.67 & 2.22 & 3.33 & 4.44 & 5.56 & 6.67 & 8.56 \\
\hline
\end{tabular}


To calculate your income you thus follow this procedure:

[overall effort $] \times[\%$ allocated to Task A $] \times[€ 2]-[$ costs of overall effort $]=$ income

\section{EXAMPLE 1}

You choose an effort level of 7 and allocate $60 \%$ on Task $A$ and the other $40 \%$ on Task B. You will then earn $7 \times 0.6 \times € 2=€ 8.40$. Choosing an effort level of 7 , however, costs you E5.56. Subtracting this, your income for this decision would be $€ 2.84$.

\section{EXAMPLE 2}

You choose an effort level of 4 and allocate $50 \%$ on Task $A$ and the other $50 \%$ on Task $B$. You will then earn $4 \times 0.5 \times E 2=64$. Choosing an effort levell of 4 , however, costs you $€ 2.22$. Subtracting this, your income for this decision would be $€ 1.78$.

\section{Important note:}

After every member of your team has made his/her decision, the decisions of all team members will be posted on the whiteboard. The team member who has the least equal (most distorted) effort allocation between Task A and Task B will be pointed out. In particular, this person who failed to contribute to the objectives of the firm and the team has to stand up and explain his/her behaviour to the team. 


\section{No Social Incentive treatments}

\section{Decision Form}

\section{Experimentall ID:}

\section{Choosing your effort level}

Your decision is to decide how much overall effort you choose to expend. Remember that each effort level has a certain cost that is subtracted from your final pay. Please circle your chosen effort level on the scale below:

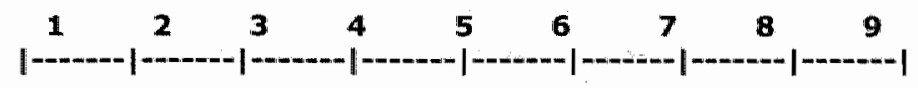

minimum

maximum

effort

effort

level

level

\section{Choosing your effort allocation}

In this decision you decide how you allocate your chosen effort between Task $A$ and Task $B$. Please write down how you allocate your chosen effort on the two tasks in \%. The sum of the two numbers must equal $100 \%$ !

Task A: $\%$

Task B: $\%$

\section{$100 \%$}

Do not forget to indicate your experimental io in the field above. Please put this completed form in the envelope! 


\section{Social Incentive treatments}

\section{Decisilon Form}

\section{Experimental ID:}

\section{Choosing vour effort level}

Your decision is to decide how much overall effort you choose to expend. Remember that each effort level has a certain cost that is subtracted from your final pay. Please circle your chosen effort level on the scale below:

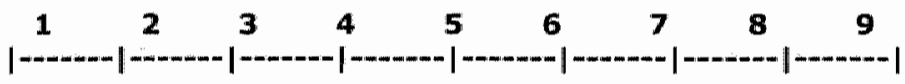

\section{minimum}

maximum

effort

effort

level

level

\section{Choosing vour effort allocation}

In this decision you decide how you allocate your chosen effort between Task A and Task B. Please write down how you allocate your chosen effort on the two tasks in \%. The sum of the two numbers must equal $100 \%$ !

Task A: $\%$

Task B: $\%$

$100 \%$

Do not forget to indicate your experimental ID in the field above. 


\section{Questionnaire}

Please fill in this questionnaire as honestly and accurately as you can. vour answers (as well as your performance during the experiment) are anonymous. There is no way to trace your answers back to you.

Experimental ID:

For each of the following statements, please indicate how true it is for you, using the following scale:

$\begin{array}{cccccccc}\begin{array}{l}\text { not at all } \\ \text { agree }\end{array} & & \text { neutral } & & \begin{array}{r}\text { strongly } \\ \text { agree }\end{array} \\ 1 & 2 & 3 & 4 & 5 & 6 & 7\end{array}$

1. I would never cheat on my taxes.

$\begin{array}{lllllll}1 & 2 & 3 & 4 & 5 & 6 & 7\end{array}$

2. I take advantage of others.

3. I obstruct others' plans.

4. I use flattery to get ahead.

5. I need the approval of others.

6. I usually do what athers do.

7. I stick to the rulles.

8. I worry what other people think of me.

9. I would cheat to get ahead.

10. I pretend to be concerned for others.

11. Ignoring the goal of the company would be unethical.

12. I want to be different from others.

13. I am not concermed with making a good impression.

14. I use others for my own ends.

$\begin{array}{lllllll}12 & 2 & 4 & 5\end{array}$

$\begin{array}{lllllll}1 & 2 & 3 & 4 & 5 & 6 & 7\end{array}$

$\begin{array}{lllllll}1 & 2 & 3 & 4 & 5 & 6 & 7\end{array}$

$\begin{array}{lllllll}1 & 2 & 3 & 4 & 5 & 6 & 7\end{array}$

$\begin{array}{lllllll}1 & 2 & 3 & 4 & 5 & 6 & 7\end{array}$

$\begin{array}{lllllll}1 & 2 & 3 & 4 & 5 & 6 & 7\end{array}$

$\begin{array}{lllllll}1 & 2 & 3 & 4 & 5 & 6 & 7\end{array}$

$\begin{array}{lllllll}1 & 2 & 3 & 4 & 5 & 6 & 7\end{array}$

$\begin{array}{lllllll}1 & 2 & 3 & 4 & 5 & 6 & 7\end{array}$

$\begin{array}{lllllll}1 & 2 & 3 & 4 & 5 & 6 & 7\end{array}$

15. I conform to others' opinions.

16. I know how to get around the rules.

$\begin{array}{lllllll}1 & 2 & 3 & 4 & 5 & 6 & 7\end{array}$

$\begin{array}{lllllll}1 & 2 & 3 & 4 & 5 & 6 & 7\end{array}$

17. I don't care what others think.

$\begin{array}{lllllll}1 & 2 & 3 & 4 & 5 & 6 & 7\end{array}$

$\begin{array}{lllllll}1 & 2 & 3 & 4 & 5 & 6 & 7\end{array}$

$\begin{array}{lllllll}1 & 2 & 3 & 4 & 5 & 6 & 7\end{array}$

$\begin{array}{lllllll}1 & 2 & 3 & 4 & 5 & 6 & 7\end{array}$ 
18. I feel it is OK that some people don't like me. $\quad \begin{array}{lllllllll}1 & 2 & 3 & 4 & 5 & 6 & 7\end{array}$

19. I want to amount to something special in $\begin{array}{lllllll}1 & 2 & 3 & 4 & 5 & 6 & 7\end{array}$ other's eves.

20. I want to form my own opinions.

21. I put people under pressure.

22. The others in the room and 1 form one production team.

$\begin{array}{lllllll}1 & 2 & 3 & 4 & 5 & 6 & 7\end{array}$

$\begin{array}{lllllll}1 & 2 & 3 & 4 & 5 & 6 & 7\end{array}$

$\begin{array}{lllllll}1 & 2 & 3 & 4 & 5 & 6 & 7\end{array}$

23. If I allocated no effort on Task $B_{s}$ others in the $\quad \begin{array}{llllllll}1 & 2 & 3 & 4 & 5 & 6 & 7\end{array}$ group will find that out for sure.

24. During the experiment you are paid. The money you receive changes with your chosen effort level, as effort levels are costly and these costs are subtracted from your finall pay. However, once you have chosen your effort level (and the costs for that), your income in this experiment

$\checkmark$ does not depend on your effort allocation.

¿ changes, depending on how much I allocate to task A or to task B.

25. What is your gender?

i male $\quad *$ female

26. What is your age? (years)

27. Please indicate your nationality. $₫$ Dutch $\$$ German $\$$ Belgian $\$$ other

Here, you can give any comment you like concerning the experiment and/or the choices you made. 


\section{Appendix B}

This appendix includes the experimental material for the study described in chapter 5 on career concerns in multi-task settings. The instructions for $Z$ players are exactly the same as for $Y$-players, except for the fact that instead of $Y$-player they refer to Z-player and vice versa. As in Appendix A, I have titled the instructions with the relevant treatment for reasons of clarity. Further, this appendix includes the questionnaires used in this study. 


\section{Instructions "Equally Weighted Financial Incentives / No Career Concerns"}

Welcome.

You are about to participate in an experiment in decision making behavior. This experiment will last approximately 40 minutes. Your participation is compensated with money. How you are compensated is explained later.

In the following instructions you will find all information that is necessary for you in this experiment. Communication is not allowed. Subjects ignoring this rule will be exempted from the experiment and all payments.

The experiment consists of 5 periods. Each period lasts 2 minutes. In the experiment you are working for an experimental firm.

On your desk you will find an envelope with 3 items in it: a performance sheet, 2 decading tables and a paper card with an ID number on it (for anonymity reasons). You have one performance sheet with two-digit numbers on it, where one half represents task $A$ (titled) and the other half represents task $B$ (titled). In both tasks you are asked to decode as many 2-digit numbers as possible into letters based on a decoding table. After every period an instructor will collect your performance sheets. Do not forget to fill in your experimentall ID. Your performance during the whole experiment stays absolutely anonymous!

Decoding works as follows: The first digit specifies the row, and the second digit specifies the column of the table where you can find the decoded letters. To decode the number 34 with the table bellow you will find the decoded letter in the $3^{\text {rd }}$ row and the $4^{\text {th }}$ column. The decoded letter combination is thus " $q r^{\prime}$. The decoded value for the number 53 is the letter " $x y$ ".

\begin{tabular}{|c|c|c|c|c|c|c|}
\hline & $\mathbf{1}$ & $\mathbf{2}$ & $\mathbf{3}$ & $\mathbf{4}$ & $\mathbf{5}$ & $\mathbf{6}$ \\
\hline $\mathbf{1}$ & $\mathrm{yy}$ & $\mathrm{gh}$ & $\mathrm{pq}$ & $\mathrm{mn}$ & $\mathrm{ww}$ & $\mathrm{Im}$ \\
\hline $\mathbf{2}$ & $\mathrm{qq}$ & $\mathrm{oo}$ & $\mathrm{bc}$ & $\mathrm{jk}$ & $\mathrm{no}$ & $\mathrm{pp}$ \\
\hline $\mathbf{3}$ & $\mathrm{xx}$ & $\mathrm{kl}$ & $\mathrm{dd}$ & $\mathrm{qr}$ & $\mathrm{kk}$ & $\mathrm{za}$ \\
\hline $\mathbf{4}$ & $\mathrm{mm}$ & $\mathrm{w}$ & $\mathrm{tu}$ & $\mathrm{rr}$ & $\mathrm{uv}$ & $\mathrm{uu}$ \\
\hline $\mathbf{5}$ & $\mathrm{hi}$ & $\mathrm{yz}$ & $\mathrm{xy}$ & $\mathrm{jj}$ & $\mathrm{ss}$ & $\mathrm{tt}$ \\
\hline $\mathbf{6}$ & $\mathrm{cd}$ & $\mathrm{gg}$ & $\|$ & $\mathrm{nn}$ & $\mathrm{bb}$ & $\mathrm{hh}$ \\
\hline $\mathbf{7}$ & ef & $\mathrm{de}$ & $\mathrm{wx}$ & $\mathrm{zz}$ & $\mathrm{ee}$ & $\mathrm{fg}$ \\
\hline $\mathbf{8}$ & aa & $\mathrm{w}$ & $\mathrm{cc}$ & & & \\
\hline
\end{tabular}

Decoding numbers of $A$ and $B$ is equal in terms of difficulty. The decoding keys for $A$ and $B$ are different, though. For the experimental firm an equal amount of decoded numbers of task $\mathrm{A}$ and task $\mathrm{B}$ is desirable. 
Your performance in a period is measured as follows:

result task A: $\quad r_{\mathrm{A}}=30+$ amount of correctly decoded numbers of task $\mathrm{A}$

result task $B$ : $\quad r_{B}=30+$ amount of correctly decoded numbers of task $B+$

At the beginning of each period you always receive 30 points. Per correctly decoded number of $A$ and $B$ you receive an additional point. Whereas your performance on task $A$ is measured precisely, your performance on task B is measured imprecisely. The performance measure on task $B$ will include a random number $e$ between -20 and 20 (all numbers with an equal chance) that is added to the amount of decoded numbers of $B$.

To illustrate this, an example:

\section{Example}

You have correctly decoded 25 numbers of task $A$ and 25 numbers of task $B$, thus equal amounts on both tasks. Imagine the random number " $\mathrm{e}$ " that is added to your performance on task $B$ would be " $-12^{\prime \prime}$. In this example your results would be:

$r_{A}=55$

$r_{B}=43$

However, there is an equal chance that the random number " $e$ " is not -12 , but for example +12 . In this case $r_{B}$ would change and your results would be:

$r_{A}=55$

$r_{B}=67$

Thus, your effort on task $A$ is exactly reflected in $\pi_{A}$, whereas there is an equal chance that your result in $r_{B}$ is indicated higher or lower than your actual performance on task $B$.

\section{Compensation}

You are compensated as follows:

Per point above 30 of $r_{A}$ and $r_{B}$ you will receive 60,06 .

Using the example above, if $r_{A}=55$ and $r_{B}=43$, you would earn $(25 * 60.06)+(13 *$ $(0.06)=61.50+60.78=62.28$ in this period. 


\section{Instructions " Equally Weighted Financial Incentives / Career Concerns"}

Welcome.

You are about to participate in an experiment in decision-making behavior. This experiment will last approximately 40 minutes. Your participation is compensated with money. How you are compensated is explained later.

In the following instructions you will find all information that is necessary for you in this experiment. Communication is not allowed. Subjects ignoring this rule will be exempted from the experiment and all payments.

There are 3 types of players in this experiment, $X$-players ( 10 in total), one $Y$-player and one $Z$-player. You are an $X$-player. $X$-players are working for experimental firms represented by either the $Y$-or the $Z$-player.

The experiment consists of 5 periods. Each period lasts 2 minutes. In the first period, you are randomly assigned to the firm of either the $Y$-or the $Z$-player.

On your desk you will find an envelope with 3 items in it: a performance sheet, 2 decoding tables and a paper card with an ID number on it (for anonymity reasons). You have one performance sheet with two-digit numbers on it, where one half represents task $A$ (titled) and the other half represents task B (titled). In both tasks you are asked to decode as many 2-digit numbers as possible into letters based on a decoding table. After every period an instructor will collect your performance sheets. Do not forget to fill in your experimental ID. Your performance during the whole experiment stays absolutely anonymous!

Decoding works as follows: The first digit specifies the row, and the second digit specifies the column of the table where you can find the decoded letters. To decode the number 34 with the table below you will find the decoded letter in the $3^{\text {rd }}$ row and the $4^{\text {th }}$ column. The decoded letter combination is thus "qr". The decoded value for the number 53 is the letter " $x y "$.

\begin{tabular}{|c|c|c|c|c|c|c|}
\hline & $\mathbf{1}$ & $\mathbf{2}$ & $\mathbf{3}$ & $\mathbf{4}$ & $\mathbf{5}$ & $\mathbf{6}$ \\
\hline $\mathbf{1}$ & $\mathrm{yy}$ & $\mathrm{gh}$ & $\mathrm{pq}$ & $\mathrm{mn}$ & $\mathrm{ww}$ & $\mathrm{Im}$ \\
\hline $\mathbf{2}$ & $\mathrm{qq}$ & $\mathrm{oo}$ & $\mathrm{bc}$ & $\mathrm{jk}$ & $\mathrm{no}$ & $\mathrm{pp}$ \\
\hline $\mathbf{3}$ & $\mathrm{xx}$ & $\mathrm{kl}$ & $\mathrm{dd}$ & $\mathrm{qr}$ & $\mathrm{kk}$ & $\mathrm{za}$ \\
\hline $\mathbf{4}$ & $\mathrm{mm}$ & $\mathrm{ww}$ & $\mathrm{tu}$ & $\mathrm{rr}$ & $\mathrm{uv}$ & $\mathrm{uu}$ \\
\hline $\mathbf{5}$ & $\mathrm{hi}$ & $\mathrm{yz}$ & $\mathrm{xy}$ & $\mathrm{jj}$ & $\mathrm{ss}$ & $\mathrm{tt}$ \\
\hline $\mathbf{6}$ & $\mathrm{cd}$ & $\mathrm{gg}$ & $\mathrm{I}$ & $\mathrm{nn}$ & $\mathrm{bb}$ & $\mathrm{hh}$ \\
\hline $\mathbf{7}$ & $\mathrm{ef}$ & $\mathrm{de}$ & $\mathrm{wx}$ & $\mathrm{zz}$ & $\mathrm{ee}$ & $\mathrm{fg}$ \\
\hline $\mathbf{8}$ & $\mathrm{aa}$ & $\mathrm{w}$ & $\mathrm{cc}$ & & & \\
\hline
\end{tabular}


Decoding numbers of $A$ and $B$ is equal in terms of difficulty. The decoding keys for $A$ and $B$ are different, though. For the firm you are currently assigned to, an equal amount of decoded numbers of task $A$ and task $B$ is desirable.

After every period the $Y$ - and the $Z$-player compete as firms for the $X$-players with high decoding abilities. Hence, the $Y$ - and the $Z$-player are interested in finding out your actual decoding ability. Your performance in a period is measured as follows:

result task $\mathrm{A}: \quad r_{\mathrm{A}}=30+$ amount of correctly decoded numbers of task $\mathrm{A}$

result task $B: \quad r_{B}=30+$ amount of correctly decoded numbers of task $B+e$

At the beginning of each period you always receive 30 points. Per correctly decoded number of $A$ and $B$ you receive an additional point. Whereas your performance on task $A$ is measured precisely, your performance on task $B$ is measured imprecisely. The performance measure on task $\mathrm{B}$ will include a random number e between -20 and 20 (all numbers with an equal chance) that is added to the amount of decoded numbers of $B$. This means your "decoding ability" cannot be assessed precisely on $\mathrm{r}_{\mathrm{g}}$, the measure for task $\mathrm{B}$.

To illustrate this, an example:

\section{Example}

You have correctly decoded 25 numbers of task $A$ and 25 numbers of task $B$, thus equal amounts on both tasks. Imagine the random number " $e$ " that is added to your performance on task $B$ would be "-12". In this example your results would be:

$r_{\mathrm{A}}=55$

$r_{B}=43$

The $Y$ - and the $Z$-player will see these two numbers after a period and will evaluate your decoding ability based on them. They will not see the actual random number "e", only the two numbers $r_{A}$ and $r_{B}$ as shown above.

However, there is an equal chance that the random number " $\mathrm{e}$ " is not -12 , but for example +12 . In this case $r_{\mathrm{B}}$ would change and your results would be:

$r_{\mathrm{A}}=55$

$r_{B}=67$

Thus, your effort on task $A$ is exactly reflected in $r_{A s}$ whereas there is an equal chance that your result in $r_{B}$ is indicated higher or lower than your actwal performance on task $B$.

\section{Compensation}

You are compensated as follows:

Per point above 30 of $r_{A}$ and $r_{B}$ you will receive $€ 0,06$.

Using the example above, if $r_{A}=55$ and $r_{B}=43$, you would earn $(25 *$ co.06) * (13* $\epsilon 0.06)=€ 1.50+\epsilon 0.78=€ 2.28$ in this period. However, you can earn additional money based on the evaluation of your decoding ability. Based on the results, the $Y$ - and the $Z$ player assess the abilities of $X$-pllayers. They know that $r_{A}$ is a precise measure and that $r_{B}$ is an imprecise measure of your decoding ability. In competing for $X$-players with 
high decoding ablities, both the firm of the $Y$-and the $Z$-player can offer you a fixed wage of $60, E 1$ or $E 2$ for the next period in addition to the compensation above. You will automatically receive the highest offer of elther the $Y$ - or the $Z$-player, which means you are assigned to and work for the particular experimental firm of the $Y$ - or $Z$-player who has offered you the highest additional wage for the next period. 


\section{Instructions "Fixed Wage / No Career Concerns"}

Welcome.

You are about to participate in an experiment in decision-making behavior. This experiment will last approximately $\mathbf{4 0}$ minutes. Your participation is compensated with money. How you are compensated is explained later.

In the following instructions you will find all information that is necessary for you in this experiment. Communication is not allowed. Subjects ignoring this rule will be exempted from the experiment and all payments.

The experiment consists of 5 periods. Each period lasts 2 minutes. In the experiment you are working for an experimental firm.

On your desk you will find an envelope with 3 items in it: a performance sheet, 2 decoding tables and a paper card with an ID number on it (for anonymity reasons). You have one performance sheet with two-digit numbers on it, where one half represents task $A$ (titled) and the other half represents task B (titled). In both tasks you are asked to decode as many 2-digit numbers as possible into letters based on a decoding table. After every period an instructor will collect your performance sheets. Do not forget to fill in your experimental ID. Your performance during the whole experiment stays absolutely anonymous!

Decoding works as follows: The first digit specifles the row, and the second digit specifies the calumn of the table where you can find the decoded letters. To decode the number 34 with the table below you will find the decoded letter in the $3^{\text {rd }}$ row and the $4^{\text {th }}$ column. The decoded letter combination is thus "qr". The decoded value for the number 53 is the letter "xy".

\begin{tabular}{|c|c|c|c|c|c|c|}
\hline & $\mathbf{1}$ & $\mathbf{2}$ & $\mathbf{3}$ & $\mathbf{4}$ & $\mathbf{5}$ & $\mathbf{6}$ \\
\hline $\mathbf{1}$ & $\mathrm{yy}$ & $\mathrm{gh}$ & $\mathrm{pq}$ & $\mathrm{mn}$ & $\mathrm{ww}$ & $\mathrm{Im}$ \\
\hline $\mathbf{2}$ & $\mathrm{gq}$ & $\mathrm{oo}$ & $\mathrm{bc}$ & $\mathrm{jk}$ & $\mathrm{no}$ & $\mathrm{pp}$ \\
\hline $\mathbf{3}$ & $\mathrm{xx}$ & $\mathrm{kl}$ & $\mathrm{dd}$ & $\mathrm{qr}$ & $\mathrm{kk}$ & $\mathrm{za}$ \\
\hline $\mathbf{4}$ & $\mathrm{mm}$ & $\mathrm{ww}$ & $\mathrm{tu}$ & $\mathrm{rr}$ & $\mathrm{uv}$ & $\mathrm{uu}$ \\
\hline $\mathbf{5}$ & $\mathrm{hi}$ & $\mathrm{yz}$ & $\mathrm{xy}$ & $\mathrm{jj}$ & $\mathrm{ss}$ & $\mathrm{tt}$ \\
\hline $\mathbf{6}$ & $\mathrm{cd}$ & $\mathrm{gg}$ & $\mathrm{Il}$ & $\mathrm{nn}$ & $\mathrm{bb}$ & $\mathrm{hh}$ \\
\hline $\mathbf{7}$ & $\mathrm{ef}$ & $\mathrm{de}$ & $\mathrm{wx}$ & $\mathrm{zz}$ & $\mathrm{ee}$ & $\mathrm{fg}$ \\
\hline $\mathbf{8}$ & $\mathrm{aa}$ & $\mathrm{w}$ & $\mathrm{cc}$ & & & \\
\hline
\end{tabular}

Decoding numbers of $A$ and $B$ is equal in terms of difficulty. The decoding keys for $A$ and $B$ are different, though. For the experimental firm an equal amount of decoded numbers of task $A$ and task $B$ is desirable. 
Performance in a period is measured as follows:

result task A: $\quad r_{A}=30+$ amount of correctly decoded numbers of task $A$

result task $B: \quad r_{B}=30+$ amount of correctly decoded numbers of tasik $B+e$

At the beginning of each period 30 points are added to $r_{A}$ and $r_{B}$. Per correctly decoded number of $A$ and $B$ an additional point is added. Whereas performance for task $A$ is measured precisely, performance on task $\mathrm{B}$ is measured imprecisely. The performance measure on task $\mathrm{B}$ will include a random number e between -20 and 20 (all numbers with an equal chance) that is added to the amount of decoded numbers of $B$.

To illustrate this, an example:

\section{Example}

You have correctly decoded 25 numbers of task $A$ and 25 numbers of task $B$, thus equal amounts on both tasks. Imagine the random number " $\mathrm{e}$ " that is addled to performance on task $\mathrm{B}$ would be " -12 ". In this example your results would be:

$r_{A}=55$

$r_{B}=43$

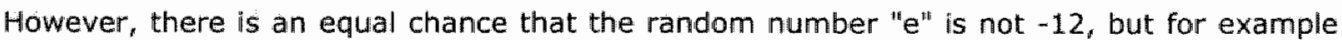
+12 . In this case $r_{B}$ would change and the results would be:

$r_{\mathrm{A}}=55$

$r_{B}=67$

\section{Compensation}

Irrespective of the results of $r_{A}$ and $r_{B}$, you are always compensated with a fixed amount of $€ 2$ per period. 


\section{Instructions "Fixed Wage / Career Concerns"}

Welcome.

You are about to participate in an experiment in decision-making behavior. This experiment will last approximately 40 minutes. Your participation is compensated with money. How you are compensated is explained later.

In the following instructions you will find all information that is necessary for you in this experiment. Communication is not allowed. Subjects ignoring this rule will be exempted from the experiment and all payments.

There are 3 types of players in this experiment, $X$-players ( 10 in total), one $Y$-player and one $Z$-player. You are an $X$-player. $X$-players are working for experimental firms represented by either the $Y$ - or the $Z$-player.

The experiment consists of 5 periods. Each period lasts 2 minutes. In the first period, you are randomly assigned to the firm of either the $Y$ - or the $Z$-player.

On your desk you will find an envelope with 3 items in it: a performance sheet, 2 decoding tables and a paper card with an ID number on it (for anonymity reasons). You have one performance sheet with two-digit numbers on it, where one half represents task $A$ (titled) and the other half represents task B (titled). In both tasks you are asked to decode as many 2 -digit numbers as possible into letters based on a decoding table. After every period an instructor will collect your performance sheets. Do not forget to fill in your experimental ID. Your performance during the whole experiment stays absolutely anonymous!

Decoding works as follows: The first digit specifies the row, and the second digit specifies the column of the table where you can find the decoded letters. To decode the number 34 with the table below you will find the decoded letter in the $3^{\text {rd }}$ row and the $4^{\text {th }}$ column. The decoded letter combination is thus "qr". The decaded value for the number 53 is the letter " $x y^{\prime \prime}$.

\begin{tabular}{|c|c|c|c|c|c|c|}
\hline & 1 & 2 & $\mathbf{3}$ & $\mathbf{4}$ & $\mathbf{5}$ & $\mathbf{6}$ \\
\hline $\mathbf{1}$ & $\mathrm{yy}$ & $\mathrm{gh}$ & $\mathrm{pq}$ & $\mathrm{mn}$ & $\mathrm{ww}$ & $\mathrm{Im}$ \\
\hline $\mathbf{2}$ & $\mathrm{qq}$ & $\mathrm{oo}$ & $\mathrm{bc}$ & $\mathrm{jk}$ & $\mathrm{no}$ & $\mathrm{pp}$ \\
\hline $\mathbf{3}$ & $\mathrm{xx}$ & $\mathrm{kl}$ & $\mathrm{dd}$ & $\mathrm{qr}$ & $\mathrm{kk}$ & $\mathrm{za}$ \\
\hline $\mathbf{4}$ & $\mathrm{mm}$ & $\mathrm{ww}$ & $\mathrm{tu}$ & $\mathrm{rr}$ & $\mathrm{uv}$ & $\mathrm{uu}$ \\
\hline $\mathbf{5}$ & $\mathrm{hi}$ & $\mathrm{yz}$ & $\mathrm{xy}$ & $\mathrm{jj}$ & $\mathrm{ss}$ & $\mathrm{tt}$ \\
\hline $\mathbf{6}$ & $\mathrm{cd}$ & $\mathrm{gg}$ & $\mathrm{Il}$ & $\mathrm{nn}$ & $\mathrm{bb}$ & $\mathrm{hh}$ \\
\hline $\mathbf{7}$ & $\mathrm{ef}$ & $\mathrm{de}$ & $\mathrm{wx}$ & $\mathrm{zz}$ & $\mathrm{ee}$ & $\mathrm{fg}$ \\
\hline $\mathbf{8}$ & $\mathrm{aa}$ & $\mathrm{w}$ & $\mathrm{cc}$ & & & \\
\hline
\end{tabular}

Decoding numbers of $A$ and $B$ is equal in terms of difficulty. The decoding keys for $A$ and $B$ are different, though. For the firm you are currently assigned to, an equal amount of decoded numbers of task $A$ and task $B$ is desirable. 
After every period the $Y$ - and the $Z$-player compete as firms for the $X$-players with high decoding abilities. Hence, the $Y$ - and the $Z$-player are interested in finding out your actual decoding ability. Your performance in a period is measured as follows:

$$
\begin{array}{ll}
\text { result task } A: & r_{A}=30+\text { amount of correctly decoded numbers of task } A \\
\text { result task } B: & r_{B}=30+\text { amount of correctly decoded numbers of task } B+e
\end{array}
$$

At the beginning of each period you always receive 30 points. Per correctly decoded number of $A$ and $B$ you receive an additional point. Whereas your performance on task $A$ is measured precisely, your performance on task $\mathrm{B}$ is measured imprecisely. The performance imeasure on task $B$ will include a random number e between -20 and 20 (all numbers with an equal chance) that is added to the amount of decoded numbers of $B$. This means your "decoding ability" cannot be assessed precilsely on $r_{B}$, the measure for task $B$.

To illustrate this, an example:

\section{Example}

You have correctly decoded 25 numbers of task $A$ and 25 numbers of task $B$, thus equal amounts on both tasks. Imagine the random number " $\mathrm{e}$ " that is added to your performance on task $B$ would be "-12". In this example your results would be:

$$
\begin{aligned}
& r_{A}=55 \\
& r_{B}=43
\end{aligned}
$$

The $Y$ - and the Z-player will see these two numbers after a period and will evaluate your decoding ability based on them. They will not see the actual random number "e", only the two numbers $r_{A}$ and $r_{B}$ as shown above.

However, there is an equal chance that the random number " $e$ " is not -12 , but for example +12 . In this case $r_{B}$ would change and your results would be:

$$
\begin{aligned}
& r_{A}=55 \\
& r_{B}=67
\end{aligned}
$$

Thus, your" effort on task $A$ is exactly reflected in $r_{A_{A}}$ whereas there is an equal chance that your result in $r_{i g}$ is indicated higher or lower than your actual performance on task $B$.

\section{Compensation}

You are compensated with a fixed amount of $€ 2$ per period.

However, you can earn additional money based on the evaluation of your decoding ability. Based on the results, the $Y$ - and the $Z$-player assess the abilities of $X$-players. They know that $r_{A}$ is a precise measure and that $r_{B}$ is an imprecise measure of your decoding ability. In competing for $X$-players with high decoding abilities, both the firm of the $Y$ - and the Z-player can offer you a fixed wage of $\epsilon 0, \epsilon 1$ or $€ 2$ for the next period in addition to the compensation above.

You will automatically receive the highest offer of either the $Y$ - or the Z-player, which means you are assigned to and work for the particular experimental firm of the $Y$ - or $Z$-player who has offered you the highest additional wage for the next period. 


\section{Instructions " Unequally Weighted Financial Incentives / No Career Concerns"}

Welcome.

You are about to participate in an experiment in decision-making behavior. This experiment will last approximately 40 minutes. Your participation is compensated with money. How you are compensated is explained later."

In the following instructions you will find all information that is necessary for you in this experiment. Communication is not allowed. Subjects ignoring this rule will be exempted from the experiment and all payments.

The experiment consists of 5 periods. Each period lasts 2 minutes. In the experiment you are working for an experimental firm.

On your desk you will find an envelope with 3 items in it: a performance sheet, 2 decoding tables and a paper card with an ID number on it (for anonymity reasons). You have one performance sheet with two-digit numbers on it, where one half represents task $A$ (titled) and the other half represents task B (titled). In both tasks you are asked to decode as many 2-digit numbers as possible into letters based on a decoding table. After every period an instructor will collect your performance sheets. Do not forget to fill in your experimental ID. Your performance during the whole experiment stays absolutely anonymous!

Decoding works as follows: The first digit specifies the row, and the second digit specifies the column of the table where you can find the decoded letters. To decode the number 34 with the table below you will find the decoded letter in the $3^{\text {rd }}$ row and the $4^{\text {th }}$ column. The decoded letter combination is thus "qr". The decoded value for the number 53 is the letter " $x y^{\prime \prime}$.

\begin{tabular}{|c|c|c|c|c|c|c|}
\hline & $\mathbf{1}$ & $\mathbf{2}$ & $\mathbf{3}$ & $\mathbf{4}$ & $\mathbf{5}$ & $\mathbf{6}$ \\
\hline $\mathbf{1}$ & $\mathrm{yy}$ & $\mathrm{gh}$ & $\mathrm{pq}$ & $\mathrm{mn}$ & $\mathrm{ww}$ & $\mathrm{Im}$ \\
\hline $\mathbf{2}$ & $\mathrm{qq}$ & $\mathrm{oo}$ & $\mathrm{bc}$ & $\mathrm{jk}$ & $\mathrm{no}$ & $\mathrm{pp}$ \\
\hline $\mathbf{3}$ & $\mathrm{xx}$ & $\mathrm{kl}$ & $\mathrm{dd}$ & $\mathrm{qr}$ & $\mathrm{kk}$ & $\mathrm{za}$ \\
\hline $\mathbf{4}$ & $\mathrm{mm}$ & $\mathrm{w} w$ & $\mathrm{tu}$ & $\mathrm{rr}$ & $\mathrm{uv}$ & $\mathrm{uu}$ \\
\hline $\mathbf{5}$ & $\mathrm{hi}$ & $\mathrm{yz}$ & $\mathrm{xy}$ & $\mathrm{jj}$ & $\mathrm{ss}$ & $\mathrm{tt}$ \\
\hline $\mathbf{6}$ & $\mathrm{cd}$ & $\mathrm{gg}$ & $\mathrm{ll}$ & $\mathrm{nn}$ & $\mathrm{bb}$ & $\mathrm{hh}$ \\
\hline $\mathbf{7}$ & $\mathrm{ef}$ & $\mathrm{de}$ & $\mathrm{wx}$ & $\mathrm{zz}$ & $\mathrm{ee}$ & $\mathrm{fg}$ \\
\hline $\mathbf{8}$ & aa & $\mathrm{w}$ & $\mathrm{cc}$ & & & \\
\hline
\end{tabular}

Decoding numbers of $A$ and $B$ is equal in terms of difficulty. The decoding keys for $A$ and $B$ are different, though. For the experimental firm an equal amount of decoded numbers of task $A$ and task $B$ is desirable. 
Your performance in a period is measured as follows:

result task A: $\quad r_{A}=30+$ amount af correctly decoded numbers of task $A$

result task $B: \quad r_{B}=30+$ amount of correctly decoded numbers of task $B+\mathbf{e}$

At the beginning of each period you always receive 30 points. Per correctly decoded number of $A$ and $B$ you receive an additional point. Whereas your performance on task $A$ is measured precisely, your performance on task B is measured imprecisely. The performance measure on task $B$ will include a random number e between -20 and 20 (all numbers with an equal chance) that is added to the amount of decoded numbers of $B$.

To illustrate this, an example:

\section{Example}

You have correctly decoded 25 numbers of task $A$ and 25 numbers of task $B$, thus equal amounts on both tasks. Imagine the random number " $e$ " that is added to your performance on task $B$ would be "-12". In this example your results would be:

$r_{\mathrm{A}}=55$

$r_{B}=43$

However, there is an equal chance that the random number " $\mathrm{e}$ " is not -12 , but for example +12 . In this case $r_{B}$ would change and your results would be:

$r_{A}=55$

$r_{B}=67$

Thus, your effort on task $A$ is exactly reflected in $r_{A}$ whereas there is an equal chance that your result in $r_{B}$ is indicated higher or lower than your actual performance on task $B$.

\section{Compensation}

You are compensated as follows:

Per point above 30 of $r_{A}$ you will receive $C 0.04$, but per point above 30 of $r_{B}$ you will receive co.08.

Using the example above, if $r_{A}=55$ and $r_{B}=43$, you would earn $(25 * 60.04)+(13 *$ $(0.08)=61.00+€ 1.04=62.04$ in this period. 


\section{Instructions " Unequally Weighted Financial Incentives / Career Concerns"}

Welcome.

You are about to participate in an experiment in decision-making behavior. This experiment will last approximately 40 minutes. Your participation is compensated with money. How you are compensated is explained later.

In the following instructions you will find all information that is necessary for you in this experiment. Communication is not allowed. Subjects ignoring this rule will be exempted from the experiment and all payments.

There are 3 types of players in this experiment, $X$-players ( 10 in total), one $Y$-player and one $Z$-player. You are an $X$-player. $X$-players are working for experimental firms represented by either the $Y$ - or the $Z$-player.

The experiment consists of 5 periods. Each period lasts 2 minutes. In the first period, you are randomly assigned to the firm of either the $Y$ - or the $Z$-player.

On your desk you will find an envelope with 3 items in it: a performance sheet, 2 decoding tables and a paper card with an ID number on it (for anonymity reasons). You have one performance sheet with two-digit numbers on it, where one half represents task A. (titled) and the other half represents task B (titled). In both tasks you are asked to decode as many 2-digit numbers as possible into letters based on a decoding table. After every period an instructor will collect your performance sheets. Do not forget to fill in your experimental ID. Your performance during the whole experiment stays absolutely anonymous!

Decoding works as follows: The first digit specifies the row, and the second diglt specifies the column of the table where you can find the decoded letters. To decode the number 34 with the table below you will find the decoded letter in the $3^{\text {rd }}$ row and the $4^{\text {in }}$ column. The decoded letter combination is thus "qr" . The decoded value for the number 53 is the letter" " $x y^{\prime \prime}$.

\begin{tabular}{|c|c|c|c|c|c|c|}
\hline & $\mathbf{1}$ & $\mathbf{2}$ & $\mathbf{3}$ & $\mathbf{4}$ & $\mathbf{5}$ & $\mathbf{6}$ \\
\hline $\mathbf{1}$ & $\mathrm{yy}$ & $\mathrm{gh}$ & $\mathrm{pq}$ & $\mathrm{mn}$ & $\mathrm{ww}$ & $\mathrm{Im}$ \\
\hline $\mathbf{2}$ & $\mathrm{qq}$ & $\mathrm{oo}$ & $\mathrm{bc}$ & $\mathrm{jk}$ & $\mathrm{no}$ & $\mathrm{pp}$ \\
\hline $\mathbf{3}$ & $\mathrm{xx}$ & $\mathrm{kl}$ & $\mathrm{dd}$ & $\mathrm{qr}$ & $\mathrm{kk}$ & $\mathrm{za}$ \\
\hline $\mathbf{4}$ & $\mathrm{mm}$ & $\mathrm{ww}$ & $\mathrm{tu}$ & $\mathrm{rr}$ & $\mathrm{uv}$ & $\mathrm{uu}$ \\
\hline $\mathbf{5}$ & $\mathrm{hi}$ & $\mathrm{yz}$ & $\mathrm{xy}$ & $\mathrm{jj}$ & $\mathrm{ss}$ & $\mathrm{tt}$ \\
\hline $\mathbf{6}$ & $\mathrm{cd}$ & $\mathrm{gg}$ & $\mathrm{Il}$ & $\mathrm{nn}$ & $\mathrm{bb}$ & $\mathrm{hh}$ \\
\hline $\mathbf{7}$ & ef & $\mathrm{de}$ & $\mathrm{wx}$ & $\mathrm{zz}$ & $\mathrm{ee}$ & $\mathrm{fg}$ \\
\hline $\mathbf{8}$ & aa & $\mathrm{w}$ & $\mathrm{cc}$ & & & \\
\hline
\end{tabular}


Decoding numbers of $A$ and $B$ is equal in terms of difficulty. The decoding keys for $A$ and $B$ are different, though. For the firm you are currently assigned to, an equal amount of decoded numbers of task $A$ and task $B$ is desirable.

After every period the $Y$ - and the $Z$-player compete as firms for the $X$-players with high decoding abilities. Hence, the $Y$ - and the $Z$-player are interested in finding out your actual decoding ability. Your performance in a period is measured as follows:

result task A: $\quad r_{A}=30+$ amount of correctly decoded numbers of task $A$

result task $B$ : $\quad r_{B}=30+$ amount of correctly decoded numbers of task $B+e$

At the beginning of each period you always receive 30 points. Per correctly decoded number of $A$ and $B$ you receive an additional point. Whereas your performance on task $A$ is measured precisely, your performance on task $\mathrm{B}$ is measured imprecisely. The performance measure on task B will include $a$ random number between -20 and 20 (all numbers with an equal chance) that is added to the amount of decoded numbers of $\mathrm{B}$. This means your "decoding ability cannot be assessed precisely on $r_{B}$ the measure for task $B$.

To illustrate this, an example:

\section{Example}

You have correctly decoded 25 numbers of task $\mathrm{A}$ and 25 numbers of task $\mathrm{B}$, thus equal amounts on both tasks. Imagine the random number " $e$ " that is added to your performance on task $\mathrm{B}$ would be " $-12^{\text {"I }}$. In this example your results would be:

$r_{A}=55$

$r_{B}=43$

The $\gamma$-and the $Z$-player will see these two numbers after a period and will evaluate your decoding ability based on them. They will not see the actual random number " $e^{n}$, only the two numbers $r_{A}$ and $r_{B}$ as shown above.

However, there is an equall chance that the random number " $\mathrm{e}$ " is not -12 , but for example +12 . In this case $r_{B}$ would change and your results would be:

$r_{A}=55$

$P_{B}=67$

Thus, your effort on task $A$ is exactly reflected in $r_{A,}$ whereas there is an equal chance that your result in $r_{B}$ is indicated higher or lower than your actual performance on task $B$.

\section{Compensation}

You are compensated as follows:

Per point above 30 of $r_{A}$ you will receive 60,04 , but per point above 30 of $r_{B}$ you will receive c0.08.

Using the example above, if $r_{A}=55$ and $r_{B}=43$, you would earn $(25 * 60.04)+(13 *$ $€ 0.08)=€ 1.00+61.04=€ 2.04$ in this period. However, you can earn additional money based on the evaluation of your decoding ability. Based on the results, the $Y$ - and the $Z$ player assess the abilities of $X$-players. They know that $r_{A}$ is a precise measure and that 
$r_{B}$ is an imprecise measure of your decoding ability, In competing for $X$-players with high decoding abilities, both the firm of the $Y$ - and the $Z$-player can offer you a fixed wage of $60, \epsilon 1$ or $€ 2$ for the next period in addition to the compensation above. You will automatically receive the highest offer of either the $Y$ - or the $Z$-player, which means you are assigned to and work for the particular experimental firm of the Y-or Z-player who has offered you the highest additional wage for the next periad. 


\section{Instructions "'Y-Player"}

Welcome.

You are about to participate in an experiment in decision-making behavior. This experiment will last approximately 30 minutes. If you understand the instructions and make careful decisions you may earn a considerable amount of cash, which will be paid to you at the end of the experiment. There are 3 types of players in this experiment, $x$-players $(10$ in total), one $Y$-player and one $Z$-player. You are a $Y$-player. In the following instructions you will find all information that is necessary for you in this experiment. Communication is not allowed. Subjects ignoring this rule will be exempted from the experiment and all payments.

The experiment consists of 5 periods. Each period lasts 2 minutes. In the first period, $5 x$ players (of $10 \mathrm{X}$-players in total) are assigned to you. The other $5 \mathrm{X}$-players are assigned to the $Z$-player. During the experiment, $X$-players work on a decoding task where they have to decode as many numbers as possible on two tasks, task $A$ and task $B$ based on a decoding table. Both tasks are equal in terms of difficulty.

\section{Your task is to evaluate the performance of $\mathrm{X}$-players.}

After the first period, an instructor will transfer the results of all X-players to you. Results of $X$-players are measured as follows:

task $\mathrm{A}: \quad r_{\mathrm{A}}=30+$ amount of correctly decoded numbers

task $\mathrm{B}: \quad \mathrm{P}_{\mathrm{B}}=30+$ amount of correctly decoded numbers $+\mathrm{e}$

At the beginning of each period $X$-players always receive 30 points for $r_{A}$ and $r_{B}$. Per correctly decoded number an X-player receives an additional point. Whereas the result of task $A$ is precise, the result for task $B$ includes a random number e between -20 and 20 (all numbers with an equal chance) that is added to the amount of decoded numbers of $B$.

\section{Example}

An X-player has correctly decoded 25 numbers of task $A$ and 25 numbers off task $B$, thus equal amounts on both tasks. Imagine the random number " $e$ " that is added to the performance on task $\mathrm{B}$ would be "-12". In this example the results transferred to you would be:

$r_{A}=55$

$r_{\theta}=43$

However, there is an equal chance that the random number " $e$ " is not -12 , but for example +12. $r_{i}$ would change and the transferred results would be:

$r_{A}=55$

$r_{B}=67$ 
Thus, effort on task $A$ is exactly reflected in $r_{A}$, whereas there is an equal chance that the result of an $X$-player on $r_{B}$ is indicated higher or lower than the actual performance on task B.

In evaluating the performance of $X$-players, you will first receive an overvlew of $r_{A}$ and $r_{B}$ of all $X$-players on performance cards. In addition to an evaluation, you need to decide whether you pay X-players an additional fixed wage (1 or 2 Euro) or not. An X-player is then assigned to you if your offer was higher than that of the Z-player. You can earn money only with X-players that are assigned to you in a period. You thus compete with the Z-player for $X$-players. If your offer is the same as the offer of the $Z$-player, an $X$-player stays assigned as in the previous period.

You first make offers on the decision card for X-players assigned to the $Z$-player (similarly, the $Z$-player is making offers for the $X$-players assigned to you). After this, your decision cards are exchanged and you make a counter offer. The highest offer "wins", i.e., an $X$ player will be assigned to you if you have offered him the highest additional fixed wage. In case of equal offers of you and the $Z$-player the $X$-player stays assigned as in the previaus period and no change occurs.

X-players are then informed on their possible additional fixed wages and the next period starts.

\section{Compensation}

You will earn money based on the performance of the $X$-players that are assigned to you in a period. You will not earn any money on the results of period 1 , though! You will earn 60,03 per point above 30 of $r_{A}$ and $r_{B}$ of an $X$-player. In case $r_{B}$ is below 30 you will receive nothing for task $B$. Possible fixed wage payments to $X$-players (who are then assigned to you) are subtracted from your compensation!

\section{Example}

Your offer for an $X$-player in period 2 was higher than that of the $Z$-player, so the X-player is assigned to you in period 2. Your offer was a fixed wage of $C 1$. The results of the X-player in period 2 are

$r_{\mathrm{A}}=65$

$r_{10}=59$

As only points above 30 (per task) are counted for compensation purposes, this player has earned you 35 points on task A and 29 on task B. This leads to a total of 64 points. You are paid 60.03 per point, which makes 61.92 . Furthermore, the wage payment of $E 1$ is subtracted, so that you have earned $€ 0.92$ with this particular $\mathrm{K}$-player.

From June 24 onwards you can pick up your money by indicating your experimental code in room 2.023 b (Tongersestraat 53). 


\section{Interim Questionnaire 1 (Career Concerns)}

Please fill in this questionnaire as honestly and accurately as you can. Your answers (as well as your performanice during the experiment) are anonymous. There is no way to trace your answers back to you.

Experimental Code:

For each of the following statements 1 to 21 , please indicate how true it is for you, using the following scale:

$\begin{array}{cc}\text { not at all neutral } & \text { wery } \\ \text { true } & \text { true }\end{array}$

$\begin{array}{lllllll}1 & 2 & 3 & 4 & 5 & 6 & 7\end{array}$

1. I put a lot of effort into this experiment.

$\begin{array}{lllllll}1 & 2 & 3 & 4 & 5 & 6 & 7\end{array}$

2. I think $I$ am pretty good at the experimental tasks. $\begin{array}{llllllll}1 & 2 & 3 & 4 & 5 & 6 & 7\end{array}$

3. I feel wery tense while doing this experiment. $\quad \begin{array}{llllllllll} & 1 & 2 & 3 & 4 & 5 & 6 & 7\end{array}$

4. Often I worry what people think of me.

5. I am anxious while working on the experiment.

6. I am not bothered by difficult social situations.

7. I conform to others' opinions.

8. I often obstruct the plans of others.

9. I pretend to be concerned for others.

10. I try very hard on this experiment.

11. It is important to me to do well at this experiment.

12. I need the approval of others.

13. I am very relaxed in doing the experiment.

14. I take advantage of the work of others.

15. I enjoy doling this experiment very much.

16. I don't put much energy into the experiment.

17. I am not easily embarrassed.

$\begin{array}{lllllll}1 & 2 & 3 & 4 & 5 & 6 & 7\end{array}$

$\begin{array}{lllllll}1 & 2 & 3 & 4 & 5 & 6 & 7\end{array}$

$\begin{array}{lllllll}1 & 2 & 3 & 4 & 5 & 6 & 7\end{array}$

$\begin{array}{lllllll}1 & 2 & 3 & 4 & 5 & 6 & 7\end{array}$

$\begin{array}{lllllll}1 & 2 & 3 & 4 & 5 & 6 & 7\end{array}$

$\begin{array}{lllllll}1 & 2 & 3 & 4 & 5 & 6 & 7\end{array}$

$\begin{array}{lllllll}1 & 2 & 3 & 4 & 5 & 6 & 7\end{array}$

$\begin{array}{lllllll}1 & 2 & 3 & 4 & 5 & 6 & 7\end{array}$

$\begin{array}{lllllll}1 & 2 & 3 & 4 & 5 & 6 & 7\end{array}$

$\begin{array}{lllllll}1 & 2 & 3 & 4 & 5 & 6 & 7\end{array}$

$\begin{array}{lllllll}1 & 2 & 3 & 4 & 5 & 6 & 7\end{array}$

$\begin{array}{lllllll}1 & 2 & 3 & 4 & 5 & 6 & 7\end{array}$

$\begin{array}{lllllll}1 & 2 & 3 & 4 & 5 & 6 & 7\end{array}$

$\begin{array}{lllllll}1 & 2 & 3 & 4 & 5 & 6 & 7\end{array}$

18. I don't feel nervous at all while doing this experiment. $\begin{array}{llllllll}1 & 2 & 3 & 4 & 5 & 6 & 7\end{array}$

19. I want to be regarded as someone special by others. $\begin{array}{lllllllll}1 & 2 & 3 & 4 & 5 & 6 & 7\end{array}$

20. I often use others for my own ends. $\quad \begin{array}{llllllll} & 1 & 2 & 3 & 4 & 5 & 6 & 7\end{array}$

21. Without a good performance I cannot increase my pay $\begin{array}{lllllllll}1 & 2 & 3 & 4 & 5 & 6 & 7\end{array}$ at this experiment. 


\section{Interim Questionnaire 2 (Career Concerns)}

Please fill in this questionnaire as honestly and accurately as you can. Your answers (as well as your performance during the experiment) are anonymous: There is no way to trace your answers back to you.

Experimental Code:

For each of the following statements 1 to 21 , please indicate how true it is for you, using the following scale:

\begin{tabular}{ccccccc}
$\begin{array}{c}\text { not at all } \\
\text { true }\end{array}$ & & \multicolumn{3}{c}{ neutral } & & wery \\
1 & 2 & 3 & 4 & 5 & 6 & 7
\end{tabular}

1. Ifind it difficult to approach others.

2. I think this is a boring activity.

3. Generally, I would cheat to go ahead.

4. I feel pressured while doing this experiment.

$\begin{array}{lllllll}1 & 2 & 3 & 4 & 5 & 6 & 7\end{array}$

$\begin{array}{lllllll}1 & 2 & 3 & 4 & 5 & 6 & 7\end{array}$

$\begin{array}{lllllll}1 & 2 & 3 & 4 & 5 & 6 & 7\end{array}$

5. I would describe this experiment as very interesting. $\begin{array}{lllllllll}1 & 2 & 3 & 4 & 5 & 6 & 7\end{array}$

6. This experiment does not hold my attention at all. $\begin{array}{lllllllll}1 & 2 & 3 & 4 & 5 & 6 & 7\end{array}$

7. While I am working on the experiment I am $\quad \begin{array}{lllllllll}1 & 2 & 3 & 4 & 5 & 6 & 7\end{array}$ thinking about how much I enjay it.

8. I don't try very hard to do well at this experiment. $\begin{array}{lllllllll}1 & 2 & 3 & 4 & 5 & 6 & 7\end{array}$

9. I usually do what others do. $\quad 1 \quad 2 \quad \begin{array}{lllllll} & 3 & 4 & 5 & 6 & 7\end{array}$

10. I am easily intimidated.

11. I am often afraid that I will do the wrong thing.

12. I use flattery to get ahead.

13. I think I am doing pretty well at this experiment, compared to other students.

14. I don't care what others think of me.

15. This experiment is an activity that I cannot do well

16. I am able to stand up for myself.

17. I know how to get around the rules.

18. I put people under pressure.

19. I onlly feel comfortable with friends.

$\begin{array}{lllllll}1 & 2 & 3 & 4 & 5 & 6 & 7\end{array}$

$\begin{array}{lllllll}1 & 2 & 3 & 4 & 5 & 6 & 7\end{array}$

$\begin{array}{lllllll}1 & 2 & 3 & 4 & 5 & 6 & 7\end{array}$

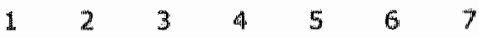

20. I am not concerned with making a good impression. $\begin{array}{llllllll}1 & 2 & 3 & 4 & 5 & 6 & 7\end{array}$

21. If I show high effort at this experiment $\quad \begin{array}{lllllllll}1 & 2 & 3 & 4 & 5 & 6 & 7\end{array}$ I can get a better pay. 


\section{Interim Questionnaïre 3 (Career Concerns)}

Please fill in this questionnaire as honestly and accurately as vou can. Your answers (as well as your perfomance duning the experiment) are anonymous. There is no way to trace your answers back to you.

Experintentall Code:

For each of the following statements 1 to 21 , please indicate how true it is for you, using the following scale:

$\begin{array}{ll}\text { not at all neutral } & \text { very } \\ \text { true } & \text { true }\end{array}$

$\begin{array}{lllllllll}1 & 2 & 3 & 4 & 5 & 6 & 7\end{array}$

1. Good effort will be recognized by the Y-and Z-players $1 \quad 2 \quad \begin{array}{llllll} & 1 & 4 & 5 & 6\end{array}$ at this experiment.

2. I would never cheat on my taxes.

3. I am satisfled with my performance.

4. This experiment is fun to do.

5. I am pretty skilled at the experimental task.

6. I think this experliment is quite enjoyable.

7. I am comfortable also in unfamiliar situations.

8. I feel it is OK that some people don't like me.

9. After worked at this experiment for a while, I feel pretty competent.

10. I stick to the rules.

11. I am afraid to draw attention to myself.

12. I often stumblie over my words.

13. dilways want to form my own opingons.

1.4. If want to be different from others.

15. I complete tasks successfully.

$\begin{array}{lllllll}1 & 2 & 3 & 4 & 5 & 6 & 7\end{array}$

$\begin{array}{lllllll}1 & 2 & 3 & 4 & 5 & 6 & 7\end{array}$

$\begin{array}{lllllll}1 & 2 & 3 & 4 & 5 & 6 & 7\end{array}$

$\begin{array}{lllllll}1 & 2 & 3 & 4 & 5 & 6 & 7\end{array}$

$\begin{array}{lllllll}1 & 2 & 3 & 4 & 5 & 6 & 7\end{array}$

$\begin{array}{lllllll}1 & 2 & 3 & 4 & 5 & 6 & 7\end{array}$

$\begin{array}{lllllll}1 & 2 & 3 & 4 & 5 & 6 & 7\end{array}$

$\begin{array}{lllllll}1 & 2 & 3 & 4 & 5 & 6 & 7\end{array}$

16. It is important for me that others think highly of me. $\begin{array}{llllllll}1 & 2 & 3 & 4 & 5 & 6 & 7\end{array}$

17. I excel in what $\mathbb{1}$ do.

18. Id don't see the consequences of things.

19. I handle tasks smoothly.

20. misjudge situations.

21. I am sure of my ground.

$\begin{array}{lllllll}1 & 2 & 3 & 4 & 5 & 6 & 7\end{array}$

$\begin{array}{lllllll}1 & 2 & 3 & 4 & 5 & 6 & 7\end{array}$

$\begin{array}{lllllll}1 & 2 & 3 & 4 & 5 & 6\end{array}$

$\begin{array}{lllllll}1 & 2 & 3 & 4 & 5 & 6 & 7\end{array}$

$\begin{array}{lllllll}1 & 2 & 3 & 4 & 5 & 6 & 7\end{array}$

$\begin{array}{lllllll}1 & 2 & 3 & 4 & 5 & 6 & 7\end{array}$

$\begin{array}{lllllll}1 & 2 & 3 & 4 & 5 & 6 & 7\end{array}$

$\begin{array}{lllllll}1 & 2 & 3 & 4 & 5 & 6 & 7\end{array}$

$\begin{array}{lllllll}1 & 2 & 3 & 4 & 5 & 6 & 7\end{array}$

$\begin{array}{lllllll}1 & 2 & 3 & 4 & 5 & 6 & 7\end{array}$

$\begin{array}{lllllll}1 & 2 & 3 & 4 & 5 & 6 & 7\end{array}$




\section{Interim Questionnalire 4 (Career Concerns)}

Please fill in this questionnaire as honestly and accurately as you can. Your answers (as well as your performance during the experiment) are anonymous. There is no way to trace your answers back to you.

Experimental code:

For each of the following statements 1 to 10, please indicate how true it is for you, using the following scale:

\begin{tabular}{cccccccc}
$\begin{array}{c}\text { not at all } \\
\text { true }\end{array}$ & & \multicolumn{3}{c}{ neutral } & & $\begin{array}{c}\text { very } \\
\text { true }\end{array}$ \\
1 & 2 & 3 & 4 & 5 & 6 & 7
\end{tabular}

1. It is important for me that athers recognize my $\quad \begin{array}{lllllllll} & 1 & 2 & 3 & 4 & 5 & 6 & 7\end{array}$ qualities.

2. I don't understand things.

$\begin{array}{lllllll}1 & 2 & 3 & 4 & 5 & 6 & 7\end{array}$

3. I really care about the opinion that others have of me. $\begin{array}{llllllll}1 & 2 & 3 & 4 & 5 & 6 & 7\end{array}$

4. I am concerned about what other people think of me. $1 \begin{array}{llllllll}1 & 2 & 3 & 4 & 5 & 6 & 7\end{array}$

5. I have little to contribute. $14 \begin{array}{lllllll} & 1 & 3 & 4 & 5 & 6 & 7\end{array}$

6. My reputation is important to me. $\quad 1 \quad 2 \quad 3 \quad 4 \quad 5 \quad 6 \quad 7$

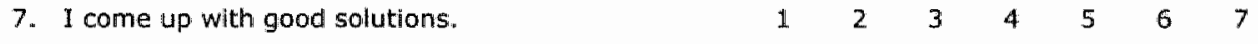

8. It matters to me whether others have a high opinion $1 \begin{array}{lllllllll} & 1 & 2 & 3 & 4 & 5 & 6 & 7\end{array}$ of me.

9. I know how to get things done. $\quad \begin{array}{lllllllll} & 1 & 2 & 3 & 4 & 5 & 6 & 7\end{array}$

10. I think that at the end of the experiment those people $\begin{array}{lllllllll}1 & 2 & 3 & 4 & 5 & 6 & 7\end{array}$ with low performance received no pay increase.

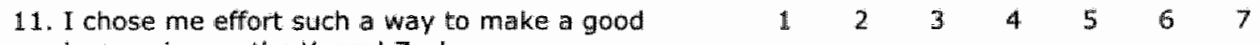
impression on the $Y$ - and $Z$-players.

12. I was impartant to me to receive extra wage offers by $\begin{array}{llllllll}1 & 2 & 3 & 4 & 5 & 6 & 7\end{array}$ the $Y$ - and the $Z$-player.

13. I am happy with the size of my salary without the $\quad \begin{array}{llllllll}1 & 2 & 3 & 4 & 5 & 6 & 7\end{array}$ extra payments by the $Y$ - and the Z-player.

14. I am happy with my overall pay during the whole $\quad \begin{array}{llllllll}1 & 2 & 3 & 4 & 5 & 6 & 7\end{array}$ experiment.

Now there are only few questions left.

15. $Y *$ and $Z$-players evaluated my performance and could both make wage offers.

ITrue ifalse 
16. For points above 30 on $r_{A}$ and $r_{B} I$ am compensated.

la flxed wage irrespective of my performance

i performance-based financial incentives that are equal on both tasks

i performance-based financial incentives with higher incentives on results of $r_{B}$ than on $r_{A}$

17. Assume you are working full time for a company. You are compensated with a fixed sallary of 1500 , - per month.

Furthermore assume you had the choice between the following alternatives for the next month:

Alternative 1: You will earn again $\subset 1500$,- with certainty.

Alternative 2: You will earn $€ 600$, with certainty with a probability $p$ you will receive an additional bonus of $\epsilon 1800,-$.

How large must the probability $P$ be for you to accept alternative 2 ?

The last three questions are some demographic multiple-choice questions.
18. What is your gender?
imale
i female
19. What is your age?
$\uplus<20 \quad \omega 20-24$
$+25-30$
$+>30$
20. Please indicate your nationality.
i Dutch
i German
i Belgian
sother

Thanks very much for filling out this questioninaire. 


\section{Interim Questionnaire 1}

Please fill in this questionnaire as honestly and accurately as you can. Your answers (as well as your performance during the experiment) are anonymous. There is no way to trace yout" answers back to you.

Experimental Code:

For each of the following statements 1 to 21 , please indicate how true it is for you, using the following scale:

$\begin{array}{cccccccc}\begin{array}{c}\text { not at all } \\ \text { true }\end{array} & & \text { neutral } & & \begin{array}{c}\text { very } \\ \text { true }\end{array} \\ 1 & 2 & 3 & 4 & 5 & 6 & 7\end{array}$

2. I put al lot of effort into this experiment.

2. I think I am pretty good at the experimental tasks. $\begin{array}{lllllllll}1 & 2 & 3 & 4 & 5 & 6 & 7\end{array}$

3. I feel very tense while doing this experiment. $\quad \begin{array}{lllllllll}1 & 2 & 3 & 4 & 5 & 6 & 7\end{array}$

4. Often I worry what people think of me.

5. I am anxious while working on the experiment.

6. I am not bothered by difficult social situations.

7. I conform to others' opinions.

8. I often obstruct the plans of athers.

10. I pretend to be concerned for athers.

10. I try very hard on this experiment.

11. It is important to me to do well at this experiment.

12. I need the approval of athers.

13. I am very relaxed in doing the experiment.

14. I take advantage of the work of others.

15. I enjoy doing this experiment very much.

16. I don't put much energy into the experiment.

$\begin{array}{lllllll}1 & 2 & 3 & 4 & 5 & 6 & 7\end{array}$

$\begin{array}{lllllll}1 & 2 & 3 & 4 & 5 & 6 & 7\end{array}$

$\begin{array}{lllllll}1 & 2 & 3 & 4 & 5 & 6 & 7\end{array}$

$\begin{array}{lllllll}1 & 2 & 3 & 4 & 5 & 6 & 7\end{array}$

$\begin{array}{lllllll}1 & 2 & 3 & 4 & 5 & 6 & 7\end{array}$

$\begin{array}{lllllll}1 & 2 & 3 & 4 & 5 & 6 & 7\end{array}$

$\begin{array}{lllllll}1 & 2 & 3 & 4 & 5 & 6 & 7\end{array}$

17. I am not easily embarrassed.

$\begin{array}{lllllll}1 & 2 & 3 & 4 & 5 & 6 & 7\end{array}$

18. I don't feel nervous at all while doing this experiment. $\begin{array}{llllllll}1 & 2 & 3 & 4 & 5 & 6 & 7\end{array}$

19. I want to be regarded as someone special by others. $\begin{array}{llllllll}1 & 2 & 3 & 4 & 5 & 6 & 7\end{array}$

$\begin{array}{llllllllll}\text { 20. I often use athers for my own ends. } & 1 & 2 & 3 & 4 & 5 & 6 & 7\end{array}$

21. Without a good performance I cannot increase my pay $\begin{array}{lllllllll}1 & 2 & 3 & 4 & 5 & 6 & 7\end{array}$ at this experiment. 


\section{Interim Questionnaire 2}

Please fil in this guestion aive as honestly and accuratelly as you can. Your answers (as well as your performance during the experment) are alnonymous. There is no way to trace your answers back to you.

Experimental Code:

For each of the following statements 1 to 21 , please indicate how true it is for you, using the following scalle:

\begin{tabular}{cccccccc}
$\begin{array}{c}\text { not at all } \\
\text { true }\end{array}$ & & \multicolumn{3}{c}{ neutrall } & & $\begin{array}{c}\text { very } \\
\text { true }\end{array}$ \\
1 & 2 & 3 & 4 & 5 & 6 & 7
\end{tabular}

1. I find it difficult to approach others.

2. I think this is a boring activity.

3. Generally, I would cheat to go ahead.

4. I feel piressured while doing this experiment.

$\begin{array}{lllllll}1 & 2 & 3 & 4 & 5 & 6 & 7\end{array}$

5. I would describe this experiment as very interesting.

6. This experiment does not hold my attention at all.

7. While I am working on the experiment 1 am thinking about how much II enjoy it.

8. I don't try very hard to do well at this experiment.

9. I visually do what others do.

10. I am easily intimidated.

11. I am often afraid that I will do the wrong thing.

12. I use flattery to get ahead.

13. I think 1 am doling pretty well at this experiment. compared to other students.

14. I don't care what others think of me.

15. This experiment is an activity that I cannot do well

15. I am able to stand up for myself.

17. I know how to get around the rulles.

18. I put people under pressure.

19. I only feel comfortable with firiends.

20. I am not concerned with making a good impression.

21. If I show high effort at this experiment I can get a better pay.

\begin{tabular}{|c|c|c|c|c|c|c|}
\hline & & & & & & \\
\hline 1 & 2 & 3 & 4 & 5 & 6 & 7 \\
\hline 1 & 2 & 3 & 4 & 5 & 6 & 7 \\
\hline 1 & 2 & 3 & 4 & 5 & 6 & 7 \\
\hline 1 & 2 & 3 & 4 & 5 & 6 & \\
\hline 1 & 2 & 3 & 4 & 5 & 6 & 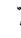 \\
\hline 1 & 2 & 3 & 4 & 5 & 6 & \\
\hline 1 & 2 & 3 & 4 & 5 & 6 & \\
\hline 1 & 2 & 3 & 4 & 5 & 6 & \\
\hline 1 & 2 & 3 & 4 & 5 & 6 & 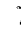 \\
\hline 1 & 2 & 3 & 4 & 5 & 6 & 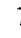 \\
\hline $\mathbb{1}$ & 2 & 3 & 4 & 5 & 6 & , \\
\hline 1 & 2 & 3 & 4 & 5 & 6 & 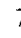 \\
\hline 1 & 2 & 3 & 4 & 5 & 6 & 7 \\
\hline $\mathbb{1}$ & 2 & 3 & 4 & 5 & 6 & 7 \\
\hline 1 & 2 & 3 & 4 & 5 & 6 & 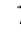 \\
\hline 1 & 2 & 3 & 4 & 5 & 6 & 7 \\
\hline $\mathbb{1}$ & 2 & 3 & 4 & 5 & 6 & 7 \\
\hline $\mathbb{1}$ & 2 & 3 & 4 & 5 & 6 & 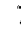 \\
\hline $\mathbb{1}$ & 2 & 3 & 4 & 5 & 6 & 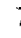 \\
\hline $\mathbb{1}$ & 2 & 3 & 4 & 5 & 6 & 7 \\
\hline
\end{tabular}




\section{Interim Questionnaire 3}

Please fill in this questionnaire as honestly and accurately as you can. Your answers (as well as your performance during the experiment) are anonymous. There is no way to trace your answers back to you.

Experimental Code:

For each of the following statements 1 to 21 , please indicate how true it is for you, using the following scale:

$\begin{array}{ccccccc}\begin{array}{c}\text { not at all } \\ \text { true }\end{array} & & \text { neutral } & & \begin{array}{c}\text { very } \\ \text { true }\end{array} \\ 1 & 2 & 3 & 4 & 5 & 6 & 7\end{array}$

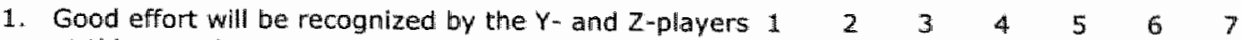
at this experiment.

2. I would never cheat on my taxes.

3. I am satisfied with my performance.

4. This experiment is fun to do.

5. I am pretty skilled at the experimental task.

6. I think this experiment is quite enjoyable.

7. I am comfortable also in unfamiliar situations.

8. I feet it is OK that some people don't like me.

9. After worked at this experiment for a while, I feel pretty competent.

10. I stick to the rules.

11. I am afraid to draw attention to myseif.

12. I often stumble gver my words.

13. I always want to form my own opinions.

14. I want to be different from others.

15. I complete tasks successfully.

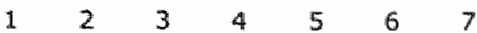

$\begin{array}{lllllll}1 & 2 & 3 & 4 & 5 & 6 & 7\end{array}$

$\begin{array}{lllllll}1 & 2 & 3 & 4 & 5 & 6 & 7\end{array}$

$\begin{array}{lllllll}1 & 2 & 3 & 4 & 5 & 6 & 7\end{array}$

$\begin{array}{lllllll}1 & 2 & 3 & 4 & 5 & 6 & 7\end{array}$

$\begin{array}{lllllll}1 & 2 & 3 & 4 & 5 & 6 & 7\end{array}$

$\begin{array}{lllllll}1 & 2 & 3 & 4 & 5 & 6 & 7\end{array}$

$\begin{array}{lllllll}1 & 2 & 3 & 4 & 5 & 6 & 7\end{array}$

16. It is important for me that others thirk highly of me. $\begin{array}{lllllllll}1 & 2 & 3 & 4 & 5 & 6 & 7\end{array}$

17. I excel in what I do.

18. I don't see the consequences of things.

19. I handle tasks smoothly.

20. I misjudge situations.

$\begin{array}{lllllll}1 & 2 & 3 & 4 & 5 & 6 & 7\end{array}$

$\begin{array}{lllllll}1 & 2 & 3 & 4 & 5 & 6 & 7\end{array}$

$\begin{array}{lllllll}1 & 2 & 3 & 4 & 5 & 6 & 7\end{array}$

$\begin{array}{lllllll}1 & 2 & 3 & 4 & 5 & 6 & 7\end{array}$

$\begin{array}{lllllll}1 & 2 & 3 & 4 & 5 & 6 & 7\end{array}$

$\begin{array}{lllllll}1 & 2 & 3 & 4 & 5 & 6 & 7\end{array}$

21. I am sure of my ground.

$\begin{array}{lllllll}1 & 2 & 3 & 4 & 5 & 6 & 7 \\ 1 & 2 & 3 & 4 & 5 & 6 & 7 \\ 1 & 2 & 3 & 4 & 5 & 6 & 7 \\ 1 & 2 & 3 & 4 & 5 & 6 & 7 \\ 1 & 2 & 3 & 4 & 5 & 6 & 7\end{array}$




\section{Exit Questionnaire}

Please fill in this questionnaile as honestly and accurately as you can. Your answers (as well as your performance during the experiment) are anonymous. There is no way to trace your answers back to you.

Experimental Code:

For each of the following statements 1 to 10 , please indicate how true it is for you, using the following scale:

$\begin{array}{cc}\begin{array}{c}\text { not at all } \\ \text { true }\end{array} & \text { neutral } \\ & \text { true }\end{array}$

11. It is important for me that others recognize my $\quad \begin{array}{lllllllllll}1 & 2 & 3 & 4 & 5 & 6 & 7\end{array}$ qualities.

12. I don't understand things. $\quad \begin{array}{lllllllll} & 1 & 2 & 3 & 4 & 5 & 6 & 7\end{array}$

13. I really care about the opinion that others have of me. $\begin{array}{llllllll}1 & 2 & 3 & 4 & 5 & 6 & 7\end{array}$

14. I am concerned about what other people think of me. $\begin{array}{llllllll}1 & 2 & 3 & 4 & 5 & 6 & 7\end{array}$

15. I have little to contribute. $\quad 1 \quad \begin{array}{lllllll} & 3 & 3 & 4 & 5 & 6 & 7\end{array}$

16. My reputation is important to me. $\quad 1 \quad \begin{array}{lllllll}3 & 3 & 4 & 5 & 6 & 7\end{array}$

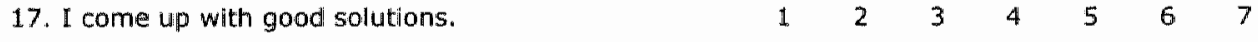

18. It matters to me whether others have a high opinion $\begin{array}{llllllll}1 & 2 & 3 & 4 & 5 & 6 & 7\end{array}$ of me.

19. I know haw to get things done.

10. [ am happy with my overall pay during the whole $\quad \begin{array}{llllllllll}1 & 2 & 3 & 4 & 5 & 6 & 7\end{array}$ experiment.

11. The performance measures $\mathbb{A} A$ and $\mathrm{rB}$ played an $\quad \begin{array}{llllllll}1 & 2 & 3 & 4 & 5 & 6 & 7\end{array}$ important role for me during the experiment.

Now there are only few questions left.

12. In this experiment I am generally compensated with

I f fixed wage irrespective of my performance

i performance-based financial incentives that are equal on both tasks

performance-based financial incentives with higher incentives on results of $r_{B}$ than on $r_{A}$ 
13. Assume you arre working full time for a company. You are compensated with a fixed sialary of 1500 ; - per month.

Furthermore assume you had the choice between the following alternatives for the next month:

Alternative 1: You will earn again 61500 , - with certainty.

Alternative 2: You will earn $€ 1200$ with certainty and with a probability p you will receive an additional bonus of $\in 600$, .

How large must the probability p be for you to accept alternative 2 ?

The last three questions are some demographic multiple-choice questions.

14. What is your gender?

15. What is your age?

16. Please indicate your nationality.

1 male 1 femaile

$$
a<20
$$

$-20-24$

Dutch

i German

Thanks very much for filling out this questionnaire. 
Dit proefschrift omschrijft twee experimenten over financiële en niet-financiële prikkels, die personen motiveren te werken. Beide experimenten belichten een principaal-agent situatie in een zogenaamde multi-task omgeving, waar de principaal van zijn agent verwacht zich ter gelijkertijd op meerdere taken te richten.

Het eerste hoofdstuk bevat de inleiding van het proefschrift en beschrijft hoe de onderzochte vragen in de management accounting literatuur passen. Een van de meest belangrijke kwesties in management accounting is de vraag, hoe men het gedrag van individuen kan stimuleren/beïnvloeden in de richting van de doelstellingen van de organisatie. Een van de vele manieren om werknemers te motiveren is het geven van financiële prikkels op basis van hun prestaties. Op basis van een prestatiemaatstaf kunnen beloningen verstrekt worden. Een specifiek probleem binnen multi-task omgevingen is het verschil in meetbaarheid van de verschillencle prestatiemaatstaven die gebruikt worden voor verschillende taken. Prestaties op een bepaalde taak kunnen wellicht beter gemeten worden dan prestaties op een andere taak. Deze verschillen kunnen tot een allocatie van werk leiden die overeenstemt met de voorkeur van de werknemer, maar niet met de doelen van de organisatie. De meetbaarheid en daarmee de kwaliteit van prestatiemaatstaven is dus van invloed op de allocatie van werk tussen de te verrichten taken. In een extreem voorbeeld zijn prestaties op een bepaalde taak perfect te meten, terwijl deze onmeetbaar zijn voor een andere taak. Vervolgens zal een werknemer zich wellicht alleen op die taak richten, die ook gemeten kan worden om zijn eigen evaluatie en beloning te verbeteren. 
De vragen die in dit proefschrift centraal staan, zijn:

1) Welke invloed hebben expliciete beloningsystemen op de allocatie van werk in een multi-task orngeving?

2) Welke rol spelen andere vormen van motivatie, zoals sociale druk of lange termijn effecten?

In hoofdstuk 2 beschrijf ik de economische modellen, die voor dit proefschrift van belang zijn. Een expliciet en prestatieafhankelijk contract tussen een principaal en een agent is in een single-task omgeving optimaal om de agent te motiveren om zich in zijn werk te richten op de doelstellingen van de organisatie. Modellen van een multi-task omgeving laten echter zien, dat in een dergelijke situatie een expliciet en prestatieafhankelijk contract niet altijd optimaal is voor een organisatie. In een multi-task omgeving kan een expliciet contract leiden tot een verdeling van taken die niet in lijn is met de doelen van de organisatie.

Hoofdstuk 3 beschrijft de empirische literatuur op het gebied van principaal-agent theorie. De empirische literatuur bevestigt economische theorie en laat zien dat financiële prikkels van invloed zijn op het gedrag van individuen. Verder toon ik in hoofdstuk 3 aan, dat de empirische literatuur sommige aannames van economische theorie niet steunt. Individuen zijn blijkbaar niet alleen geïnteresseerd hun eigen beloning te maximeren, maar hechten ook belang aan reciprociteit, sociale reputatie en lange termijn effecten van hun werk. Dit zijn meestal impliciete prikkels.

De eerste studie van dit proefschrift beschrijf ik in hoofdstuk 4. In deze studie bestudeer ik de effecten van financiële en sociale prikkels op de verdeling van werk in een multi-task omgeving. In een $2 \times 2$ experiment met twee onafhankelijke taken, waarvan prestaties op een taak meetbaar en op een andere taak niet meetbaar zijn, vind ik dat individuen met financiële prikkels hun inspanning op de meetbare taak verhogen ten koste van hun inspanning op de andere, niet meetbare, taak. De resultaten tonen aan dat de voorkeur voor de taak die precies gemeten wordt, zowel in statistische als economische termen, beduidend wordt verminderd door sociale en 
ethische druk. Met andere woorden, de verdeling van werk over de twee taken wordt niet alleen gedreven door financiéle prikkels, maar ook door de wens voor sociale goedkeuring en persoonlijke waarden. Verder zijn deelnemers indifferent tussen de twee taken als er een vaste prestatieonafhankelijke beloning verstrekt wordt. De bevindingen hebben belangrijke implicaties voor zowel theorie als praktijk. Dit experiment toont aan dat sociale reputatie en ethische waarden een belangrijke rol spelen binnen management controle en dat financiële prikkels ongewenste effecten kunnen hebben met betrekking tot de verdeling van werk over taken. Verdere analyse van de resultaten laat zien dat er een afweging gemaakt moet worden tussen een optimale verdeling van werk en een optimaall inspanningsniveau. Hoewel een prestatieonafhankelijke beloning tot een gelijke verdeling van werk tussen taken leidt, is het inspanningsniveau van de agent beduidend lager.

Hoofdstuk 5 beschrijft de tweede studie van dit proefschrift. In een experimentele arbeidsmarkt, waarin principalen de prestaties van agenten op twee taken evalueren, onderzoek ik de rol van impliciete prikkels (middels reputatie-effecten ten opzichte van de arbeidsmarkt) en expliciete financiële prikkels van agenten. De prestaties worden precies gemeten op één taak en met ruils op een andere taak. Bij een prestatieafhankelijke beloning op beide taken richten agenten zich meer op de taak die precies gemeten wordt, en duidelijk minder op de taak die met ruis gemeten wordt. Deze verdeling blijft ook bestaan bij de aanwezigheid van een arbeidsmarkt, omdat agenten proberen vanuit carrièrebelang hun prestaties proberen te signaleren. Agenten prefereren de precieze maatstaf om een signaal aan de arbeidsmarkt te geven. Net als in de studie in hoofistuk 4 zijn agenten bij een vaste beloning in afwezigheid van een arbeidsmarkt indifferent tussen beide taken. Echter, in aanwezigheid van een arbeidsmarkt die de prestaties van agenten evalueert, richten agenten zich meer op de precies gemeten taak. Dus, in aanwezigheid van carrièrebelang is een vast loon niet noodzakelijk optimaal voor de verdeling van werk tussen taken, die met verschillende kwaliteit gemeten worden. Agenten met expliciete financiële prikkels met een hoger gewicht op de taak die met ruis gemeten wordt, richten hun werk meer op deze taak. Agenten zijn bijna 
indifferent tussen taken als er bovendien nog een carrièrebelang aanwezig is. Een hoger gewicht op de maatstaf met ruis kan dus voor de principaal voordelig zijn. Dit is niet in overeenstemming met standaardvoorspellingen. Expliciete financiële prikkels en impliciete prikkels gedreven door reputatie op een arbeidsmarikt zijn dus complementair in een multi-task omgeving, en in contrast met theoretische voorspellingen kan de relatie tussen risico en gewichten op expliciete prikkels positief zijn. Verder laten bevindingen van deze studie zien dat de werkgevers in de experimentele arbeidsmarkt hun aanstellingsbeslissing nemen op basis van beide prestatiemaatstaven, maar groter belang hechten aan de precieze maatstaf. Dit komt overeen met theoretische voorspellingen.

In hoofdstuk 6 vat ik de resultaten van dit proefschrift samen en trek de valgende conclusies:

Ten eerste, hebben financiële prikkels een sterke invloed op de verdeling van werk in een multi-task omgeving. Desalniettemin worden individuen nast financiële prikkels ook gemotiveerd door andere mechanismen, zoals impliciete financiële prikkels in een arbeidsmarkt evenals sociale groep en individuele normen.

Ten tweede, hoeft het voor een principaal niet voordelig te zijn om vaste lonen aan te bieden, omdat de vaste lonen tot een lager algemeen inspanningsniveau kunnen leiden. Verder stemmen de inspanningen onder vaste lonen, in aanwezigheild van een carrièrebelang, niet noodzakelijk overeen met de doelstellingen van de principaal, omdat de werkverdeling van de agent door carrièrezorgen en signalen aan een arbeidsmarkt wordt beinvloed.

Ten derde, terwijl expliciete financiële prikkels en carrièrezorgen volgens de lïteratuur substituten zijn, brengen de resultaten van dit proefschrift naar voren dat. deze twee elkaar aanvullen.

Ten vierde voorspelt de theorie dat er een negatief verband bestaat tussen ruis in prestatiemaatstaven en de gewichten op expliciete financiële prikkels. Dit. 
proefschrift toont een situatie aan waar deze verhouding niet negatief maar positief is.

Hoofdstuk 6 wordt afgesloten met een bespreking van de tekortkomingen van het experimenteel onderzoek en er worden aambevelingen gedaan voor toekomstig onderzoek op het gebied van beloningsystemen in een multi-task omgeving. 


\section{CURRICULUM VITAE}

Alexander Brüggen was born on September 1, 1976, in Cologne, Germany. From 1997 until 2001 he studies Business Administration at Maastricht University and the Hong Kong University of Science and Technology. After graduation, he worked for four years as a PhD student at the Department of Accounting and Information Management at Maastricht University. Since September 2005, he is working as an Assistant Professor at that institution. 